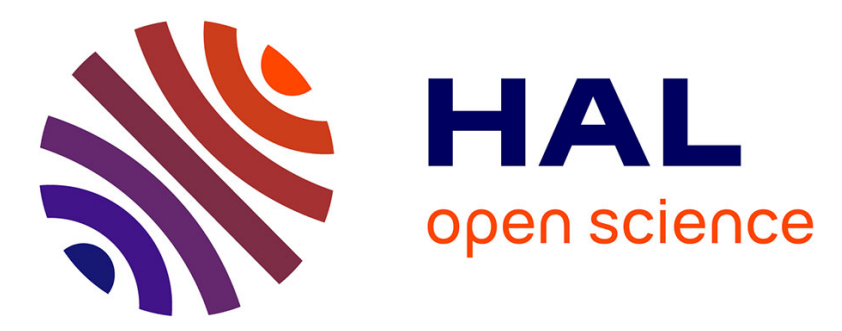

\title{
The Phalangopsidae crickets (Orthoptera, Grylloidea) of the Seychelles Archipelago: Taxonomy of an ecological radiation
}

\author{
Sylvain Hugel, Ben H Warren, Laure Desutter-Grandcolas
}

\section{- To cite this version:}

Sylvain Hugel, Ben H Warren, Laure Desutter-Grandcolas. The Phalangopsidae crickets (Orthoptera, Grylloidea) of the Seychelles Archipelago: Taxonomy of an ecological radiation. Zootaxa, 2021, 5047 (3), pp.201-246. 10.11646/zootaxa.5047.3.1 . hal-03366692

\section{HAL Id: hal-03366692 https://hal.science/hal-03366692}

Submitted on 1 Nov 2021

HAL is a multi-disciplinary open access archive for the deposit and dissemination of scientific research documents, whether they are published or not. The documents may come from teaching and research institutions in France or abroad, or from public or private research centers.
L'archive ouverte pluridisciplinaire $\mathbf{H A L}$, est destinée au dépôt et à la diffusion de documents scientifiques de niveau recherche, publiés ou non, émanant des établissements d'enseignement et de recherche français ou étrangers, des laboratoires publics ou privés. 
The Phalangopsidae crickets (Orthoptera, Grylloidea) of the Seychelles Archipelago: Taxonomy of an ecological radiation

SYLVAIN HUGEL ${ }^{(1)}$

BEN H. WARREN (2)

LAURE DESUTTER-GRANDCOLAS ${ }^{(2)}$

${ }^{(1)}$ INCI, UPR 3212 CNRS, Université de Strasbourg, Strasbourg, France

(2) Institut de Systématique, Evolution, Biodiversité (ISYEB), Muséum national d'Histoire naturelle, CNRS, Sorbonne Université, EPHE, Université des Antilles, Paris, France 


\section{Abstract}

The Phalangopsidae crickets (Grylloidea) from the Seychelles are examined following extensive field sampling on several main islands of the archipelago (Mahé, Silhouette, Praslin, La Digue). Despite the small area of these islands, six genera (12 species) are documented, including one new genus and five new species. The type species of the genus Seychellesia Bolivar, 1912 is transferred to the genus Paragryllodes Karny, 1909 as Paragryllodes nitidula (Bolivar, 1912) n. comb. The other species described in Seychellesia are transferred to the genus Seselia Hugel \& Desutter-Grandcolas, n. gen., as Seselia longicercata (Bolivar, 1912) n. comb. and Seselia patellifera (Bolivar, 1912) n. comb. Two new species are also described in the genus Seselia Hugel \& Desutter-Grandcolas, n. gen., Seselia coccofessei Hugel \& Desutter-Grandcolas, n. gen., n. sp. (type species of the genus) and Seselia matyoti Hugel \& Desutter-Grandcolas, n. gen., n. sp. The genera Phaeogryllus Bolivar, 1912 and Phalangacris Bolivar, 1895 are redescribed, including Phalangacris ferlegro Hugel \& DesutterGrandcolas, n. sp. and Phalangacris sotsote Hugel \& Desutter-Grandcolas, n. sp. that are new to science. The genus Gryllapterus Bolivar, 1912 is redescribed and transferred from the Landrevinae (Gryllidae) to the Cachoplistinae (Phalangopsidae). New tribes are defined for the genus Paragryllodes (Paragryllodini Hugel \& Desutter-Grandcolas, n. tribe) on the one hand, and for Seselia Hugel \& Desutter-Grandcolas, n. gen., Phalangacris, Phaeogryllus and Gryllapterus (Seselini Hugel \& Desutter-Grandcolas, n. tribe) on the other, using morphological characters and the results of molecular phylogenetic studies (Warren et al. 2019). Phaloria (Papuloria) insularis (Bolivar, 1912) (Phaloriinae) is redescribed and restricted to Mahé, and its calling song is documented for the first time, while Phaloria (Papuloria) bolivari Hugel \& Desutter-Grandcolas, n. sp. is newly described from Silhouette. Identification keys are proposed for the genera of Seselini Hugel \& DesutterGrandcolas, n. tribe, and for the species of Seselia Hugel \& Desutter-Grandcolas, n. gen. and Phalangacris. The confusion between the Mogoplistidae Ornebius succineus Bolivar, 1912 and the Phalangopsidae Heterotrypus succineus Bolivar, 1910 is discussed, and the name Subtiloria succineus (Bolivar, 1912) considered a nomen nudum.

\section{Résumé}

Les grillons Phalangopsidae (Grylloidea) des Seychelles sont étudiés sur la base d'un échantillonnage intensif sur plusieurs îles principales de l'archipel (Mahé, Silhouette, Praslin, La Digue). Malgré la petite taille de ces îles, six genres (12 espèces) sont documentés, dont un genre nouveau et cinq espèces nouvelles. L'espèce type du genre Seychellesia Bolivar, 1912 est transférée dans le genre Paragryllodes Karny, 1909 en tant que Paragryllodes nitidula (Bolivar, 1912) n. comb. Les autres espèces décrites dans Seychellesia sont transférées dans le genre Seselia Hugel \& Desutter- 
Grandcolas, n. gen., en tant que Seselia longicercata (Bolivar, 1912) n. comb. et Seselia patellifera (Bolivar, 1912) n. comb. Le genre Seselia Hugel \& Desutter-Grandcolas, n. gen. comprend d'autre part Seselia coccofessei Hugel \& Desutter-Grandcolas, n. gen., n. sp. (espèce type du genre) et Seselia matyoti Hugel \& Desutter-Grandcolas, n. gen., n. sp. Les genres Phaeogryllus Bolivar, 1912 et Phalangacris Bolivar, 1895 sont redécrits, Phalangacris ferlegro Hugel \& Desutter-Grandcolas, n. sp. et Phalangacris sotsote Hugel \& Desutter-Grandcolas, n. sp. sont nouveaux pour la science. Le genre Gryllapterus Bolivar, 1912 est redécrit et transféré des Landrevinae (Gryllidae) aux Cachoplistinae (Phalangopsidae). Des tribus nouvelles sont définies pour le genre Paragryllodes (Paragryllodini Hugel \& Desutter-Grandcolas, n. tribu) d'une part, et pour Seselia Hugel \& Desutter-Grandcolas, n. gen., Phalangacris, Phaeogryllus et Gryllapterus (Seselini Hugel \& Desutter-Grandcolas, n. tribu) d'autre part, sur la base de la morphologie et des données de phylogénie moléculaire (Warren et al. 2019). Phaloria (Papuloria) insularis (Bolivar, 1912) (Phaloriinae) est finalement redécrite de Mahé, et son chant d'appel documenté pour la première fois, tandis que Phaloria (Papuloria) bolivari Hugel \& Desutter-Grandcolas, n. sp. est nouvellement décrite de Silhouette. Des clés d'identification sont proposées pour les genres de Seselini Hugel \& Desutter-Grandcolas, n. tribu, ainsi que pour les espèces de Seselia Hugel \& Desutter-Grandcolas, n. gen. et Phalangacris. La confusion entre Ornebius succineus Bolivar, 1912 (Mogoplistidae) et Heterotrypus succineus Bolivar, 1910 (Phalangopsidae) est discutée, et le nom Subtiloria succineus (Bolivar, 1912) considéré comme un nomen nudum.

Key words: Indian Ocean, Systematics, Bioacoustics, Habitats

Mots clés: Océan indien, Systématique, Bioacoustique, Habitats 


\section{INTRODUCTION}

Although Orthoptera from the Seychelles have been repeatedly and specifically sampled and studied in the past (Bolivar 1895, 1912, 1924; Gorochov 1994, 2006), intensive sampling effort in native habitats allowed the recent discovery of several new species (Hugel \& Matyot 2006; Hugel 2012; Hsu et al. 2020). The cricket family Phalangopsidae is particularly well-diversified in the Seychelles, with five genera reported today from the archipelago: Phaeogryllus Bolivar, 1912 (one species), Phalangacris Bolivar, 1895 (two species), Phaloria Stål, 1877 (one species), Seychellesia Bolivar, 1912 (three species) and Subtiloria Gorochov, 1999 (one species). A large-scale molecular phylogeny of crickets (Warren et al. 2019) supports Phalangacris, Seychellesia p.p. and Phaeogryllus belonging to one clade, which is the sister group of Gryllapterus Bolivar, 1912. Gryllapterus is a monotypic genus endemic to the Seychelles, tentatively classified within the Landrevinae subfamily of the Gryllidae family (Gorochov 1982), later considered as a Phalangopsinae sensu Eades et al. (2008) (Hugel 2009) and finally moved again to Landrevinae (Gorochov 2017). Seychellesia nitidula Bolivar, 1912, the type species of the genus, groups with Paragryllodes species from Madagascar and Africa within the Paragryllinae subfamily.

In the present article, we revise the taxonomy of the Phalangopsidae taxa from the Seychelles, as a preliminary step in the study of the evolution of Seychellois biotas (Warren et al. in prep.).

Diagnosis and full descriptions of each known genus and species are given. The genus Seychellesia Bolivar, 1912 is synonymized with Paragryllodes Karny, 1909, and Seychellesia nitidula redescribed as Paragryllodes nitidula (Bolivar, 1912) n. comb. The genus Seselia Hugel \& DesutterGrandcolas, n. gen. is erected for Seselia longicercata (Bolivar, 1912) n. comb., Seselia patellifera (Bolivar, 1912) n. comb., Seselia matyoti Hugel \& Desutter-Grandcolas, n. gen., n. sp and Seselia coccofessei Hugel \& Desutter-Grandcolas, n. gen., n. sp. (type species of the genus). The male sex of Phaeogryllus fuscus is described for the first time. Phalangacris alluaudi Bolivar, 1895 is redescribed, while Phalangacris ferlegro n. sp. and Phalangacris sotsote n. sp. are newly described from Praslin and La Digue respectively. Gryllapterus Bolivar, 1912 and its type species, Gryllapterus tomentosus Bolivar, 1912, are redescribed, and its morphology and male genitalia compared to other Gryllidae (Landrevinae, Gryllinae, Odontogryllini) and Phalangopsidae crickets. Phaloria insularis (Bolivar, 1912) is redescribed with a distribution restricted to Mahé, and its calling song newly documented. A new species, Phaloria bolivari Hugel \& Desutter-Grandcolas, n. sp. is described from Silhouette.

The taxonomic position of these taxa is discussed, and the tribes Paragryllodini Hugel \& Desutter-Grandcolas, n. tribe and Seselini Hugel \& Desutter-Grandcolas, n. tribe are defined for Paragryllodes on one hand, and for Seselia Hugel \& Desutter-Grandcolas, n. gen., Phaeogryllus, Phalangacris and Gryllapterus on the other hand. Identification keys are proposed for the Seychellois genera, and for the species of Phalangacris and Seselia Hugel \& Desutter-Grandcolas, n. gen.

Finally, Subtiloria succineus (Bolivar, 1912) is considered a nomen nudum resulting from a confusion between the species names of the Mogoplistidae Ornebius succineus Bolivar, 1912 and the 
Phalangopsidae Heterotrypus succineus Bolivar, 1910 in Gerlach \& Haas (2008). The genus

Subtiloria Gorochov, 1999 does not occur in the Seychelles.

The diversity of Phalangopsidae crickets in the Seychelles contribute substantially to the rich and unique biodiversity of the archipelago, already noted by Bolivar for Orthoptera (Bolivar 1912): “Les Orthoptères (...) observés aux Seychelles dépassent, à ne pas douter, le nombre de ceux qu’on pourrait espérer trouver dans cette faune" [Orthopterans observed in the Seychelles surely exceed the number one could expect to find in this fauna] (Bolivar 1912, our traduction). This remarkable fauna urgently needs to be preserved (Matyot 1998; Currie et al. 2003). It furthermore represents a unique model clade to study the origin and diversification of the Seychellois biotas.

\section{MATERIALS AND METHODS}

The taxonomy involves the subfamilial framework resulting from recent molecular phylogenetic analyses (Chintauan-Marquier et al. 2013, 2016), since all subfamilies of Phalangopsidae (sensu Cigliano et al. 2021), except Phaloriinae (sensu Desutter-Grandcolas 2015), were recently found to be polyphyletic (Warren et al. 2019).

Observed specimens. Specimens were collected and/or observed in July-August 2003 and 2010 by SH (research approved by the Seychelles Bureau of Standards, Authorization number A0347 and A0157).

\section{Descriptions}

Male genitalic structures follow Desutter (1987) and Desutter-Grandcolas (2003). Membranous parts are figured with dots. In the figures, structures seen through the membranes are displayed with dotted lines.

Movable and articulated leg outgrowths are called spurs whereas immovable outgrowths are called spines. Apical spurs (a) are referred to according to their location on the tibia, i.e. on outer or inner side (o, i), and dorsal, median or ventral (d, m, v) on each side. Hind tibial subapical spurs (sa) are counted from TIII apex upward, on inner and outer margins, and their number is indicated as the following formula in species descriptions: "number of inner/number of outer" subapical spurs; when necessary, each spur is named after its location: for example, osa1 is the first (= most apical) outer subapical spur, and ias3 the third inner subapical spur. Wing venation is named after DesutterGrandcolas et al. (2017), modified after Schubnel et al. (2019), using observations and homology settings in X-ray tomography, which allow the identification of the post-cubital vein bearing the stridulatory file.

\section{Song recording and analysis}

The recordings have been performed with an Audiotechnica AT822 stereo microphone, on a HDR HC1E Sony camcorder (sampling rate: $48 \mathrm{kHz}$ ) on the nightshot mode (to follow the insect 
behaviour). Songs have been analyzed with the software Avisoft SASLab-Pro (version 4.40, Specht 2008) and Raven Pro (version 1.6.1, Center for Conservation Bioacoustics 2019), and described using the terminology of Ragge \& Reynolds (1998). Song files are deposited in the MNHN Sound Library, https://sonotheque.mnhn.fr/

\section{Abbreviations and symbols}

Specimens.

fn field number.

Male genitalia.

A-, B-, C-Scl. pseudepiphallic sclerites A, B and C, as defined by Desutter-Grandcolas (1992a);

arc ectophallic arc;

ec. a. ectophallic apodeme;

ec. f. ectophallic fold;

en. a. endophallic apodeme;

en. s. endophallic sclerite;

E. I. epi-ectophallic invagination;

ps. m. l. median lobes of pseudepiphallus;

ps. l. h. hook of pseudepiphallic lateral lobe;

ps. p. pseudepiphallic parameres;

ps. s. $\quad$ pseudepiphallic sclerite;

r. rami.

General morphology.

I, II, III anterior, median, posterior (leg, tarsomere);

DD pronotum dorsal disc;

FW forewing;

HW hindwing;

$\mathrm{iad} / \mathrm{m} / \mathrm{v}$ inner apical spur dorsal/median/ventral of tibia;

isa(n) $\quad \mathrm{n}^{\text {th }}$ inner subapical spur of hind tibia;

LL pronotum lateral lobe;

$\mathrm{oad} / \mathrm{m} / \mathrm{v}$ outer apical spur dorsal/median/ventral of tibia;

osa(n) $\quad n^{\text {th }}$ outer subapical spur of hind tibia;

$\mathrm{PCu}$ forewing postcubital vein (bearing the stridulatory file).

Repository.

CUMZ Cambridge University Museum of Zoology, Cambridge;

LEM Lyman entomological Museum and Research Laboratory, McGill University, Ste Anne de Bellevue; 
MNCN Museo Nacional de Ciencias Naturales, Madrid;

MNHN Muséum national d'Histoire naturelle, Paris;

NHM Natural History Museum, London;

Coll. SH Collection Sylvain Hugel, Strasbourg.

Material for comparisons. We used the phylogenetic topologies generated by Chintauan-Marquier et al. (2013, 2016) and Warren et al. (2019) with molecular data to choose several species of Phalangopsidae and Gryllidae to compare with Gryllapterus. Specimens and their metadata are available on the MNHN collection database at the following address, https://science.mnhn.fr/institution/mnhn/collection/eo/item/search, using the specimen inventory numbers.

Phalangopsidae, Cachoplistinae:

Cacoplistus rogenhoferi Saussure, 1877, male, MNHN-EO-ENSIF11545; female, MNHN-EOENSIF2960;

Gryllomorpha dalmatina (Ocksay, 1832), male, MNHN-EO-ENSIF11546; female, MNHN-EOENSIF11547;

Homoeogryllus xanthographus Guérin-Méneville, 1847, male, MNHN-EO-ENSIF3101; female, MNHN-EO-ENSIF2944;

Homoeogryllus cavicola Chopard, 1950, male MNHN-EO-ENSIF3088;

Laranda major Desutter-Grandcolas, 1994: female, MNHN-EO-ENSIF5385;

Meloimorpha japonica (Haan, 1842), male, MNHN-EO-ENSIF11544; female, MNHN-EOENSIF2963;

Petaloptila andreinii Capra, 1936, male, MNHN-EO-ENSIF11540; female, MNHN-EO-ENSIF11541; Petaloptila pallescens Bolivar, 1927, male, MNHN-EO-ENSIF11542; female, MNHN-EOENSIF11543;

Socotracris kleukersi Felix \& Desutter-Grandcolas, 2012, male (NCB, Leiden); female, MNHN-EOENSIF2933.

Gryllidae, Landrevinae:

Apiotarsoides semialatus Chopard, 1931, male, MNHN-EO-ENSIF5049; female, MNHN-EOENSIF5050;

Duolandrevus semialatus CHopard, 1930, female, MNHN-EO-ENSIF5071;

Duolandrevus karnyi Otte, 1988, male, MNHN-EO-ENSIF5075; female, MNHN-EO-ENSIF5074;

Endolandrevus pubescens Chopard, 1930, female, MNHN-EO-ENSIF11548;

Jareta insignis (Walker, 1869), male, MNHN-EO-ENSIF11549;

Landreva angustifrons Chopard, 1956, male, MNHN-EO-ENSIF5076;

Landreva hemiptera (Bolivar, 1899(1900)), female, MNHN-EO-ENSIF5078; 
Landreva subaptera Chopard, 1925, female, MNHN-EO-ENSIF5077;

Paralandrevus hector (Saussure, 1877), female, MNHN-EO-ENSIF5057;

Odontogryllodes brevicauda Chopard, 1967, male, MNHN-EO-ENSIF5087; female, MNHN-EO-

ENSIF5088.

Gryllidae, not Landrevinae after Chintauan-Marquier et al. (2013, 2016):

Microlandreva notabilis Chopard, 1958 male, MNHN-EO-ENSIF3405; female, MNHN-EO-

ENSIF3403;

Microlandreva parvotibialis Hugel, 2009, male, MNHN-EO-ENSIF5052;

Odontogryllus sp. aff. setosus Saussure, 1877: male, MNHN-EO-ENSIF12263; female, MNHN-EO-

ENSIF12264;

Brasilodontus riodocensis de Mello, 1992: male, MNHN-EO-ENSIF11550; female, MNHN-EO-

ENSIF11551;

Several undescribed species of Odontogryllini present in the MNHN collections.

\section{List of studied taxa.}

Phalangopsidae Blanchard, 1845

Paragryllinae Desutter, 1987

Paragryllodini Hugel \& Desutter-Grandcolas, n. tribe

Paragryllodes Karny, 1909 (n. syn for Seychellesia Bolivar, 1912)

Paragryllodes nitidula (Bolivar, 1912) n. comb.

Cachoplistinae Saussure, 1877

Seselini Hugel \& Desutter-Grandcolas, n. tribe

Seselia Hugel \& Desutter-Grandcolas, n. gen.

Seselia longicercata (Bolivar, 1912) n. comb.

Seselia patellifera (Bolivar, 1912) n. comb.

Seselia matyoti Hugel \& Desutter-Grandcolas, n. gen., n. sp.

Seselia coccofessei Hugel \& Desutter-Grandcolas, n. gen., n. sp.

Phaeogryllus Bolivar, 1912

Phaeogryllus fuscus Bolivar, 1912

Phalangacris Bolivar, 1895

Phalangacris alluaudi Bolivar, 1895

Phalangacris phaloricephala Gorochov, 2006

Phalangacris sotsote Hugel \& Desutter-Grandcolas, n. sp. 
Phalangacris ferlegro Hugel \& Desutter-Grandcolas, n. sp.

Gryllapterus Bolivar, 1912

Gryllapterus tomentosus Bolivar, 1912

Phaloriinae Gorochov, 1985

Phaloria Stål, 1877

Phaloria (Papuloria) insularis (Bolivar, 1912)

Phaloria (Papuloria) bolivari Hugel \& Desutter-Grandcolas, n. sp.

\section{RESULTS}

\section{Synonymy between Paragryllodes and Seychellesia.}

The genus Seychellesia Bolívar, 1912 has been proposed by Bolívar to include three species from the Seychelles: S. nitidula, S. longicercata and S. patellifera. S. nitidula is described from Silhouette, whereas S. longicercata and S. patellifera are from both Mahé and Silhouette. Otte (1994) has designated S. nitidula as the type species of the genus. Gorochov (2006) examined the syntypes of $S$. longicercata and S. patellifera and pointed that Bolivar has described adult specimens (with tympana) under the name S. longicercata and juveniles (without tympana) under the name S. patellifera. Gorochov (2006) designated a lectotype of S. longicercata from Silhouette and suggested that both species may be synonyms.

Chopard (1936) described Seychellesia ceylonica from Sri Lanka. This species was later transferred under Paragryllodes Karny, 1909 by Chopard (1968) and to Pseudendacustes Chopard, 1928 by Gorochov (2018a). This species is beyond the scope of the present work.

Both morphology and molecular data indicate that Seychellesia nitidula belongs to Paragryllodes Karny, 1909. Hence, we consider that Seychellesia Bolívar, 1912 is a synonym of Paragryllodes Karny, 1909 n.syn. The new genus Seselia Hugel \& Desutter-Grandcolas, n. gen. is proposed to include $S$. longicercata and S. patellifera. New specimens collected by SH allow specimens from Mahé and Silhouette to be differentiated and to describe two new species, Seselia matyoti Hugel \& DesutterGrandcolas, n. gen., n. sp. from La Digue and Seselia coccofessei Hugel \& Desutter-Grandcolas, n. gen., n. sp. from Praslin.

\section{Phalangopsidae Blanchard, 1845}

Paragryllinae Desutter, 1987

Paragryllodini Hugel \& Desutter-Grandcolas, n. tribe 
Type genus. Paragryllodes Karny, 1909, here designated.

Diagnosis. At this stage, one single genus is included in this new tribe. The diagnosis of Paragryllodini, therefore, is that of Paragryllodes (see infra).

Remark. Paragryllodes was tentatively placed in the subtribe Mexiaclina Gorochov, 2014 under the tribe Paragryllini Desutter, 1987 (Gorochov 2015). Molecular data clearly indicate that Paragryllodes is not related to Paragryllini. We therefore propose here the new tribe Paragryllodini n. tribe for the genus Paragryllodes, which represents a well-supported monophyletic clade within the Paragryllinae subfamily.

In the molecular phylogeny of Chintauan-Marquier et al. (2013, 2016), the Paragryllodes clade is very well-supported within the Phalangopsidae clade E2 (Chintauan-Marquier et al. 2016: Fig. 4; 100\% ML bootstrap support, 1 posterior probability), a result confirmed with a more extended data set (Warren et al. 2019 and in prep.).

\section{Paragryllodes Karny, 1909}

(Figs 1A, 2)

Paragryllodes Karny, 1909: 478.

Seychellesia Bolivar, 1912: 286, n. syn.

Type species. Paragryllodes borgerti Karny, 1909 by original monotypy.

Emended diagnosis. Size variable. Cuticula shiny. Coloration black brown mottled with yellow (Fig. 1A); main yellow line on the face transverse or vertical. Fastigium (Fig. 2A) very narrow, grooved, sharply separated from the vertex, lower than head dorsum and separated from it by a transverse furrow; lateral ocelli close to each other, compared to their distance to the median ocellus; median ocellus in frontal position, apical on fastigium. Eyes strongly protruding (Fig. 2A, B). Scapes very large, longer than wide. Pedicels with a tooth of variable size. Last joint of maxillary palpi moderately elongate, slightly widened toward the apex and with apical truncation (Fig. 2B). Legs usually patterned with yellow and dark blown. Tibiae I with two apical, ventral spurs; inner tympanum present, outer tympanum absent. Tibiae II with three apical spurs. Tibiae III strongly serrulated on their basal two thirds and without spines between the first subapical spurs; with 3-4/4 subapical spurs, and three outer (the median the longest) and three inner (the median and dorsal subequal in length) apical spurs. Basitarsomeres III serrulated. FWs always present in both males and females, not covering the whole 
abdomen. Wings lacking. Cerci very long. Male. Metanotum and tergites without clear glandular structure (in particular, no metanotal area covered with dense setae and no eversible tergal region). Apical spurs of tibiae III not modified. Posterior angles of supra-anal plate not elongate. Length of subgenital plate variable. FWs usually completely overlapping, sometimes scaliform; not corneous. Stridulum variably developed, absent in micropterous species; when present, harp with many oblique, parallel veins; mirror usually short, often not clearly separated from distal field venation. Male genitalia characterized by the development of ectophallic dorsal valves and shape of pseudepiphallic sclerite: pseudepiphallic sclerite transverse or quadrate, with raised basal part; rami variable in length but not separate from the main sclerite. Pseudepiphallic parameres well developed, often partly covered with long setae, massive, not hook-shaped. Epi-ectophallic apodemes long and thick. Ectophallic dorsal valves elongate and acute, most often extending beyond pseudepiphallic distal margin, their shape differing in each species group. Endophallic apodeme comprising a small, median and vertical crest and a variable apodeme on each side of the endophallic sclerite; without a large dorsal cavity. Female. FWs always present, overlapping or not. Length of ovipositor variable. Female genitalia: copulatoty papilla forming a sclerotized chamber, long and tubular, or short and triangular in shape.

Remark. In Paragryllodes, female copulatory papilla forms an elongated sclerotized chamber of various width; Paragryllodes nitidula n. comb. papilla (Fig. 2D) is similar to that of African species (see for example Desutter-Grandcolas 1999). We illustrate here the variation of Paragryllodes copulatory papilla with that of P. milloti Chopard, 1958 since it is particularly wide in this species (Fig. 2E). This species is not related to other species of the subgenus Cortigryllus where it has recently been tentatively placed (Gorochov 2015); a review of species from Comoros will be addressed separately (Desutter-Grandcolas \& Hugel in prep).

\section{Paragryllodes nitidula (Bolivar, 1912) n. comb.}

(Figs 1A, 2A-D, Table 1)

Seychellesia nitidula Bolivar, 1912: 286 - Gorochov 2006: 445.

Type locality. Seychelles, Silhouette, near Mare aux Cochons, over 1000 feet (Bolivar (1912).

Type material. Lectotype female (designated by Gorochov 2006), Seychelles, Silhouette island [”Silhouette, ‘08, Seychelles Exp. 21”, “type”, “Figured specimen”, “Holotype”, “Seychellia gen. n. nitidula sp. n.”, “Seychelles, Percy Sladen Trust Expedition, 1913-170”, “syntype”] (NHM). According to Cigliano et al. (2021), the syntypes were deposited in CUMZ. 
Other material examined. Seychelles, Silhouette, Jardin Marron vers Mt Pot à eau, 550 m, vue de nuit, 1 female (2010SEYSH200), 5.x.2010, S. Hugel, MNHN-EO-ENSIF12094.

Molecular sampling. LDG 375 in Warren et al. (2019).

Remarks. Seychellesia nitidula is only known by females, but both molecular data (Chintauan-Marquier et al. 2013, 2016) and morphology (see below) indicate that Seychellesia nitidula belongs to Paragryllodes Karny, 1909 and is not related to the other species from the Seychelles described under the name Seychellesia (i.e. Seychellesia patellifera Bolivar, 1912 and Seychellesia longicercata Bolivar, 1912), for which we describe here the new genus Seselia Hugel \& Desutter-Grandcolas, n. gen. Seychellesia nitidula shares the following characters with Paragryllodes: shiny cuticula; eyes strongly protruding; fastigium lower than head dorsum, and separated from it by a transverse furrow; median ocellus in frontal position, apical on fastigium; maxillary palpi moderately elongate, article 4 distinctively shorter that articles 3 and 5; pronotum sulcated; LL more or less perpendicular to DD; female copulatory papilla forming a sclerotized chamber (Fig. 2D).

\section{Redescription}

Size small for the genus.

General morphology. Antennae: pedicel with very small tooth on dorsal/inner side. Face shiny black with a single longitudinal light band below median ocellus (Fig. 2B); sometimes with one short vertical line on each side above clypeus edges and an indistinct light spot below each antennal pit (Fig. 2B, no in lectotype). Eyes surrounded with a faint light band. Occiput with 3 indistinct longitudinal bands. LL black, DD black with few small light patterns, lateral angles with a light longitudinal band. TI with small rounded inner tympanum. FIII (Fig. 2C) particularly short and wide, with a median longitudinal black pattern, with two large diagonal patterns, with a pregenicular black ring, with black knee; without regular parallel stripes.

Male. Unknown.

Female. FWs (Fig. 1A) reaching the middle of abdomen; touching or slightly overlapping, dark with light patterns on dorsal field. Longitudinal veins well marked, subparallel. Lateral field with 4 longitudinal veins, dorsal field with 5-6 veins. Ovipositor long, compressed laterally; dorsal valve enlarged apically (Fig. 1A).

Female genitalia. Copulatory papilla forming an elongated sclerotized chamber (Fig. 2D).

TABLE 1. Measurements of Paragryllodes nitidula (Bolivar, 1912) n. comb. (in mm). Measurement of the female lectotype of P. nitidula n. comb. after Bolivar (1912) and Gorochov (2006). 


\begin{tabular}{|l|c|c|c|c|c|c|c|c|c|}
\hline & Body & iod & PrnL & PrnW & FWL & FIIIL & wFIII & TIIIL & Ovs \\
\hline Female Lectotype & & & & & & & & & \\
$(\mathrm{n}=1)$ & & & & & & & & & \\
Bolivar 1912 & 11 & - & 2 & - & 4.5 & - & - & - & 7.5 \\
Gorochov 2006 & 10.5 & - & 2 & - & 4.4 & 8.8 & - & - & 8.0 \\
\hline Non type Female & 11.3 & 1.2 & 2.2 & 3.1 & 4.2 & 9.8 & 2.7 & (damaged) & 8.5 \\
$(\mathrm{n}=1)$ & & & & & & & & & \\
\hline
\end{tabular}

Habitat. This species has been observed between 300 and $600 \mathrm{~m}$ alt, in the undergrowth of Seychelles rainforest. Specimens were observed standing by night on low vegetation and on trunks.

\section{Subfamily Phalangopsinae Blanchard, 1845}

\section{Subtribe Heterogryllina Saussure, 1874}

Type genus. Heterogryllus Saussure, 1874

Remarks. Saussure (1874) defined the genus Heterogryllus for one female originating from Brazil, described as Heterogryllus ocellaris. Two other species have been described in the genus, Heterogryllus crassicornis Saussure, 1878 and Heterogryllus bordoni Chopard, 1970, transferred to Aclodes Hebard, 1928 and Paraclodes Desutter-Grandcolas, 1992 respectively (see DesutterGrandcolas 1992b, 2014). In molecular-based phylogenetic analyses (Chintauan-Marquier et al. 2013, 2016; Warren et al. 2019), Aclodes and Paraclodes constitute a well-separate clade within the Paragryllinae (not the Phalangopsinae), defined elsewhere as the tribe Aclodini Desutter-Grandcolas, 2020 (Desutter-Grandcolas \& Faberon 2020). Heterogryllus is presently included in the subtribe Heterogryllina of the subfamily Phalangopsinae (Cigliano et al. 2021).

Hebard (1928a) reconsidered the cricket genera gathered by Saussure (1878) in the «Légion Phalangopsites» (= Bruner’s 1916 Phalangopsitidae) and distributed their Neotropical representatives into two assemblages, which he named the group Luzarae (Hebard 1928a) and the group Heterogrylli (Hebard 1928b). While the Luzarae are clearly defined by Hebard in his first 1928 paper (Hebard 1928a: 2), the Heterogrylli are not. Hebard (1928b) just listed some genera in this group, i.e.

Eugryllina Hebard, 1928b (now a Strogulomorphina, see Desutter-Grandcolas 1991), Acla Hebard, 1928b (synonymized with Aclodes by Desutter-Grandcolas 2014), Aclodes Hebard, 1928b, and Ectecous Saussure, 1878, with short comments on the descriptions of the new taxa. Gorochov (2014) used the subtribe Heterogryllina Hebard, 1928 within his Phalangopsinae subfamily, for Uvaroviella Chopard, 1923 (subdivided into nine subgenera) and possibly Heterogryllus, to which Gorochov (2015) added six genera, i.e. Phalangacris Bolivar, 1895 and Seychellesia Bolivar, 1912 
from the Seychelles, Phaeophilacris Walker, 1871 from Africa, Aspidogryllus Chopard, 1933 from India, Howeta Otte and Rentz, 1985 from Lord Howe island and Hemicophus Saussure, 1878 from the Neotropics.

Molecular phylogenetic evidence (Chintauan-Marquier et al. 2013, 2016; Warren et al. 2019) clearly showed that Heterogryllina sensu Gorochov is a polyphyletic assemblage. Phaeophilacris, which constitutes a monophyletic clade, has anyway been accommodated in a different subtribe of the Heterogryllini, the Phaeophilacridina (Gorochov 2020). Following Chintauan-Marquier et al. (2013, 2016), Uvaroviella and its nine subgenera have been reviewed and transferred to the tribe Aclodini of the Paragryllinae subfamily (Desutter-Grandcolas \& Faberon 2020). Here we remove Phalangacris Bolivar, 1912 and Phaeogryllus Bolivar, 1912 from the phalangopsine Heterogryllina to transfer them in the Seselini Hugel \& Desutter-Grandcolas, n. tribe of the Cachoplistinae subfamily (see below).

\section{Subfamily Cacoplistinae Saussure, 1877}

Remarks. Chintauan-Marquier et al. (2013, 2016) support the cricket tribe Homoeogryllini Gorochov, 1986, including the genera Homoeogryllus Guérin-Méneville, 1847 and Meloimorpha Walker, 1870, but also the genus Socotracris Desutter-Grandcolas, 2012 originating from Socotra, presently classified within the Phalangopsinae subfamily (Cigliano et al. 2021). Morphological characters show that the Homoeogryllini are the sister group of the Indian and Chinese monogeneric tribe Cachoplistini Saussure, 1877, within the Cachoplistinae subfamily.

Apart from Paragryllodes nitidula n. comb. (Paragryllinae) and species of Phaloria (Papuloria) (Phaloriinae), all the Phalangopsidae crickets from the Seychelles gather as a well-supported clade, which is the sister group of the Homoeogryllini, with Gryllapterus as the sister genus of (Phalangacris - Phaeogryllus) Seselia Hugel \& Desutter-Grandcolas, n. gen.). To acknowledge this relationship, we define here the Seselini Hugel \& Desutter-Grandcolas, n. tribe, endemic from the Seychelles, for the genera Phalangacris, Phaeogryllus, Seselia Hugel \& Desutter-Grandcolas, n. gen. and Gryllapterus.

Tribe Seselini Hugel \& Desutter-Grandcolas, n. tribe

Type genus. Seselia Hugel \& Desutter-Grandcolas, n. gen.

Included genera. Seselia Hugel \& Desutter-Grandcolas, n. gen., Phalangacris Bolivar, 1912, Phaeogryllus Bolivar, 1912, Gryllapterus Bolivar, 1912.

Distribution. The granitic Seychelles Archipelago. 
Diagnosis. Large to very large species with elongate legs (except Gryllapterus). Coloration clear and contrasted (except Phaeogryllus, entirely dull brown); cuticula not shiny. Head not very long for Phalangopsidae crickets. TI with two apical, ventral spurs; with inner tympanum, outer tympanum lacking (present in Phaeogryllus). TII with three (Seselia Hugel \& Desutter-Grandcolas, n. gen., Gryllapterus) or four (Phaeogryllus, Phalangacris) apical spurs. TIII with three inner and three outer apical spurs; 4/4 subapical spurs; serrulated between and above subapical spurs.

Male. FWs very short, not or only slightly overlapping; main veins longitudinal. Stridulatory structures lacking, even the file. Wings lacking. FWs without glandular structures (except in Phalangacris). Tergites not glandular, except in Seselia Hugel \& Desutter-Grandcolas, n. gen. and Gryllapterus, where both meso and metanotum present glandular pits and areas with long setae. Male genitalia: pseudepiphallic sclerite flat, wider than long, more or less triangular; two short apical median lophi, separated by a V- or U-shaped emargination, with slightly raised apex bearing short setae; an additional sclerite on each latero-ventral side of pseudepiphallic sclerite, developed as ventral hooks in Gryllapterus (pseudepiphallic lateral lophi ?). Pseudepiphallic parameres made of two wellseparated sclerites, a dorsal (close to pseudepiphallic sclerite) one, simpler, and a ventral one, larger and subdivided into an inner (smaller) and an outer (bigger) parts. Ectophallic arc complete or nearly so, located in a very anterior location between the apex of ectophallic apodemes and the pseudepiphallic parameres: ectophallic sclerotization thus having the shape of an elongate $\mathrm{H}$. No ectophallic dorsal valves. Endophallic sclerite located posteriorly to the arc. No endophallic cavity. Female. Ovipositor apex neither widened, nor ornamented. Female genitalia: copulatory papilla not forming a closed chamber.

Key to genera of Seselini Hugel \& Desutter-Grandcolas n. tribe (adults only)

1. Species with dull brown coloration. Tibiae I with both inner and outer tympana.

Phaeogryllus Bolivar, 1912

1'. Species with very contrasted coloration. Tibiae I with inner tympanum only.

2.

2(1). Small crickets (body < $10 \mathrm{~mm}$ ) with short legs. Fastigium wide; ocelli widely separate, even lateral ones. Gryllapterus Bolivar, 1912

2'. Large crickets (body > 15 mm long); legs very elongate. Fastigium narrow, with lateral ocelli very close to one another. 3.

3(2). A continuous yellow band running along the eye, pronotum, forewing and part of abdomen. Tibiae II with three apical spurs. Male forewing without a glandular inner margin. 
3'. Colour contrasted but without such a continuous yellow line. Tibiae II with four apical spurs. Male forewing inner margin glandular with a long setose area.

Phalangacris Bolivar, 1912

\section{Genus Seselia Hugel \& Desutter-Grandcolas n. gen.}

(Figs 3- 9)

Type species. Seselia coccofessei Hugel \& Desutter-Grandcolas, n. gen., n. sp., by original designation.

Distribution. South Western Indian Ocean, endemic to granitic Seychelles.

Included species. Seselia longicercata (Bolivar, 1912) n. gen., n. comb [Seychelles, Silhouette], Seselia patellifera (Bolivar, 1912) n. gen., n. comb [Seychelles, Mahé], Seselia matyoti Hugel \& Desutter-Grandcolas, n. gen., n. sp. [Seychelles, La Digue], Seselia coccofessei Hugel \& DesutterGrandcolas, n. gen., n. sp. [Seychelles, Praslin]

Diagnosis. Cuticula not shiny; coloration with a retroocular light pattern continuing on DD lateral sides, often continuing on FW at the angle between dorsal and lateral fields and on abdominal tergites; legs weakly or not annulated (Figs 3-5). Eyes not particularly protruding. Fastigium alongside of head dorsum, not separated from head dorsum by a furrow. Median ocellus dorsal. Maxillary palpi relatively elongate; articles 3-4-5 about the same size. TI with a small inner tympanum, without outer tympanum. TIII with four inner and four outer subapical spurs; three inner and three outer apical spurs. FW slightly longer than pronotum, with only longitudinal veins, identical in males and females (Fig. 6E-H). Male. FWs not reaching tergite 1 distal margin. Metanotal gland present (Fig. 6I-L); subgenital plate hind margin pointing forward in the middle. Male genitalia (Fig. 8): pseudepiphallic sclerite with a V-shaped distal emargination; pseudepiphallic parameres small, rounded, concave, the concavity facing the distal end. Female. Ovipositor slightly shorter than FIII. Female genitalia (Fig. 9): copulatory papilla weakly sclerotized more of less ring-shaped around a wide aperture.

\section{Description.}

Size. Medium to large.

General morphology. Fastigium relatively wide, alongside of head dorsum, not separated from head dorsum by a furrow. Eyes not particularly protruding. Median ocellus dorsal, subapical on fastigium; lateral ocelli not very close to each other; distance between one lateral ocellus and median ocellus slightly greater than distance between lateral ocelli. Scape large. Maxillary palpi relatively elongate; articles 3, 4 and 5 about the same size; article 5 the longest, truncate apically. DD with inconspicuous furrows, not shiny; distal margin widely bordered with white setae; LL shallow; angle between DD and 
LL obtuse. TI with a small inner tympanum; without outer tympanum; two apical spurs similar in size. TII with three apical spurs; apical spurs of similar size or dorsal inner the longest; dorsal outer spur missing. FIII regular. TIII with four inner and four outer subapical spurs; three inner and three outer apical spurs, median spur the longest on both sides, median inner spur reaching the middle of basitarsomere III. TIII serrulated over their whole length with numerous, widely separate, very small spines. Basitarsomeres III very long; two rows of small dorsal spines. FW present and identical in males and females (Fig. 6E-H); slightly longer than pronotum, with only longitudinal veins.

Coloration. Figs 3-5, 6A-D, 7. Variegated yellow and brown; face yellow and brown, wide dark sagittal bands below the eyes and below the fastigium; a faint light stripe below median ocellus, a retroocular light pattern continuing on DD lateral sides, often continuing on FW at the angle between dorsal and lateral fields and on abdominal tergites; legs weakly or not annulated, hind knees darker.

Male. Metanotal gland (Fig. 6I-L) present, with one pad of setae on each side; setae sometimes also present on mesonotum. Supra anal plate without glandular areas. Subgenital plate hind margin pointing forward in the middle, forming a small triangular concavity at the distal end of the subgenital plate.

Male genitalia. Fig. 8. Pseudepiphallic sclerite with a V-shaped distal emargination separating triangular pseudepiphallic median lophi (dorsal view); pseudepiphallic median lophi slightly upcurved dorsally (side view); pseudepiphallic parameres small, rounded, concave, the concavity facing the distal end; rami wide, contacting pseudepiphallic sclerite.

Female. Ovipositor slightly shorter than FIII.

Female genitalia. Fig. 9. Copulatory papilla weakly sclerotized, with three connected sclerites surrounding a large opening.

Habitat. Forest-dwelling species, mostly restricted to preserved forest. Most species are active by night on palm leaves. They hide during the day above the ground, on dry palm leaves.

\section{Seselia longicercata (Bolivar, 1912) n. gen., n. comb}

(Figs 3A, 4A, 5A, 6A, E, I, 7A, 8A-C, 9A, Table 2)

Seychellesia longicercata Bolívar, 1912: 287.

Distribution. Seychelles, Silhouette.

Type material. Holotype and paratypes, Seychelles, Silhouette, forest near Mt. Pot-à-eau, 1500 ft., VIII. 1908, CUMZ (not examined). 
Other specimens examined. Seychelles, Silhouette, vers Jardin Marron, 400 m, vue de nuit, 5.viii.2010, S. Hugel leg., 1 male (2010SEYSH169), MNHN-EO-ENSIF12095; 1 female (2010SEYSH170), MNHN-EO-ENSIF12096; 1 female (2010SEYSH171), coll. SH.

Molecular sampling. LDG 370 in Warren et al. (2019).

Emended diagnosis. In addition to generic characters. Size small for the genus. Coloration: dark sagittal stripe on face very contrasted and extended to clypeus and labrum (Fig. 6A); white parasagittal stripe below antennae with small dark spot; DD variegated (Figs 3A, 4A); legs I and II with distinct annulations (Figs 3A, 4A); FIII with dark patterns (Fig. 7A); FWs (Fig. 6E) with distinct white band at the angle between dorsal and lateral fields; parasagittal white lines on abdominal tergites abdomen weakly defined, made of white spots (Figs 4A, 5A). FW dorsal field with four longitudinal veins. Male metanotal gland as on Fig. 6I. Male genitalia (Fig. 8A-C): parameres relatively small; dorsal part of parameres pointing sharply toward basis of pseudepiphallic emargination; rami widely contacting pseudepiphallic sclerite. Female genitalia: copulatory papilla as on Fig. 9A.

TABLE 2. Measurements of Seselia longicercata (Bolivar, 1912) n. gen., n. comb. (in mm).

\begin{tabular}{lccccccc}
\hline & BodyL & PrnL & PrnW & FWL & FIIIL & TIIIL & Ovs \\
\hline $\begin{array}{l}\text { Males } \\
\left(\mathrm{n}=1^{*}\right)\end{array}$ & $12-16^{*}$ & $2.2-2.8^{*}$ & 2.9 & $3.0-3.5^{*}$ & 10.8 & 11.6 & - \\
$\begin{array}{l}\text { Bolivar } \\
(1912)\end{array}$ & 12 & 2.2 & - & 2.8 & 11 & - & - \\
& & & & & & & \\
\hline Females & $15.9-19.5$ & $2.4-3.3^{*}$ & $3.2-3.4$ & $3.2-3.3^{*}$ & $12.4-13.6$ & $11.8-12.1$ & $11.2-12.8^{*}$ \\
$\left(\mathrm{n}=2^{*}\right)$ & & & & & & & \\
$\begin{array}{l}\text { Bolivar } \\
(1912)\end{array}$ & 18 & 3.1 & - & 3 & 14 & - & 12
\end{tabular}

* These measurements include ranges given in Gorochov (2006).

Seselia patellifera (Bolivar, 1912) n. gen., n. comb

(Figs 3B, 4B, 5B, 6B, F, J, 7B, 8D-F, 9B, Table 3)

Seychellesia patellifera Bolívar, 1912: 287.

Distribution. Seychelles, Mahé. 
Type material. Mahé, Morne Seychellois, 1905; Cascade Estate, 800 ft. or over, 1908-9; Mare aux Cochons district, about $1500 \mathrm{ft}$. or over. CUMZ (not examined).

Other specimens examined. Seychelles, Mahé, Le Niol, 140m alt., vue de nuit, 19.vii.2010, S. Hugel leg., 1 male (2010SEYSH032), MNHN-EO-ENSIF12097; same, 1 female (2010SEYSH029), MNHNEO-ENSIF12098; same, 1 female (2010SEYSH030), MNHN-EO-ENSIF12099; same, 1 female (2010SEYSH031), MNHN-EO-ENSIF12100; Seychelles, Mahé, Morne Blanc, 140m alt., vue de nuit, 18.vii.2010, S. Hugel leg., 1 female (2010SEYSH008), coll. SH; Seychelles, Mahé, jardin botanique, vue de jour, 16.vii.2003, S. Hugel leg., 1 female, coll. SH.

Molecular sampling. LDG 368 in Warren et al. (2019).

Emended diagnosis. In addition to generic characters. Size small for the genus (Fig. 4B).

Coloration: dark sagittal stripe on face feebly contrasted (Fig. 6B); white parasagittal stripe below antennae with a large dark spot extended from the dark band below the eye (Figs 5B, 6B); DD dark (Fig. 4B); legs I and II with faint annulations (Figs 3B, 4B); FIII without dark patterns (Fig. 7B); FWs with distinct white band at the angle between dorsal and lateral fields (Figs 4B, 6F); parasagittal white lines on abdominal tergites relatively continuous and well defined (Fig. 4B). FW dorsal field with 4 longitudinal veins. Male metanotal gland as on Fig. 6J. Male genitalia (Fig. 8D-F): parameres relatively small; dorsal part of parameres forming a plate widening toward the midline; contact between pseudepiphallic sclerite and rami of medium size. Female genitalia: copulatory papilla as on Fig. 9B.

TABLE 3. Measurements of Seselia patellifera (Bolivar, 1912) n. gen., n. comb. (in mm).

\begin{tabular}{lccccccc}
\hline & BodyL & PrnL & PrnW & FWL & FIIIL & TIIIL & Ovs \\
\hline Males & $12.5-12.8$ & 2.2 & 3.0 & $3.0-3.3$ & $10.5-11.0$ & $9.2-9.6$ & - \\
$(\mathrm{n}=2)$ & & & & & & & \\
Females & $12.0-16.4$ & $2.7-3.0$ & $3.5-3.6$ & $2.5-3.0$ & $13.6-14.2$ & $12.6-13.6$ & $11.0-13.4$ \\
$(\mathrm{n}=4)$ & 14.9 & 2.9 & 3.5 & 2.8 & 14.0 & 13.0 & 12.2 \\
\hline
\end{tabular}

Seselia matyoti Hugel \& Desutter-Grandcolas n. gen., n. sp.

(Figs 3C, 4C, 5C , 6C, G, K, 7C, 8G-I, 9C, Table 4)

Distribution. Seychelles, La Digue.

Type material. Holotype male. Seychelles, La Digue, Veuve Réserve, vue de nuit, 29.vii.2010, S. Hugel leg., (2010SEYSH147), MNHN-EO-ENSIF12111. Paratypes, 3 males, 4 females. Same as 
holotype, vue de jour, 1 male (2010SEYSH113), coll. SH; Seychelles, La Digue, Nid d'Aigle, 26.vii.2003, 1 female, coll. SH.; same, 29.vii.2010, vue de nuit, 1 male (2010SEYSH130), MNHN-EOENSIF12112; same, 1 male (2010SEYSH131), coll. SH; same, 1 female (2010SEYSH132), MNHNEO-ENSIF12113; Seychelles, La Digue, La Retraite, 25.vii.2003, S. Hugel leg., 1 female, coll. SH.; Seychelles, La Digue, Anse Coco, vue de nuit, 28.vii.2010, S. Hugel leg., 1 female (allotype) (2010SEYSH112), MNHN-EO-ENSIF12114.

Molecular sampling. LDG 367, LDG 374 in Warren et al. (2019).

Etymology. This species is dedicated to our friend and colleague, the naturalist and journalist Pat Matyot.

Diagnosis. Within the genus, middle-sized species characterized by the small size of the white spot on FW base, and the dark spot behind the eye

\section{Description.}

In addition to generic characters. Size medium for the genus.

Coloration: dark sagittal and parasagittal (infero ocular) stripe on face contrasted (Fig. 6C); white parasagittal stripe below antennae without dark pattern (Fig. 5C); DD variegated (Fig. 4C); legs I and II with annulations (Figs 3C, 4C); FIII with dark patterns (Fig. 7C); FW (Figs 4C, 5C) with a distinct white spot at basis (Fig. 6G), without distinct white band at the angle between dorsal and lateral fields; parasagittal white lines on abdominal tergites weakly defined, made of white spots (Fig. 5C). FW dorsal field with 5 longitudinal veins.

Male. Metanotal gland as on Fig. 6K.

Male genitalia. Fig. 8G-I. Pseudepiphallic sclerite not wider in anterior (proximal) part; with parameres relatively large, oval; dorsal part of parameres forming a short wide plate at midline side; contact between pseudepiphallic sclerite and rami narrow (Fig. 8C).

Female genitalia. Copulatory papilla as on Fig. 9C.

TABLE 4. Measurements of Seselia matyoti Hugel \& Desutter-Grandcolas, n. gen., n. sp. (in mm).

\begin{tabular}{lccccccc}
\hline & BodyL & PrnL & PrnW & FWL & FIIIL & TIIIL & Ovs \\
\hline Holotype & 13.2 & 2.3 & 2.8 & 3.1 & 11.4 & 11.0 & - \\
mâle & & & & & & & \\
Males & $12.1-13.2$ & $2.3-2.4$ & $2.6-3.1$ & $3.1-3.2$ & $11.4-12.5$ & $11.0-12.2$ & - \\
$(\mathrm{n}=4)$ & 12.9 & 2.4 & 2.9 & 3.1 & 12.1 & 11.5 & 13.2 \\
\hline
\end{tabular}

Allotype 


\begin{tabular}{lccccccc}
\hline female & & & & & & & \\
Females & $13.9-17.4$ & $2.7-3.0$ & $3.3-3.7$ & $2.7-3.2$ & $12.8-13.6$ & $12.9-13.3$ & $11.3-13.1$ \\
$(\mathrm{n}=4)$ & 16.1 & 2.9 & 3.5 & 2.9 & 13.2 & 13.1 & 12.5 \\
\hline
\end{tabular}

Seselia coccofessei Hugel \& Desutter-Grandcolas n. sp. n. gen., n. sp.

(Fig. 3D, 4D, 5D, 6D, H, L, 7D, 8J-L, 9D, Table 5)

Distribution. Seychelles, Praslin.

Type material. Holotype male. Seychelles, Praslin, PN Vallée de Mai, Vue de Nuit, 24.vii.2010, S Hugel leg. (2010SEYSH083), MNHN-EO-ENSIF12115.

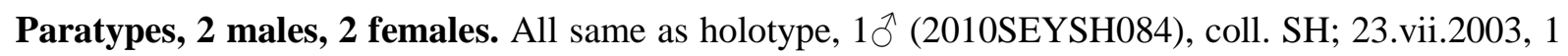
male, coll. SH; 22.vii.2010, 1 female (allotype) (2010SEYSH057), MNHN-EO-ENSIF12116; 22.vii.2010, 1 female (2010SEYSH058), coll. SH.

Molecular sampling. LDG 369 and LDG372 in Warren et al. (2019).

Diagnosis. Within the genus, large species with a black DD; parasagittal white bands on pronotum, forewing and tergites very wide and contrasted.

\section{Description.}

In addition to generic characters. Size large for the genus.

Coloration: dark sagittal stripe on face contrasted, not extending to labrum (Fig. 6D); white parasagittal stripe below antennae without distinct dark pattern ; DD black (Fig. 4D), parasagittal white lines very well defined (Figs 4D, 5D); legs I and II with indistinct annulations (Figs 3D, 4D); FIII without dark patterns (Fig. 7D); FW with a distinct white band at the angle between dorsal and lateral fields (Fig. $6 \mathrm{H}$ ); parasagittal white lines on abdominal tergites very well defined (Figs 3D, 4D). FW dorsal field with six longitudinal veins.

Male. Metanotal gland as on Fig. 6L.

Male genitalia. Fig. 8J-L. Pseudepiphallic sclerite wider in anterior (proximal) part; with parameres relatively large, oval; dorsal part of parameres forming a short wide plate at midline side; contact between pseudepiphallic sclerite and rami narrow.

Female genitalia. Copulatory papilla as on Fig. 9D.

TABLE 5. Measurements of Seselia coccofessei Hugel \& Desutter-Grandcolas, n. gen., n. sp. (in mm).

$\begin{array}{lllllll}\text { BodyL } & \text { PrnL } & \text { PrnW } & \text { FWL } & \text { FIIIL } & \text { TIIIL } & \text { Ovs }\end{array}$




\begin{tabular}{lccccccc}
\hline Holotype $\hat{0}$ & 18.0 & 2.9 & 3.3 & 4.4 & 15.1 & 14.9 & - \\
Males (n=3) & $12.4-18.0$ & $2.9-3.0$ & $3.1-3.5$ & $3.7-4.8$ & $14.5-15.2$ & $14.4-15.0$ & - \\
& 15.5 & mean (2.9) & 3.3 & 4.3 & 14.9 & 14.8 & \\
\hline Allotype & 17.6 & 4.8 & 4.9 & 4.7 & 19.0 & 18.3 & 17.0 \\
$q$ & & & & & & & \\
\hline Females & $17.2-17.6$ & $4.6-4.8$ & $4.6-4.9$ & 4.7 & $17.0-19.0$ & 18.3 & $16.7-17.0$ \\
$(\mathrm{n}=2)$ & & & & & & & \\
\hline
\end{tabular}

Key to species of Seselia Hugel \& Desutter-Grandcolas n. gen.

1. Large, FIII length > $14.5 \mathrm{~mm}$; FW dorsal field with six longitudinal veins (Praslin). Seselia coccofessei Hugel \& Desutter-Grandcolas, n. gen., n. sp.

1’. Small or medium, FIII length $<14.5 \mathrm{~mm}$; FW dorsal field with not more than five longitudinal veins (Seychelles but not Praslin). 2.

2(1). FW with a white spot at basis; FW dorsal field with five longitudinal veins (La Digue). Seselia matyoti Hugel \& Desutter-Grandcolas, n. gen., n. sp.

2'. FW with a white band at the angle between dorsal and lateral fields; FW dorsal field with four longitudinal veins (Mahé, Silhouette) 3.

3(2). FIII with dark patterns (inner, dorsal, outer); DD variegated between the white parasagittal stripes; abdominal white parasagittal stripes made of white spots, weakly defined (Silhouette).....

Seselia longicercata (Bolivar, 1912) n. gen., n. comb.

3’. FIII without dark patterns (inner, dorsal, outer); DD dark between the white parasagittal stripes; abdominal white parasagittal stripes relatively continuous and distinct (Mahé) ...... Seselia patellifera (Bolivar, 1912) n. gen., n. comb.

\section{Genus Phaeogryllus Bolivar, 1912}

(Figs 10-12)

Phaeogryllus Bolivar, 1912: 285.

Type species. Phaeogryllus fuscus Bolivar, 1912, by monotypy.

Distribution. South Western Indian Ocean, endemic to granitic Seychelles. 
Emended diagnosis. Within the Seselini Hugel and Desutter-Grandcolas, n. tribe, middle-sized but wide crickets, with uniform dull-brown coloration; cuticula hardly shining. TI with both inner and outer tympana. Male. FWs long and coriaceous with strong longitudinal veins and weaker transverse veins, without glandular structures. Tergites not glandular. Paraprocts longer than epiproct, wide and deeply concave distally. Male genitalia: lateral margins of pseudepiphallic sclerite convex in dorsal view; median lophi very closely set, making a very narrow apex compared to pseudepiphallic sclerite, separated by a truncated V-shaped emargination. Rami articulated with pseudepiphallic sclerite, with very thin apex. Dorsal sclerite of pseudepiphallic paramere well-sclerotized, rounded; ventral sclerite with sigmoidal base, the inner part smaller with teeth on inner and distal margins, the outer part larger and thicker, with regular margins. Ectophallic fold elongate but not reaching pseudepiphallic distal margin; sclerotized dorsally. Ectophallic apodemes regularly wide, somewhat longer than the sclerotization of epi-ectophallic invagination, and regularly divergent. Female. Apterous. Ovipositor short; apex unarmed, short, hardly separated by small notches. Female genitalia: copulatory papilla very small, broadly quadrangular in dorsal or ventral view, sclerified ventrally and membranous dorsally.

\section{Redescription.}

Middle-sized, stocky crickets with uniform dull-brown coloration, and dense setation (Figs 10A, 11A). General morphology. Head vertical, but thick (Fig. 10D). Eyes small, little protruding. Fastigium (Fig. 10B, C) longer than wide, not furrowed; narrowed distally, its base wider than the scapes, its apex narrower that the scapes; separated from the vertex by a very faint transverse furrow; very slightly lower than the vertex in side view; fastigium bearing two close rows of strong setae on midline. Ocelli all large; almost in equilateral triangle. Lateral ocelli at fastigium base, separated from inner margin of eyes by a shallow crest; median ocellus vertical, subapical on fastigium. Vertex flat between the eyes. Maxillary palpi long, even articles 1 and 2 (Fig. 10B); article 4 longer than article 3; article 5 the longest, regularly widened toward apex, its apex truncate obliquely, its dorsal margin concave. Scapes longer than wide. Pedicel with a tooth. Pronotum large, wider than long, but not transverse; DD anterior margin concave, posterior margin very slightly bisinuate, almost straight; LL anterior half distinctly raised, its lower margin rounded; LL distal half shorter. Legs I and II thin, legs III distinctly short and thick. Coxae I largely separated. TI shorter than FI; two apical spurs, quite long, the inner longer than the outer by one third of its length; inner and outer tympana both present, small and obliterate, inner tympanum shorter and more rounded, outer tympanum longer and narrower. Coxae II well separated. TII shorter than FII; four apical spurs; inner spurs longer than outer spurs; inner ventral spur the longest and the thickest. FIII distinctly thick, slightly longer than TIII; TIII serrulated between and above subapical spurs, with numerous triangular, thick and flat spines, only TIII base close to the knee without spines; TIII flat between serrulation rows; four pairs of subapical spurs with hook-like apices; inner subapical spurs lower on TIII and shorter than the outers; first inner subapical spur very 
close to inner apical spurs; three inner and three outer apical spurs, the inners longer than the outers; dorsal inner spur longer than the median, and the longest, about two third basitarsomere III length; median spur the longest on outer side, about half length of inner median spur. Tarsi III about half TIII length; basitarsomere III with two rows on dorsal spines in addition to apical spines, the inner row with fewer spines; inner apical spur of basitarsomere III reaching midlength of distal tarsomere. Abdomen wide and quite flat. Cerci shorter than FIII.

Male. FWs (Fig. 10C, D) coriaceous, only partly overlapping; short, not reaching tergite III midlength; without yellow lateral bands. No stridulatory apparatus. Venation made of strong and thick longitudinal veins (two on lateral field, six on dorsal field), separated by numerous, thinner and weaker transverse veins. No glandular structures on metanotum, tergites and supra-anal plate. Subgenital plate short and low, with a short distal furrow. Paraprocts longer dorsally than epiproct, enlarged distally and deeply concave (Fig. 10F).

Male genitalia. Fig. 12. Very flat. Pseudepiphallic sclerite somewhat shorter than the rami, slightly transverse, with convex lateral margins; two short median lobes, raised dorsally at apex with short setae. Rami long, articulated to the pseudepiphallic sclerite on its ventral side. Pseudepiphallic parameres with a thick dorsal sclerite located against the pseudepiphallic sclerite, and a larger ventral sclerite, sinuate basally and subdivided by a deep furrow into an inner part, with a denticulate distal margin, and an outer part, lamella-shaped and slightly concave. Epi-ectophallic invagination welldevelopped, flat; apodemes shorter than the rami, wide, divergent; arc nearly complete, very narrow. Ectophallic fold elongate, not reaching pseudepiphallic sclerite margin; sclerotized dorsally; apex broadened and truncate; ventral margins slightly sclerotized. Endophallic sclerite reduced to a pair of long and thin plates, on each part of a very thin median sclerite; endophallic apodeme as a thin median longitudinal crest. No dorsal cavity.

Female. Fig. 11A. Distinctly larger than male. Apterous. Epiproct and paraprocts not modified. Subgenital plate short and wide; apex truncate. Ovipositor (Fig. 11B) short, compressed laterally; apex short, without ornamentation, hardly separate by a dorsal and a ventral notch.

Female genitalia. Copulatory papilla very small, membranous dorsally, sclerotized ventrally with a distinct quadrangular process (Fig. 11C-E).

Habitat. Phaeogryllus fuscus lives on the ground with leaf litter or at the bottom of tree trunks as does Amphiacusta Saussure, 1874 in the Caribbean. It has only been observed in native forest at middle to high altitude.

\section{Phaeogryllus fuscus Bolivar, 1912}

(Figs 1D-E, 10, 11, 12, Table 6)

Phaeogryllus fuscus Bolivar, 1912: 286. 
Type locality. Seychelles, Silhouette, viii.1908 (Lectotype, here designated); Mahé, Cascade Estate, ii.1909 (paralectotype, here designated).

Type material. Two female syntypes exist for this species, one from Mahé (NHM), and the other from Silhouette (CUMZ) (see Paris (1991)). Both are identified by Bolivar (manuscript labels), but additional labels not from Bolivar indicate 'type' for the female from Mahé, and 'cotype' for the female from Silhouette; Huxley also identified the female from Mahé as a "lectotype" but never published it. As no specimen from $P$. fuscus could be found from Mahé, despite intensive search, we designated here the female from Silhouette as the lectotype of $P$. fuscus, in order to stabilize the taxonomy of this species. The female from Mahé is here designated as paralectotype, but the presence of $P$. fuscus, or a close species, on Mahé island will have to be confirmed by additional field work.

Examined material. Seychelles, Silhouette, Jardin Marron vers Mt Pot à eau, > 400m, vue de nuit, 1 male (2010SEYSH185), MNHN-EO-ENSIF12265; same, 1 female (2010SEYSH186), MNHN-EOENSIF12266; same, 1 male, in alcohol (2010SEYSH192), 5.x.2010, S. Hugel, alcohol collection tube 684; MNHN-EO-ENSIF12267; same, 1 female in alcohol (2010SEYSH193), 5.x.2010, S. Hugel, alcohol collection tube 685; MNHN-EO-ENSIF12268.

Molecular sampling. LDG 135 in Chintauan-Marquier et al. (2013, 2016) and Warren et al. (2019), and LDG 373 in Warren et al. (2019).

Diagnosis. As for the genus.

\section{Redescription.}

In addition to the characters of the genus:

General morphology. TIII inner serrulation: no spine in male, zero to one spine in female before isa1; one to two spines in male, three spines in female between isa1 and isa2; three spines in males, four spines in female between isa2 and isa3; 4-5 spines in male, 5-7 spines in female between isa3 and isa4; 12 spines in male, 12-14 spines in female above isa4. TIII outer serrulation: no spine in male, zero to one spine in female before osa1; three to four spines in male, four to five spines in female between osa1 and osa2; five spines in male, four to six spines in female between osa2 and osa3; seven to eight spines in male, eight to nine spines in female between osa3 and osa4; 10-11 spines in male, 10-14 spines in female above osa4. Basitarsomeres III with one in male, none in female, inner dorsal spine; four in male, five in female outer dorsal spines, in addition to apical spines.

Coloration. Face brown (Fig. 10B); a wide yellow line from lower angle of each eye to posterior angle of mandible; a pair of short yellow lines between antennal pits and epistemal suture, widened below 
and along the eye. Ocelli yellow. Preclypeus with a short, transverse yellow line on each side. Labrum whitish more or less marked with brown. Dorsally, inner margin of eyes marked with yellow, this line prolonged as a thick band toward occiput. Fastigium black with a pair of wide and short yellow lines mediodorsally, not reaching the median ocellus, and separated by a thin black brown line bearing strong dark brown setae. Maxillary palpi brown, their dorsal margin yellow. Femora dark brown (Fig. $10 \mathrm{E}$ ); tibiae lighter but not annulate; apex of subapical TIII spurs yellow; apical spurs more yellowish, at least in males. Tergites dark brown with brown to yellowish setae.

Male. FWs brown, lighter than the body; venation yellowish brown (Fig. 10C). FW lateral field with two longitudinal veins (Fig. 10D); dorsal field with six longitudinal veins (Fig. 10C). Cerci and base of supra-anal plate dirty yellow (Fig. 10F).

Male genitalia. As on Figure 12.

Female. Ovipositor shorter than FIII (Fig. 11B).

Female genitalia. Copulatory papilla membranous dorsally and with a distinct ventral process, as on Figure 11C-E.

Table 6. Measurements of Phaeogryllus fuscus Bolivar, 1912 (in mm). Bolivar (1912) did not precise if he measured only one female of $P$. fuscus or both; these measurements thus remain ambiguous.

\begin{tabular}{lccccccc}
\hline & BodyL & PrnL & PrnW & FWL & FIIIL & TIIIL & Ovs \\
\hline $\begin{array}{l}\text { Males } \\
(\mathrm{n}=2)\end{array}$ & $18,8-19.8$ & $3.9-4.2$ & 5.1 & $4.5-5$ & $13.5-14.4$ & $12.7-13.5$ & - \\
\hline $\begin{array}{l}\text { Females } \\
(\mathrm{n}=2)\end{array}$ & $21,8-22.3$ & $4.3-5.5$ & $5.2-6.8$ & - & $15-18.7$ & $12.8-15.5$ & $12.8-16.8$ \\
\hline Bolivar & & & & & & & \\
$(1912)$ & & & & & & & \\
female & 18 & 4.5 & -- & -- & 15 & 13.5 & 15 \\
\hline
\end{tabular}

\section{Genus Phalangacris Bolivar, 1895}

(Figs 1F-G, 13 - 16)

Type species. Phalangacris alluaudi Bolivar, 1895

Other species included. Phalangacris (?) phaloricephala Gorochov, 2006 (Cousin island, near Praslin island), Phalangacris sotsote Hugel \& Desutter-Grandcolas, n. sp., Phalangacris ferlegro Hugel \& Desutter-Grandcolas, n. sp. 
Distribution. South Western Indian Ocean, endemic to granitic Seychelles.

Diagnosis. Big but very slender species, with very long legs, antennae and cerci; legs all very thin, including FIII. Contrasted coloration, with yellow, brown and black. Male. FWs short, flap like; inner margin glandular; paraprocts not modified. Male genitalia similar to those of Phaeogryllus: pseudepiphallic sclerite short, transverse, with convex lateral margins in dorsal view; median lophi very closely set, making a very narrow apex compared to pseudepiphallic sclerite, separated by an emargination not truncated as in Phaeogryllus. Rami articulated with pseudepiphallic sclerite, with very thin apex. Dorsal sclerite of pseudepiphallic parameres small, well-sclerotized; ventral sclerite with sigmoidal base, the inner part smaller with teeth on inner and distal margins, the outer part larger and thicker, with regular margins. Ectophallic fold short and wide, sclerotized dorsally. Ectophallic apodemes very thick and much shorter than in Phaeogryllus, hardly longer than the sclerotization of epi-ectophallic invagination, and regularly divergent. Female. Apterous. Ovipositor short; apex unarmed, short, without apical enlargement. Female genitalia: copulatory papilla broadly triangular, sclerified dorsally.

Phalangacris and Phaeogryllus can easily be separated by their patterns of coloration, auditory tympana, male forewing length and coloration, male paraproct shape, female ovipositor and female copulatory papilla.

\section{Redescription.}

Large species with very long and thin legs (Fig. 13). Coloration contrasted, yellow, brown and black, with distinct head pattern (Fig. 1F, G).

General morphology. Head vertical. Fastigium narrow, much longer than wide; not separated from the vertex by a distinct furrow. Three ocelli, set in an equilateral triangle; median ocellus vertical, distinctly far from fastigium apex; lateral ocelli distinctly far from fastigium base. Scapes longer than wide, pedicel with a small white tooth on inner margin, antennae very long. Maxillary palpi very long and thin; articles 1 and 2 quite long, about one fourth article 3; article 3 a little shorter than article 4; article 5 the longest, widened only at and close to rounded apex, dorsal margin straight except for concave distal third (Fig. 14A, D). Eyes protruding, pyriform; in side view, largely separated from cheek posterior and lower margins. Pronotum wider than long; DD margins both concave; LL anterior angles raised dorsally, posterior angle regressed. Legs very long and very thin. Coxae I largely separated from each other, more than coxae II. TI and TII longer than FI and FII respectively; basitarsomeres I and II longer than half TI and TII respectively. TI with two apical, ventral spurs; inner tympanum small, rounded, obliterate; outer tympanum lacking. TII with four apical spurs, inner spurs the longest, outer dorsal spur the shortest. FIII not very wide; with a long filiform apical part, between one third and one half TIII length. TIII longer than FIII; three inner and three outer short apical spurs; median and dorsal inner spurs the longest, median spur only slightly longer than dorsal 
spur; median outer spur shorter, but the longest on outer side, inner and dorsal outer apical spurs subequal. TIII with four pairs of subapical spurs, short and curved apically; inner spurs slightly lower on tibia than outer spurs. TIII serrulated between and above subapical spurs, except between isa1 and isa2. Basitarsomeres III shorter than half TIII, shorter than basitarsomeres I and II; with one row of outer dorsal spines in addition to inner and outer apical spines. Cerci extremely long, 1.5 times body length when not broken.

Male. FWs very short, flap-like, broadly triangular with straight distal margin, not overlapping, not covering tergite I midlength; lateral field reduced, as a short elongate triangle with a longitudinal vein; dorsal field venation reticulated, but with several clear longitudinal veins; inner margin of dorsal field sinuate, glandular on its distal 2/3 with a narrow area densely covered with short setae (Fig. 14G-I). No glandular structures on metanotum, tergites and supra-anal plate. Subgenital plate short, low, furrowed distally at the level of a small and acute distal median lobe.

Male genitalia. Fig. 16. Small and compact. Pseudepiphallic sclerite wider than long, as long as or shorter than rami; sclerotized laterally and partly dorsally; posterior margin with two small, median lophi with tooth-like apex. Rami connected to lower lateral part of pseudepiphallic sclerite. Pseudepiphallic parameres with a dorsal sclerite smaller, plate-like and more sclerotized (black in coloration); ventral sclerite wider, cup-shaped, with wide teeth on inner margin. Ectophallic fold short and wide, sclerotized dorsally; distal margin truncate. Epi-ectophallic apodemes short and vertical; arc very wide, complete (but with a thin and clear longitudinal line); ventral sclerite between arc and pseudepiphallic parameres very long, as in Phaeogryllus. Endophallic sclerite long ang narrow; Wshaped, with outer branches very long compared to median part. A short lamella-like endophallic apodeme. No endophallic cavity.

Female (after P. ferlegro Hugel and Desutter-Grandcolas, n. sp.). Apterous. Subgenital plate short, transverse. Ovipositor straight, shorter than FIII, without terminal enlargement (Fig. 15D). Female genitalia (after P. ferlegro Hugel and Desutter-Grandcolas, n. sp.). Copulatory papilla sclerotized, not forming a closed chamber (Fig. 15E).

Remark. Gorochov (2006) tentatively described Phalangacris ? phaloricephala from Cousin Island and mentioned that it differs from $P$. alluaudi only by its smaller size. We confirm here that this species belongs to Phalangacris, whatever the coloration of its head dorsum. Owing to observed endemism within the genus, and as Cousin Island is closer to Praslin than from Mahé (where $P$. alluaudi is present), it seems reasonable to hypothesize that $P$. phaloricephala is distinct from $P$. alluaudi; it will be necessary however to check its relation to Phalangacris ferlegro Hugel and Desutter-Grandcolas, n. sp. 
Habitat. Species of this genus are observed by night near the ground, usually on the very large rocks frequent on granitic Seychelles islands. Some species occur on semi-open habitats (summit of La Digue) or on rainforest (Vallée de Mai in Praslin).

\section{Phalangacris alluaudi Bolivar, 1895}

(Figs 13A, 14A, D, G, 15A, 16A-C, Table 7)

Phalangacris alluaudi Bolivar, 1895: 381.

Type locality. Seychelles, Mahé.

Type material. One male, one female syntypes mentioned by Bolivar (1895). Female syntype (not adult) in MNHN (MNHN-EO-ENSIF2957).

Examined material. Seychelles, Mahé, female syntype, MNHN-EO-ENSIF2957. Mahé, La Réserve, one male, 11.v.2016, A. Hochkirch, alcohol collection tube 686, MNHN-EO-ENSIF10764.

Molecular sampling. LDG 594 (Warren et al. 2019)

\section{Emended description}

In addition to the characters of the genus:

TIII inner serrulation: no spine before isa1, and between isa1 and isa2, in both male and female; three spines in male, three to four spines in female, between isa2 and isa3; seven spines in male, four to six spines in female, between isa3 and isa4; 17-18 spines in male, 19-20 spines in female, above isa4. TIII outer serrulation: no spine before osa1 in both male and female; three spines in male, two to three spines in female, between osa1 and osa2; four to five spines in male, five spines in female, between osa2 and osa3; nine spines in male, eight to nine spines in female, between osa3 and osa4; 18-21 spines in male, 19 spines in female, above osa4. Basitarsomeres III without dorsal inner spine in both male and female; with four to five in male, five to six in female, dorsal outer spines, in addition to apical spines.

Coloration (male kept in alcohol, very pale: Fig. 13A). Head yellow with dark brown to black pattern: on the face (Fig. 14A), a black longitudinal line under each antennal pit, prolonged on the mandible, and slightly bifurcated toward lower angle of eye; a black, wide longitudinal median line, reaching preclypeus, prolonged laterally on antennal pit membrane and on scape; at the same level, a short longitudinal median yellowish line. Cheeks black brown in posterior half (Fig. 14D); anterior part yellow; part just behind eye marbled brown and yellowish. Maxillary palpi: articles 1 and 2 white; article 3 - 5 brown with white upper and lower sides. Vertex and occiput with four thin longitudinal 
yellow lines, the two in median position trifurcated, the laterals prolonged toward the eye but not reaching it. Fastigium black brown between ocelli; median ocellus black brown; lateral ocelli yellow. Scape yellow with black spots on inner side; antennae brown; apical margins of basal articles yellowish, flagellum otherwise light brown. LL brown with a wide yellow spot in anterior angle and yellowish anterior margin (Fig. 14D); DD spotted yellow, brown and black (Fig. 13A). Abdomen spotted yellow, brown and black (Fig. 13A); cerci yellow with black spots on inner and more or less on outer sides. Legs brown and yellow, with dark rings and stripes: FI with three incomplete dark rings and dark lower margins; TI brown with two small yellow rings, one median and one below the knee; FII as FI, but less dark; TII as TI, but apical spot larger; FIII striated with black on outer side and with three dark rings in filiform part, including one apical on the knee (Fig. 15A); TIII as TI and TII, but with five dark rings; spurs yellow with black tip. Basitarsomeres light brown with yellow base and apex; tarsomeres 2 and 3 yellowish.

Male. FWs (Fig. 14G) not reaching distal margin of tergite 1, both lateral and dorsal fields on male dorsum; not overlapping, but inner margins of both FWs close to one another; dorsal field distally broadly perpendicular, with distal and inner margin at nearly right angle; glandular area along distal $2 / 3$, with many short setae. Venation with strong longitudinal veins and weaker transverse veins; a very strong vein (?) along distal margin, bordering the glandular area distally, distinctly light; dorsal field with three additional longitudinal veins, the two most external bifurcated at one or two thirds of their length respectively; lateral field with one longitudinal vein; transverse veins present on both dorsal and lateral fields. FWs light brown, all veins light.

Male genitalia. As on figure 16A-C.

Female. Known from a juvenile only.

TABLE 7. Measurements of Phalangacris alluaudi Bolivar, 1895 (in mm). Male syntype after Bolivar (1895).

\begin{tabular}{lccccccc}
\hline & BodyL & PrnL & PrnW & FWL & FIIIL & TIIIL & Tars1-III \\
\hline Syntype & \multirow{2}{*}{18} & 4 & - & 2.5 & 19 & 20 & 6 \\
\hline $\begin{array}{l}\text { Male } \\
(\mathrm{n}=1)\end{array}$ & 23.9 & 4.2 & 5.2 & 4 & 22.6 & 23.9 & 6.4 \\
\hline
\end{tabular}

Phalangacris ferlegro Hugel and Desutter-Grandcolas, n. sp.

(Figs 1F, 13B, 14B, E, H, 15B, D, E, 16D-F, Table 8)

Type locality. Seychelles, Praslin. 
Type material. Holotype. 1 male, Seychelles, Praslin Parc National, Vallée de Mai, Vue de nuit, 24.vii.2010, S. Hugel leg. (2010SEY080), MNHN-EO-ENSIF12117.

Paratypes, $1{ }^{\lambda}, 2$ ․ Same as holotype, 1 q (allotype), (2010SEY079), MNHN-EO-ENSIF12118; same as holotype, $1 \hat{\jmath}$ (2010SEY078), 1 q (2010SEYSH081), S. Hugel leg., coll.

Non type material. Same as holotype (2010SEY082, subadult male), MNHN (MNHN-EOENSIF12119); Seychelles, Praslin Parc National, Glacis Noir, Vue de nuit, 22.vii.2010, S. Hugel leg. (2010SEY067, very young juvenile) MNHN (MNHN-EO-ENSIF12120).

Molecular sampling. LDG 371 (Warren et al. 2019)

Etymology. Species named after the Creole expression "fer le gro", meaning "showing off", in relation to the large size of the cricket. Noun in apposition.

Diagnosis. In addition to generic characters. Size large for the genus (Body $\mathrm{L} \geq 20 \mathrm{~mm}$ ). Coloration: on the face (Fig. 14B), a faint brown longitudinal line under each antennal pit, prolonged on the mandibles; a brown, faint longitudinal median line, fading near preclypeus; a brown faint longitudinal line below the eyes. Male FW large for the genus, exceeding the middle of abdominal tergite 1; weakly narrowing toward apex (Fig. 14H); covering sides of metanotum (Fig. 14E)

\section{Description}

Fastigium with small black tubercle posterior to median ocellus. TIII inner serrulation: no spine before isa1; no spine between isa1 and isa2; 3-5 spines between isa2 and isa3, in both male and female; 4-6 spines between isa3 and isa4; 23-24 in males, 15-19 in females, above isa4. TIII outer serrulation: no spine before osa 1 in both male and female; 2-3 spines in males and females, between osa 1 and osa2; 5-6 spines in males and females, between osa2 and osa3; 7 spines in males and females, between osa3 and osa4; 18-21 spines in male, 15-17 spines in female, above osa4. Basitarsomeres III without dorsal inner spine in both male and female; with 7 in male, 3-5 in female, dorsal outer spines, in addition to apical spines.

Coloration (from male holotype and female allotype). Head light brown with dark brown patterns (Fig 14B, E): on the face (Fig. 14B), a faint brown longitudinal line under each antennal pit, prolonged on the mandibles; a brown, faint longitudinal median line, fading near preclypeus; a brown faint longitudinal line below the eyes. Cheeks brown in posterior half (Fig. 14E). Maxillary palpi: articles 1 and 2 light brown; article 3-5 darker near apices. Sockets white dorsally. Vertex and occiput with four weakly distinct longitudinal dark lines. Fastigium brown between ocelli; ocelli white. Scapes yellow with black spots on inner side; antennae brown; apical margins of basal articles yellowish, flagellum otherwise light brown. LL brown with a dark pattern on posterior margin and lighter anterior margin 
(Fig. 14E); DD brown with light patterns (Fig. 13B). Abdomen spotted light and dark brown (Fig. 13B); cerci light brown with darker apex. Legs light and dark brown, with dark rings and stripes: FI with three incomplete dark rings and dark lower margins; TI brown with two small yellow rings, one median and one below the knee; FII as FI; TII as TI; FIII striated with dark brown on outer side and with three dark rings in filiform part, including one apical on the knee (Fig. 15B); TIII as TI and TII, but with five dark rings; spurs yellow with black tip. Basitarsomeres brown with lighter base; tarsomeres 2 light brown; tarsomeres 3 brown.

Male. FW in males exceeding the middle of abdominal tergite 1 (Fig. 14H).; weakly narrowing toward apex (Fig. 14H); covering sides of metanotum (Fig. 14E).

Male genitalia. As on figure 16D-F.

Female. Ovipositor straight, shorter than FIII, without terminal enlargement (Fig. 15D).

Female genitalia. Copulatory papilla sclerotized, not forming a closed chamber (Fig. 15E).

TABLE 8. Measurements of Phalangacris ferlegro Hugel and Desutter-Grandcolas, n. sp. (in mm).

\begin{tabular}{|c|c|c|c|c|c|c|c|}
\hline & BodyL & PrnL & PrnW & FWL & FIIIL & TIIIL & Ovs \\
\hline Holotype $\sigma^{\wedge}$ & 20.0 & 4.6 & 5.8 & 4.2 & 21.5 & 23.1 & -- \\
\hline Paratype $\widehat{\delta}$ & 23.5 & 4.9 & 5.4 & 3.2 & 21.6 & 23.3 & -- \\
\hline Allotype 9 & 22.0 & 4.4 & 5.8 & 0.8 & 19.6 & 21.3 & 17.4 \\
\hline Paratype $\$$ & 21.9 & 4.5 & 6.1 & 1.0 & 19.6 & 20.4 & 18.0 \\
\hline
\end{tabular}

\section{Phalangacris sotsote Hugel and Desutter-Grandcolas, n. sp.}

(Figs 1G, 13C, 14C, F, I, 15C, 16G-I, Table 9)

Type locality. Seychelles, La Digue.

Type material. Holotype male. 29VII2010 Seychelles, La Digue, Nid d'Aigle, sous gros rochers, 29.vii.2010, S. Hugel leg. (2010SEY126), MNHN-EO-ENSIF12121.

Paratype. 1 male, same as holotype (2010SEY123), S. Hugel leg., coll.

Etymology. Species named after the Creole expression "sot sote", meaning hopping.

Diagnosis. In addition to generic characters. Size large for the genus (BodyL $\geq 20 \mathrm{~mm}$ ). Coloration: on the face (Fig. 14C), a brown longitudinal line under each antennal pit, more marked ventrally, prolonged on the mandibles; a brown longitudinal median line ventrally, forked dorsally forming two paralongitudinal lines between antennal sockets. Male. FWs narrow and short for the genus, hardly 
reaching the middle of abdominal tergite 1; triangular in shape: narrowing toward apex; not covering sides of metanotum (Fig. 14F).

\section{Description}

In addition to the characters of the genus:

Fastigium with small black tubercle posterior to median ocellus. TIII inner serrulation: no spine before isa1; no spine between isa 1 and isa2; 4 spines between isa2 and isa3; 6-7 spines between isa3 and isa4; 19-21 above isa4. TIII outer serrulation: no spine before osa1; 2-3 spines between osa1 and osa2; 5-6 spines between osa2 and osa3; 8 spines between osa3 and osa4; 18-20 spines above osa4.

Basitarsomeres III without dorsal inner spine in both male and female; with 4-5 dorsal outer spines, in addition to apical spines.

Coloration (from male holotype and paratype). Head yellow with dark brown patterns: on the face

(Fig. 14C), a brown longitudinal line under each antennal pit, more marked ventrally, prolonged on the mandibles; a brown longitudinal median line ventrally, forked dorsally forming two paralongitudinal lines between antennal sockets. Cheeks yellow with a dark posterior margin (Fig. 14F). Maxillary palpi: articles 1 and 2 yellow; article 3 - 5 darker near apices and on carinae. Sockets white dorsally. Vertex and occiput with one longitudinal dark line behind each eye, with two subcircular black patterns between eyes; ocelli white. Scape yellow, darker dorsally and on anterior side; antennae brown; apical margins of basal articles yellowish, flagellum otherwise light brown. LL dark brown with a lighter anterior spot (Fig. 14F); DD brown with light patterns, with two dark spots near anterior margin (Fig. 13C). Abdomen spotted light and dark brown (Fig. 13C); cerci light brown, darker after the middle. Legs yellow and dark brown, with dark rings and stripes: FI with three incomplete dark rings and dark lower margins; inner ventral carina dark brown; TI brown with two small yellow rings, one median and one below the knee; FII as FI; TII as TI; FIII striated with dark brown on outer side and with two dark rings in filiform part, including one apical on the knee (Fig. 15C); TIII as TI and TII, but with six dark rings; spurs yellow with dark basis and black tip. Basitarsomeres brown with lighter base; tarsomeres 2 light brown; tarsomeres 3 brown.

Male. FW hardly reaching the middle of abdominal tergite 1; narrowing toward apex; not covering sides of metanotum (Fig. 14F).

Male genitalia. As on figure 16G-I.

Female. Unknown.

TABLE 9. Measurements of Phalangacris sotsote Hugel and Desutter-Grandcolas, n. sp.

\begin{tabular}{lcccccc}
\hline & BodyL & PrnL & PrnW & FWL & FIIIL & TIIIL \\
\hline Holotype $0^{\wedge}$ & 21.7 & 4.4 & 6.4 & 3.4 & 21.2 & 22.8 \\
\hline
\end{tabular}




\begin{tabular}{lllllll}
\hline Paratype ${ }^{\lambda}$ & 20.1 & 4.4 & 6.2 & 4.0 & 21.0 & 22.4 \\
\hline
\end{tabular}

Key to species of Phalangacris Bolivar, 1895

1. Small (body < $16 \mathrm{~mm}$, FIII length $14 \mathrm{~mm}$ ) (Cousin island).

Phalangacris phaloricephala Gorochov, 2006

1’. Much larger (body > $19 \mathrm{~mm}$, FIII length > $20 \mathrm{~mm}$ ) (other islands). 2.

2(1). FW inner margin bordered with a wide band covered with light setae starting near the pronotum (Mahé, La Digue). 3

2'. FW inner margin bordered with a narrow band covered with light setae starting near FW mid length (Praslin). Phalangacris ferlegro Hugel \& Desutter-Grandcolas, n. sp.

3(2). FW shorter and thinner, triangular in shape (Fig. 14I) (La Digue)

Phalangacris sotsote Hugel \& Desutter-Grandcolas, n. sp.

3’. FW distinctly wider and more squared (Fig. 14G) (Mahé)...... Phalangacris alluaudi Bolivar, 1895.

Genus Gryllapterus Bolivar, 1912

(Figs. 17, 18)

Type species. Gryllapterus tomentosus Bolivar, 1912, by monotypy.

Distribution. Granitic Seychelles islands.

Taxonomic position. Gryllapterus has been described by Bolivar (1912) from one female from the Seychelles within the "tribu des Oecanthiens", close to the genus Landreva Walker, 1869 (as Landrevus), although Bolivar acknowledged a "relationship" between Gryllapterus and Gryllomorpha Fieber, 1853 (as Gryllomorphus): "Ce genre a des rapports avec Gryllomorphus, mais je crois devoir le placer à côté du g. Landrevus Walk. dans la tribu des Oecanthiens, parce que les jambes postérieures ont leurs bords et notamment le bord externe denticulés, non seulement à la base, mais aussi entre les deux premières épines." [This genus is related to Gryllomorphus, but I think I have to place it close to g. Landrevus Walk. in the tribe Oecanthiens, because hindleg margins, and in particular the outer margins, are serrulated, not only at base, but also between the first two spines] (Bolivar 1912, p. 284, our translation). 
Saussure (1878) separated the Oecanthiens into three "tribes", e.g. the Pentacentrites, the Oecanthites and the Phalangopsites, and he classified Gryllapterus within the Pentacentrites together with Landreva. Saussure also recognized that Gryllomorpha, until now classified with Gryllus and related genera, was actually closer to the Phalangopsites, especially to the genus Laranda Walker, 1869 (as Larandus).

Chopard (1968) gathered Gryllapterus, Landreva and Gryllomorpha, and their respective close relatives, into the Gryllomorphini tribe of the Gryllinae subfamily. Gorochov (1982) created the Landrevinae subfamily for Landreva and its close relatives, later used as a tribe within the Gryllinae by Otte \& Alexander (1983). Otte (1988) separated Landreva and Gryllapterus in the Landrevini, which he classified in the subfamily Pteroplistinae explicitly rejecting any close relationship with the Gryllinae and by extension with Gryllomorpha. Gryllapterus was later considered as a Phalangopsinae sensu Eades et al. (2008) (Hugel 2009). Finally, Gorochov (2017) proposed that Gryllapterus could belong to the Prolandrevini tribe of the Landrevinae, a subfamily whose affinity with the Gryllinae is now well established (Chintauan-Marquier et al. 2013, 2016).

Even though the cricket phylogeny obtained by Chintauan-Marquier et al. $(2013,2016)$ and Warren et al. (2019) included 45 and 65 phalangopsid genera respectively, they take into account only part of the diversity of the whole family, at best one third of present-day genera (Cigliano et al. 2021). The position of Gryllapterus, close to Gryllomorpha and Petaloptila within the clade (Homoeogryllini - Seselini Hugel \& Desutter-Grandcolas n. tribe - Cachoplistini), is, however, well supported in Warren's et al. (2019) topology (bootstrap ML support 100, posterior probability of 1 in Bayesian analyses). Morphological characters also confirm the relationships found with molecular data (see below). As a result, we include here Gryllapterus within the Seselini Hugel \& Desutter-Grandcolas n. tribe

Morphological comparison of Gryllapterus, Phalangopsidae, Landrevinae and Gryllinae. The morphology of Gryllapterus resembles that of the phalangopsid species for several characters, two of which could have a particular diagnostic value:

1, hind tibiae serrulated both between and above subapical spurs (not serrulated in Gryllinae; serrulated only above subapical spurs in true Landrevinae; Prolandrevini show one or few spines between subapical spurs (not mentioned in Gorochov $(2005,2010)$, but acknowledged in Gorochov (2011)), which demonstrates that they are not Landrevinae, but Pentacentrinae, to which they should be transferred (S. Hugel, pers. obs., see also Hugel in press),

2, fore tibiae with only two apical spurs (three apical spurs set as a triangle in Gryllinae and Landrevinae).

In the same way, several characters of male genitalia show that Gryllapterus belongs to phalangopsid crickets: 
1, the distal margin of pseudepiphallus bears both a pair of small membranous lobes bearing long setae (median lophi) and a pair of sclerotized hooks directed ventrally (lateral lophi?): these structures are particularly well-developed in Homoeogryllus, Cacoplistes and Meloimorpha. In Landrevinae, the ventro-lateral margin of pseudepiphallus extends distally as a straight processus (see Otte 1988). 2, the endophallic sclerite is flat, connected to an apodeme having the shape of a lamella; it is located close to the base of ectophallic fold, and is not separated from it by a dorsal cavity. In Landrevinae, the endophallic sclerite bears on its anterior part a heavy, "monolithic" apodeme, and is separate from the ectophallic fold by a small, posterior, dorsal cavity; a similar structure exists in the Gryllinae, in which the endophallic sclerite is at the base of a well-developed dorsal cavity.

In Gryllomorpha and Petaloptila, hindtibia serrulation is always present above subapical spurs, but vary between spurs, being either absent, or reduced to one spine between subapical spurs 3 and 4 in examined specimens. Foretibiae always have only two apical spurs however. Their genitalia are very modified, but of a clear phalangopsid type in at least some species, such as Petaloptila pallidens Bolivar, 1927.

It is not the scope of the present paper to assemble a matrix of morphological characters to complete molecular phylogenetic analysis. However, morphological and molecular data show that Gryllapterus should be removed from the gryllid subfamily Landrevinae to be classified within the phalangopsid subfamily Cachoplistinae.

Diagnosis. Very small specimens with contrasted coloration and short legs (Figs 17A, 18A). Eyes little protruding, longer than wide, well-separated from the cheek posterior margin. Fastigium triangular, very wide at base, not separate from the vertex by a distinct furrow; with very thick setae; ocelli small and rounded, set as a wide triangle (Fig. 17E). Fore tibiae with two ventral apical spurs; with a small inner tympanum. Mid tibiae with three apical spurs. Hind femora very wide; hind tibiae with four pairs of subapical spurs; serrulated between and above spurs. Male. Forewings short, not reaching tergite 2 distal margin (Fig. 17B, C), slightly overlapping, without stridulatory or glandular structure; with strong longitudinal veins, and a wide, white band along lateral margins. Metanotum glandular (Fig. 17D). Male genitalia (Fig. 17G-J): pseudepiphallic sclerite short, transverse, widely separated from distal median lophi; these lobes short and acute; latero-ventral sclerotization of pseudepiphallus (lateral lophi?) produced as a pair of wide hooks directed ventrally; pseudepiphallic parameres with a large dorsal sclerite and a smaller, bifid ventral sclerite; ectophallic apodemes thick, divergent; no endophallic cavity. Female. Apterous (Fig. 18A). Ovipositor flattened laterally; regularly narrowed toward apex; apex hardly separated and not ornamented (Fig. 18B). Female genitalia: copulatory papilla small; rectangular, widely sclerotized (Fig.18C-E).

\section{Redescription}

Very small specimens with contrasted coloration (Figs 17A, 18A). 
General morphology. Head slightly longer than wide in front view, thick in side view. Eyes somewhat protruding, longer than wide, well-separated from the posterior margin of the cheeks. Head dorsum flat, separated between the eyes from the fastigium by a very faint convex furrow. Fastigium (Fig. 17E) triangular, very wide basally, regularly narrowed toward apex; apical width about half basal width; apex about as wide as the scape; not furrowed; with strong setae dorsally. Ocelli small but wellvisible, rounded; set as a wide triangle, the distance between the lateral ocelli slightly greater than the distance between the median and one lateral ocelli; median ocellus vertical, far from fastigium apex. Scapes slightly longer than wide, rounded. Maxillary palpi (Fig. 17C) short; article 3 shorter than article 4; article 4 shorter than article 5; article 5 regularly widened toward apex from its base, concave dorsally; apex convex. Pronotum (Fig. 17B) transverse; DD anterior and posterior margins slightly convex and concave respectively, with lateral margins distinctly rounded; LL short, with sinuate lower margin, distinctly raised anteriorly (Fig. 17C). TI with a short, oval inner tympanum; no outer tympanum; two long, apical ventral spurs; no dorsal spurs. TII with three long apical spurs, the ventral the longest; dorsal outer spur missing. FIII very wide (Fig. 17F), longer than TIII. TIII slightly furrowed dorsally except near base and apex; serrulated on inner and outer ridges, between and above subapical spurs; with four inner and four outer subapical spurs, short and subequal in size, the outers slightly located more basally; with three inner and three outer apical spurs; dorsal inner spur the longest, slightly longer than median inner spur, both about two third basitarsomere III length, flat on inner side and quite wide; median outer apical spur the longest, more than twice as long as dorsal outer spur; inner and outer ventral spurs short and thin, the inner slightly longer than the outer and about one third the median inner spur. Basitarsomeres III with outer spines, growing bigger toward apex; apical spine only on inner side. Cerci shorter than FIII.

Male. FWs very short, not reaching abdominal tergite 2 midline (Fig. 17B); overlapping in their midline only; without a stridulatory design. Dorsal field with 5 longitudinal veins, the two most lateral largely separated and ivory coloured (Fig. 17C); few transverse veins. Lateral field with two longitudinal veins, in addition to the thick vein separating the dorsal and the lateral fields. Metanotum glandular (17D): in anterior part, a wide, setose depression; in posterior part, a strong median relief with two lateral crests, bordered on each side by a wide setose area, and connected to the inflated posterior margin of metanotum bearing a pair of lateral reliefs separated by a median depression. Abdomen without glandular structures. Subgenital plate short and flat.

Male genitalia. Fig. 17G-J. Flat and ovoid. Distal margin of pseudepiphallic sclerite deeply indented, with a pair of very small apical lobes (median lophi) located on the distal angle of the emargination and directed anteriorly. Latero-distal margin produced ventro-posteriorly into a pair of sclerotized hooks (lateral lophi ?), thick at base but abruptly thinner before apex, making an angle $<90^{\circ}$ with pseudepiphallic sclerite. Rami thick, convex; distal apex bifid, the dorsal branch extremely reduced. Pseudepiphallic parameres with two large sclerites, one undivided, dorsal, concave, and one ventral, bifid as a broad forceps. Ectophallic apodemes long and straight, regularly diverging from the arc. 
Ectophallic arc very wide, convex dorsally at midwidth. Ectophallic fold membranous dorsally, exceeding pseudepiphallic distal margin, truncated apically. Endophallic sclerite long and narrow, wide and less sclerotized laterally. Endophallic apodeme with a short, distal median crest. No endophallic cavity.

Female. Fig. 18A. Apterous. Subgenital plate transverse; distal margin indented. Ovipositor compressed laterally, regularly narrowed toward its tip, only a small depression delimiting the apex; apex acute, without ornementation (Fig. 18B).

Female genitalia. Copulatory papilla (Fig. 18C-E) short, very flat and almost rectangular; distal margin bisinuate; papilla largely sclerotized and somewhat concave ventrally.

Habitat. Native forests above 500 m (Matyot 1998).

\section{Gryllapterus tomentosus Bolivar, 1912}

(Figs 17-18, Table 10)

Gryllapterus tomentosus Bolivar, 1912:

Type material. Seychelles, Silhouette, near Pot-à-eau, about 1500 ft, 1 female, VIII.1908. NHM (after Cigliano et al. 2021)

Examined material. Seychelles, Silhouette island, 1 male, 3 females, VIII.1990, P. Matyot, identified Gryllapterus tomentosus Bolivar, 1912 by D.K. MCE Kevan (1991), MNHN-EO-ENSIF12269-12272; same, 1 male, 1 female, LEM.

Molecular sampling. LDG 212 (Warren et al. 2019).

Diagnosis. Same as the genus.

\section{Emended description}

In addition to the characters of the genus:

TII serrulation: no spine between subapical spurs 1 and 2; zero to one small spine between subapical spurs 2 and 3; zero to two small spines between subapical spurs 3 and 4; five to eight spines, and seven to nine spines above inner and outer subapical spurs respectively.

Coloration. Light orange, with light yellow and light brown spots and lines (Figs 17A, 18A). Lateral parts of head, pronotum and first tergites distinctly dark brown (Fig. 17C). Head dorsum light orange brown with three longitudinal light yellow stripes, one median, bordered with dark brown, and along the inner margin of each eye. Ocelli circled with black. Fastigium with light yellow lateral and apical 
margins, its sides black. Face and cheeks black brown, with a lighter reversed-Y under the median ocellus (Fig. 17E). Eyes dark brown and black. DD light orange, including its anterior and posterior margins; two brown areas in anterior half, close to anterior margin, many brown spots along median longitudinal furrow and in posterior third. LL brown; a large spot in anterior angle and the lower margin yellowish. Legs light yellow with brown marks: TI, TII with three incomplete brown rings; FI, FII with two brown rings, the apical the largest; TIII with four brown rings, the spurs light yellow at apex and brown at base; FIII with three lines of short, oblique brown lines (Fig. 17F); tarsomeres brown with basal third light yellow. Abdomen light orange brown, with wide brown spots in tergite anterior third (median spot the largest), and rows of smaller brown round spots along posterior margins. Cerci, sternites, supra-anal and subgenital plates light yellow.

Male. Fig. 17A. As for genus description.

Male genitalia. As on Fig. 17G-J.

Female. Fig. 18A. Ovipositor (Fig. 18B) shorter than FIII, longer than TIII.

Female genitalia. As on Fig. 18C-E.

TABLE 10. Measurements of Gryllapterus tomentosus Bolivar, 1912 (in mm).

\begin{tabular}{lccccccc}
\hline & BodyL & PrnL & PrnW & FWL & FIIIL & TIIIL & Ovs \\
\hline Males & $7.9-8.2$ & $1.5-1.6$ & $2.4-2.5$ & 1.3 & $5.9-6.2$ & $4.2-4.6$ & - \\
$(\mathrm{n}=2)$ & & & & & & & \\
\hline Females & $9.1-9.5$ & $1.7-2$ & $2.6-3.1$ & - & $6.6-7.5$ & $4.9-5.7$ & $6.4-7.4$ \\
$(\mathrm{n}=4)$ & $(9.4)$ & $(1.9)$ & $(2.9)$ & & $(7.1)$ & $(5.3, \mathrm{n}=3)$ & $(6.9)$ \\
\hline
\end{tabular}

Subfamily Phaloriinae Gorochov, 1985

Genus Phaloria Stål, 1877

Type species. Phaloria amplipennis Stål, 1877.

Subgenus Papuloria Gorochov, 1996

Distribution. From Indonesia in the West to Fiji islands in the East, but neither South in Australia, nor North in continental Asia.

Phaloria (Papuloria) insularis (Bolivar, 1912)

(Figs 1B, 19A-C, G-I, 20, Table 11) 
Heterotrypus insularis Bolivar, 1912: 290.

Phaloria (Phaloria) insularis - Gorochov 1996: 62.

Phaloria (Papuloria) insularis - Gorochov 2014: 83.

Type locality. Seychelles, Mahé and Silhouette.

Type specimens. Lectotype: 1 male, Mahé, 08-9, Seychelles Exped. (MNCN, not examined).

Paralectotypes, 6 males: 2 males, Silhouette, Mare aux cochons, 08-9, Seychelles Exped. (NHM, not examined); 2 males, Mahé, 08-9, Seychelles Exped. (CUMZ, not examined); 2 males, Mahé, 08-9, Seychelles Exped. (NHM, not examined). The specimens from Mahé were collected from Cascade Estate or near Morne Blanc (Bolivar 1912: 291). The paralectotypes from Silhouette will have to be dissected to verify their identity related to $P$. (P.) bolivari Hugel \& Desutter-Grandcolas, n. sp.

Specimens examined. Seychelles, Mahé, Morne Blanc, 18.VII.2010, 1M, 1F (without PIII), SH005006, male recorded, S. Hugel, MNHN-EO-ENSIF12273, 12274.

\section{Complement of description (specimens from Mahé).}

Hind tibia (after male MNHN-ENSIF-EO12273) little serrulated; inner margin: no spine between apical spur and isa1, between isa1 and isa 2, and between isa2 and isa3, with two spines between isa3 and isa4, and four spines above isa4; outer margin: no spine between apical spur and osa1, two spines between osa1 and osa 2, three spines between osa2 and osa3, four spines between osa3 and osa4, and seven spines above osa4. Hind basitarsomere with three dorsal outer spines in addition to apical spine; no inner spine.

Coloration. Head dorsum light yellow with light brown longitudinal bands, one along the inner and one along the outer margins of each eye, and two thinner median ones prolonged toward lateral ocelli. Face light yellow with median longitudinal clear-brown bands, one under the lower angle of each eye and one under median ocellus between antennal pits; this band including between the antennae two elongate yellowish spots, delimited by a thin dark brown line; a wide whitish round spot between the median brown band and each antennal pit. Palpi light yellow, article 5 distal part light brown. DD light brown, darker along posterior margin; LL distinctly lighter, with a distinct limit with dorsal brown coloration. Femora I and II light yellow with a brown subapical ring. TI and TII with three inconspicuous brown rings.

Male. Stridulatory file with 89 teeth $(\mathrm{n}=1)$. Harp crossed by seven oblique, parallel veins. Mirror crossed by two transverse, parallel veins (only one vein in the lectotype male), in addition to a strongly sinuate distal vein. Subgenital plate deeply furrowed along its basal 5/6 of its length. 
Male genitalia. Fig. 19A-C. Pseudepiphallic median lobes rectangular, membranous, with short and thick-based setae on distal half; median lophi clearly below pseudepiphallic sclerite, between pseudepiphallic sclerite (dorsal) and ectophallic fold (more ventral); median lophi separated by a distance shorter than one lobe width. Pseudepiphallic sclerite transverse, its median length shorter than median lobe length; lateral part of pseudepiphallic sclerite elongate distally as an acute lobe (pseudepiphallic lateral lophi?), which produce ventrally a small latero-ventral hook-shaped process; these lobes thick at base, due to the very convex sides of pseudepiphallic sclerite. All these sclerites symmetrical. Rami very long, with a short and thin anterior part, and a wider distal part with an acute apex. Pseupiphallic parameres with a smaller dorsal hook and a more elongate and largely bifid ventral sclerite. Ectophallic apodemes long and straight, almost vertical. Ectophallic arc incomplete but wide and high; sclerotization of epi-ectophallic invagination abruptly widened close to pseudepiphallic sclerite. Ectophallic fold nearly reaching pseudepiphallus distal margin, wide, truncate distally, with a pair of membranous, digit-shaped distal process; sclerotized laterally. Endophallic sclerite very short, concave, bearing crest- and lamella- apodemes. Dorsal cavity short but well-shaped between endophallic sclerite and apex of ectophallic fold.

Female. FWs reaching beyond the abdomen and covering the base of cerci; lateral field well shorter than dorsal field. Venation with strong longitudinal veins and few, weak transverse veins; dorsal field with 4 plain longitudinal veins, in addition to two most lateral ones, stronger and more largely separated. HWs slightly longer than FWs. Subgenital plate wider than long; distal margin largely concave. Ovipositor almost as long as FWs.

Female genitalia. Copulatory papilla small, broadly triangular with a very thin apex, very flat but concave dorsally (Fig. 19G-I).

TABLE 11. Measurements of Phaloria (Papuloria) insularis (Bolivar, 1912) (in mm) from Mahé.

\begin{tabular}{lcccccccc}
\hline & BodyL & PrnL & PrnW & FWL & HWL & FIIIL & TIIIL & Ovs \\
\hline Male & 13.8 & 2.3 & 3.8 & 10.7 & $<$ FW & 10.9 & 9.9 & - \\
\hline Female & 14.3 & 2.7 & 3.8 & 9.9 & 10.4 & - & - & 9.8 \\
\hline
\end{tabular}

Calling song. The song of Phaloria (Papuloria) insularis was recorded at Morne blanc (Mahé), at $10.00 \mathrm{pm}$ (ambient temperature $26^{\circ} \mathrm{C}$ ). It is composed of short motives emitted at length (Fig. 20). The mean duration of the motives is $370 \mathrm{msec}$ ( $\min 350$ msec., max 380 msec., $n=10$ ). The inter motive duration is quite variable, with a mean duration of 1.64 s. (min 0.87 s., $\max 2.52$ s., $n=8$ ). Each motive is made of 13 to 14 syllables (mean number 13.6, $n=10$ ), with no clear pattern of amplitude variation within each motive, or between successive motives. Syllables are very regular (duration between 11 $12 \mathrm{msec}$ ). Sound is emitted between 3900 and $5000 \mathrm{~Hz}$, with a dominant frequency about $4500 \mathrm{~Hz}$. 
Habitat. Phaloria insularis occurs in both preserved and moderately modified forested areas above $300 \mathrm{~m}$. During night hours, most males call from near the canopy, but specimens can frequently be heard and observed on bushes in the undergrowth (S. Hugel, pers. obs.).

\section{Phaloria (Papuloria) bolivari Hugel \& Desutter-Grandcolas, n. sp.}

(Fig. 19D-F, J-L, Table 12)

Distribution. Seychelles, Silhouette.

Type material. Holotype. 1 male. Seychelles, Silhouette, Jardin Marron, > 400m; 5.VIII.2010; 2010 SEY SH179; S. Hugel; MNHN-ENSIF-EO12122.

Paratypes, 2 males, 1 female. 1 male; same locality, date and collector as the holotype (2010 SEY SH167), MNHN-EO-ENSIF12123; 1 male; same locality , date and collector as the holotype (2010SEY SH180), MNHN-EO-ENSIF12124; 1 female (allotype); same locality, date and collector as the holotype (2010 SEY SH181), MNHN-EO-ENSIF12125.

Diagnosis. Species very close from $P$. (P.) insularis, from which it can be distinguished mainly by the genitalia (shape of pseudepiphallic sclerites and median lophi) and stridulatory file of the male, and the length of female ovipositor (longer than FWs).

\section{Description.}

Morphology and coloration as in Phaloria (Papuloria) insularis. Hind tibia little serrulated; inner margin: no spine between apical spur and isa1, and between isa1 and isa 2 in male and female, no spine in male, 1 spine in female between isa2 and isa3, one - two spines (mean 1 in male, 1.5 in female) between isa3 and isa4, and three to nine spines (mean 5.3) in male, five to seven spines (mean six) in female above isa4; outer margin: no spine between apical spur and osa1 in male and female, one to three (mean two) in male, two to three (mean 2.5) in female between osa1 and osa 2, three to four spines (mean 3.7 in male, mean 3.5 in female) between osa2 and osa3, three to five spines (mean four) in male, three to four spines (mean 3.5) in female between osa3 and osa4, and six to eight spines (mean seven) in male and 8 spines in females above osa4. Hind basitarsomere with three to four (mean 3.3) dorsal outer spines in male, three dorsal outer spines in female in addition to apical spine; no inner spine.

Male. Stridulatory file with 77 teeth $(\mathrm{n}=1)$. Harp crossed by seven oblique, parallel veins. Mirror crossed by one transverse vein, in addition to a strongly sinuate distal vein. Subgenital plate deeply furrowed along its basal 5/6 of its length. 
Male genitalia. As in Phaloria (Papuloria) insularis, but pseudepiphallic median lophi thinner and distinctly concave on inner margin; greatest distance between the two lobes bigger than one lobe width. Pseudepiphallic sclerite as in Phaloria (Papuloria) insularis, but lateral lobes much thinner, due to less convex sides of pseudepiphallic sclerite. Rami and pseupiphallic parameres as in Phaloria (Papuloria) insularis. Membranous digit-shaped projections of ectophallic fold longer than in Phaloria (Papuloria) insularis.

Female. Ovipositor longer than in Phaloria (Papuloria) insularis.

Female genitalia. Copulatory papilla very small, rounded with a short membranous apex bent ventrally; very flat; with an incomplete ring-shaped sclerotization (Fig. 19J-L).

TABLE 12. Measurements of Phaloria (Papuloria) bolivari Hugel \& Desutter-Grandcolas, n. sp. (in $\mathrm{mm})$.

\begin{tabular}{lcccccccc}
\hline & BodyL & PrnL & PrnW & FWL & HWL & FIIIL & TIIIL & Ovs \\
\hline Holotype M & 13.5 & 2.5 & 4 & 11.1 & $<$ FW & 10.8 & 9.8 & - \\
\hline Paratype M & 12.5 & 2.5 & 4.1 & 11 & $<$ FW & 10.3 & 9.5 & - \\
\hline Allotype F & 13.2 & 3.1 & 4 & 10.9 & 11.7 & 11.9 & 11.5 & 11.2 \\
\hline
\end{tabular}

Genus Subtiloria Gorochov, 1999

Type species. Heterotrypus subtilis Gorochov, 1999.

\section{Subtiloria succinea (Bolivar, 1912)}

Ornebius succineus Bolivar, 1912: 281.

Heterotrypus succineus - Gorochov 1996: 57.

Subtiloria succineus - Gerlach \& Haas 2008: 55.

Subtiloria succinea succinea - Gorochov 2018b: 64.

The name Subtiloria succinea (Bolivar, 1912) results from multiple confusions. Bolivar described in 1910 the Phalangopsidae Heterotrypus succineus Bolivar, 1910 from Equatorial Guinea. In 1912, he described the Mogoplistidae Ornebius succineus Bolivar, 1912 from Seychelles. Heterotrypus succineus Bolivar, 1910 was later transferred to another genus: Subtiloria succineus (Bolivar, 1910) by Gorochov (1999). Gerlach and Haas (2008), in a book on Orthoptera from Seychelles confounded both species. In the section on Phalangopsidae, they explicitly mentioned the Mogoplistidae Ornebius succineus Bolivar, 1912 as the original name of Subtiloria succineus (Bolivar, 1912), resulting in an unwanted but clearly stated new combination. In the Orthoptera 
Species File database, the Phalangopsidae Heterotrypus succineus Bolivar, 1910 was left under its original genus. Gorochov (2018b), in a study of Phalangopsidae later emended the name Subtiloria succineus as Subtiloria succinea and distinguished two subspecies under this species, without noticing the confusion. Unfortunately, no description year was mentioned by Gorochov, and the confusion was therefore not corrected in the Orthoptera Species File database. The original combination Ornebius succineus Bolivar, 1912 should therefore be considered as the right one for a scale cricket. The genus Subtiloria Gorochov, 1999 does not occur in Seychelles and the name Subtiloria succineus (Bolivar, 1912) is a nomen nudum.

\section{ACKNOWLEGMENTS}

We thank Seychelles Bureau of Standards for having allowed SH research and particularly Elvis Nicette. We are greatly indebted to Pat Matyot and Axel Hochkirch and his students Johannes Hörst and Franziska Billmaier for the opportunity to study the Phalangopsidae crickets they collected in Seychelles. We thank Gérard Rocamora, Anna Reuleaux, Christopher Kaiser-Bunbury, and François Baguette for their help. We thank Seychelles Islands Foundation and his team in Vallee de Mai, Praslin National Park, Island Development Company for their logistic support.

\section{REFERENCES}

Bolivar, I. (1895) Mission scientifique de M. Ch. Alluaud aux íles Séchelles (mars, avril, mai, 1892), 6 mémoire: Orthoptères. Annales de la Société Entomologique de France 64: 369-386.

Bolivar, I. (1912) Orthoptera Acrydiidae, Phasgonuridae, Gryllidae of the Seychelles. Transactions of the Linnean Society of London, second series, Zoologie, 15, 263-292.

Bolivar, I. (1924) Orthoptera dictyoptera (Blattidae and Mantidae), and supplement to Gryllidae, of the Seychelles and adjacent islands. Annal and Magazine of Natural History, ser. 9, 13(76): 313-359.

Bruner, L. (1916) South American crickets, Gryllotalpoidea and Achetoidea. Annals of the Carnegie Museum 10: 344-428.

Center for Conservation Bioacoustics. (2019) Raven Pro: Interactive Sound Analysis Software (version 1.6.1). Ithaca, NY: The Cornell Lab. of Ornythology.

Chintauan-Marquier, I.C., Legendre, F., Hugel, S., Robillard, T., Grandcolas, P., Nel, A., Zuccon, D. \& Desutter-Grandcolas, L. (2013) Laying the foundations of evolutionary and systematic studies in crickets (Insecta, Orthoptera): a multilocus phylogenetic analysis. Oral communication. 11th International Congres of Orthopterology, Kunming (China).

Chintauan-Marquier, I.C., Legendre, F., Hugel, S., Robillard, T., Grandcolas, P., Nel, A., Zuccon, D. \& Desutter-Grandcolas, L. (2016) Laying the foundations of evolutionary and systematic studies in crickets (Insecta, Orthoptera): a multilocus phylogenetic analysis. Cladistics 32, 5481. https://doi.org/10.1111/cla.12114 
Chopard, L. (1936) The Tridactylidae and Gryllidae of Ceylon. - Ceylon Journal of Science (Biological Science) 20: 9-87.

Chopard, L. (1968). Pars 12. Fam Gryllidae: Subfam. Mogoplistinae, Myrmecophilinae, Scleropterinae, Cachoplistinae, Pteroplistinae, Pentacentrinae, Phalangopsinae, Trigonidiinae, Eneopterinae. Fam. Oecanthidae, Gryllotalpidae. In Beier, M. (Ed.), Orthopterorum Catalogus. 's Gravenhage, Dr.W.Junk N.V., 215-500.

Cigliano, M.M., Braun, H., Eades, D.C. \& Otte, D. (2021) Orthoptera Species File. Version 5.0/5.0. [jan. 21, 2021]. http://Orthoptera.SpeciesFile.org

Currie, D., Hill, M., Fanchette, R. \& Hoareau, C. (2003) Diet of the critically endangered Seychelles Scops Owl, Otus insularis. Ostrich - Journal of African Ornithology 74: 3-4, 205-208. DOI: 10.2989/00306520309485393

Desutter, L. (1987) Structure et évolution du complexe phallique des Gryllidea (Orthoptera) et classification des Grylloidea néotropicaux. 1ère partie. Annales de la Société entomologique de France (N.S.)23, 213-239. https://gallica.bnf.fr/ ark:/12148/bpt6k6139207n

Desutter-Grandcolas L. 1991. Les Phalangopsidae néotropicaux (Orthoptera: Gryllidae). I . L (Orthoptera: Grylloidea: Phalangopsidae). Les Strogulomorphini. Annales de la Société entomologique de France (N.S.) 27: 465-481.

Desutter-Grandcolas, L. (1992a). Les Phalangopsidae de Guyane française (Orthoptères, Grylloidea): systématique, éléments de phylogénie et de biologie. Bulletin du Muséum national d'Histoire naturelle, Paris, 14, 93-177.

Desutter-Grandcolas, L. (1992b) Les Phalangopsidae néotropicaux (Orthoptera: Grylloidea). II. Le groupe des Aclodae. Annales de la Société entomologique de France (N.S.) 28: 171-199. https://gallica.bnf.fr/ark:/12148/bpt6k6133162n/

Desutter-Grandcolas, L. (1999) The genus Paragryllodes Karny, 1909 in tropical Africa (Orthoptera, Grylloidea, Phalangopsidae): nex taxa and field observations on the habitat of the species. Zoosystema 21: 495-524.

Desutter-Grandcolas, L. (2003) Phylogeny and the evolution of acoustic communication in extant Ensifera (Insecta, Orthoptera). Zoologica Scripta 32, 525-561. https://doi.org/10.1046/j.14636409.2003.00142.x

Desutter-Grandcolas, L. (2014) New taxa and data for Neotropical Phalangopsidae (Orthoptera, Grylloidea). Zootaxa 3866: 398-420. https://doi.org/10.11646/zootaxa.3866.3.5

Desutter-Grandcolas, L. (2015) Phalangopsidae crickets from Tropical Africa (Orthoptera, Grylloidea), with descriptions of new taxa and an identification key for African genera. Zootaxa 3948: 451-496. https://doi.org/10.11646/zootaxa.3948.3.5

Desutter-Grandcolas, L., Jacquelin, L., Hugel, S., Boistel, R., Garrouste R., Henrotay, M., Warren, B.H., Chintauan-Marquier, I.-C., Nel, P., Grandcolas, P. \& Nel A. (2017) 3-D imaging reveals 
four extraordinary cases of convergent evolution of acoustic communication in crickets and allies (Insecta). Scientific Reports 7(7099): 1-8. https://doi.org/10.1038/s41598-017-06840-6

Desutter-Grandcolas, L., Faberon, L. (2020) Phalangopsidae crickets (Orthoptera, Grylloidea) from the Mitaraka biological survey, French Guiana, in: Touroult J. (Ed.), “Our Planet Reviewed” 2015 large-scale biotic survey in Mitaraka, French Guiana. Zoosystema 42, 739-797. https://doi.org/10.5252/zoosystema2020v42a32

Eades, D. C. \& Otte, D. (2008) Orthoptera Species File Online. Version 2.0/3.3. $<\underline{\text { http://Orthoptera.SpeciesFile.org }>}$

Geerlach, J. \& Haas F. (2008) Orthopteroidea of the Seychelles islands. Backhuys, Leiden, 88 pp Gorochov, A.V. (1982) A new subfamily of crickets (Orthoptera, Gryllidae) from Indo-Malayan Region, in: Medvedev, L.N. (Ed.), Zhivotnyj mir Vietnama [Animals of Vietnam]. Nauka, Moscow, 147-151. (in Ru)

Gorochov, A.V. (1994) Contribution to the knowledge of Grylloidea (Orthoptera) of the Seychelles. Entomological Review 73 (9): 103-110.

Gorochov, A.V. (1996) New and little known crickets from the collection of the humbolt University and some other collectons (Orthoptera: Grylloidea). Part 2. Zoosystematica rossica 6, 29-90.

Gorochov, A.V. (1999) New and little known Phaloriinae (Orthoptera: Gryllidae). Zoosystematica Rossica 8, 27-60.

Gorochov, A.V. (2005) New and little known crickets of teh subfamilies Phaloriinae, Phalangopsinae and Landrevinae (Orthoptera, Gryllidae) from Indonesia and South Africa. Proceedings of the Russian Entomological Society, St Petersburg, 76, 25-46. (in Ru)

Gorochov, A.V. (2006) New and Little Known Crickets of the Subfamily Phalangopsinae (Orthoptera, Gryllidae): 3. Indonesia, the Philippines, and Seychelles. Zoologicheskii Zhurnal 85 (6), 691-701 [Entomological. Review 86 (4), 438-448 (2006)].

Gorochov, A.V. (2010) A review of the genus Prolandreva Gorochov (Orthoptera: Gryllidae: Landrevinae). Proceedings of the Zoological Institute RAS 314, 318-322.

Gorochov, A.V. (2011) New family-group taxa in the infraclass Polyneoptera (Insceta): making the names proposed early, available. Zoosystematica Rossica 20, 159-160.

Gorochov, A.V. (2014) Classification of Phalangopsinae subfamily group, and new taxa from the subfamilies Phalangopsinae and Phaloriinae (Orthoptera: Gryllidae). Zoosystema rossica 23: 788.

Gorochov, A.V. (2015) New and Little-Known Crickets of the subfamily Phalangopsinae (Orthoptera, Gryllidae).8. The Genus Paragryllodes and Notes on the Subfamily Classification. Zoologicheskii Zhurnal 94, 905-916 [Entomological Review 95 (5), 600-611 (2015)].

Gorochov, A.V. (2017) New data on Asiatic and Papuan crickets of the subfamily Landrevinae (Orthoptera: Gryllidae). Zoosystematica Rossica 25, 23-97. 
Gorochov, A.V. (2018a) New and little-known crickets of the subfamily Phalangopsinae (Orthoptera, Gryllidae). 12. The genus Parendacustes (part 3) and other taxa. Zoologicheskiy zhurnal, 97(1): 3-16. (In Russian). https://doi.org/10.7868/

Gorochov, A.V. (2018b) Taxonomic studies on the cricket subfamilies Pteroplistinae, Phaloriinae and Cachoplistinae (Orthoptera: Gryllidae) from the Old World. Zoosystema Rossica 27, 40-76.

Gorochov, A.V. (2020) XXXXXXX. Zoologicheskiy zhurnal 99, 12XX

Hebard, M. (1928a) The group Luzarae of the subfamily Phalangopsinae (Orthoptera: Gryllidae). Transactions of the American Entomological Society 54: 1-56.

Hebard, M. (1928b) Studies in the Dermaptera and Orthoptera of Colombia. Orthopterous family Gryllidae. Transactions of the American Entomological Society 54: 79-124.

Hsu, P.W., Hugel, S., Wetterer, J.K., Tseng, S.P., Ooi, C.S.M., Lee, C.Y. \& Yang, C.C.S. (2020) Ant crickets (Orthoptera: Myrmecophilidae) associated with the invasive yellow crazy ant Anoplolepis gracilipes (Hymenoptera: Formicidae): evidence for cryptic species and potential cointroduction with hosts. Myrmecological News 103-129. doi.org/10.25849/myrmecol.news_030:103

Hugel, S. (2009) New Landrevinae from Mascarene islands and little known Landrevinae from Africa and Comoros (Grylloidea, Landrevinae). Annales de la Société Entomologique de France (N.S.) 45(2): 193-215. https://doi.org/10.1080/00379271.2009.10697602

Hugel, S. (2012) New and little known Phisidini from Madagascar, Comoro and Seychelles (Ensifera: Meconematinae). Zoosystema 34(3): 525-552.

Hugel, S. Orthoptera. In The new natural history of Madagascar, ed. S. M. Goodman. Princeton, New Jersey: Princeton University Press. In press.

Hugel, S. \& Matyot, P. (2006) A new Myrmecophilus from Seychelles. Bulletin de la Société Entomologique de France 111(4), 469-473.

Karny, H.H. (1909) Ostafrikanische Orthopteren. Sammelausbeute von A. Borgert, 1904-1905. 9. Mitteilung. - Zoologische Jahrbücher, Abteilung für Systematik, Oekologie und Geographie der Tiere 27: 477-480.

Matyot, P. (1998) The orthopteroids of the Seychelles: a threatened island fauna. Journal of Insect conservation 2, 235-246. https://doi.org/10.1023/A:1009647930445

Otte, D. (1988) Bark crickets of the Western Pacific Region (Gryllidae: Pteroplistinae). Proceedings of the Academy of Natural Sciences of Philadelphia 140, 281-334.

Otte, D. (1994). Orthoptera species file. Number 1. Crickets (Grylloidea). Philadelphia (Orthopterists' Society and Academy of Natural Sciences of Philadelphia).

Otte, D. \& Alexander, R.D. (1983) Crickets from Australia (Orthoptera: Gryllidae). Monogr. Acad. Nat. Sci. Philadelphia 22, 477 pp.

Ragge, D.R. \& Reynolds, W.J. (1998) The songs of the grasshoppers and crickets of Western Europe. 
Colchester, England, Harley Books.

Saussure, H., de, (1874) Family Gryllidae, in: Milne Edwards, M. (Ed.), Recherches scientifiques pour servir à l'histoire de la faune de l'Amérique centrale et du Mexique. VIème partie. Imprimerie impériale, Paris, 296-515.

Saussure, H., de (1878) Mélanges orthoptérologiques. VIème fascicule. Gryllides (2 ${ }^{\text {ème }}$ partie). Mém. Soc. Phys. Hist. nat. Genève 25, 369-702.

Schubnel, T., Desutter-Grandcolas, L., Legendre F., Prokop, Y., Mazurier, A., Garrouste, R., Grandcolas, P. \& Nel, A. (2020) To be or not to be: postcubital vein in insects revealed by microtomography. Systematic Entomology 45, 327-346. https://doi. org/10.1111/syen.12399

Specht, R. (2008) Avisoft-SASLab Pro version 4.40. Avisoft Bioacoustics, Berlin. Available from: http://www.avisoft.com (accessed 10 December 2013)

Warren, B., Hugel, S. \& Desutter-Grandcolas, L. (2019) Long-legged cricket phylogeny (Orthoptera, Grylloidea, Phalangopsidae): delimiting new model groups for evolutionary studies. Oral communication. 13th International Congres of Orthopterology, Agadir (Maroc). 
Legends of figures and tables

Figure 1. Phalangopsidae crickets from the Seychelles in the wild. A, Paragryllodes nitidula (Bolivar, 1912) n. comb., female. B, Phaloria (Papuloria) bolivari Hugel \& Desutter-Grandcolas, n. sp., male. C, same, female. D, Phaeogryllus fuscus Bolivar, 1912, male. E, same, female. F, Phalangacris ferlegro Hugel \& Desutter-Grandcolas, n. sp. male, G, same, female.

Figure 2. Paragryllodes Karny, 1909: A-E, Paragryllodes nitidula (Bolivar, 1912) n. comb. A, head and pronotum in dorsal view; $\mathrm{B}$, head in face view; some of the light patterns on the black shiny cuticula are reflections and not real patterns; C, hindfemur outer side; E, copulatory papilla in ventral view. F, Paragryllodes milloti (Chopard, 1958), copulatory papilla in ventral view. Scales $1 \mathrm{~mm}$.

Figure 3. Seselia Hugel \& Desutter-Grandcolas, n. gen. in the wild. A, Seselia longicercata (Bolivar, 1912) n. gen., n. comb., female; B, Seselia patellifera (Bolivar, 1912) n. gen., n. comb.; C, Seselia matyoti Hugel \& Desutter-Grandcolas, n. gen., n. sp.; D, Seselia coccofessei Hugel \& DesutterGrandcolas, n. gen., n. sp.

Figure 4. Seselia Hugel \& Desutter-Grandcolas, n. gen., patterns of coloration of males in dorsal view: A, Seselia longicercata (Bolivar, 1912) n. gen., n. comb., specimen MNHN-EO-ENSIF12095; B, Seselia patellifera (Bolivar, 1912) n. gen., n. comb., specimen MNHN-EO-ENSIF12097; C, Seselia matyoti Hugel \& Desutter-Grandcolas, n. gen., n. sp., specimen 2010SEYSH147; D, Seselia coccofessei Hugel \& Desutter-Grandcolas, n. gen., n. sp., specimen 2010SEYSH083. Scale bars 10 $\mathrm{mm}$.

Figure 5. Seselia Hugel \& Desutter-Grandcolas, n. gen., patterns of coloration of males in side view: A, Seselia longicercata (Bolivar, 1912) n. gen., n. comb., specimen MNHN-EO-ENSIF12095; B, Seselia patellifera (Bolivar, 1912) n. gen., n. comb., specimen MNHN-EO-ENSIF12097; C, Seselia matyoti Hugel \& Desutter-Grandcolas, n. gen., n. sp., specimen MNHN-EO-ENSIF12111; D, Seselia coccofessei Hugel \& Desutter-Grandcolas, n. gen., n. sp., specimen MNHN-EO-ENSIF12115. C and $\mathrm{D}$ are right views flipped for comparison purpose. Scale bars $10 \mathrm{~mm}$.

Figure 6. Seselia Hugel \& Desutter-Grandcolas, n. gen. A-D, face coloration; E-H, forewing coloration; I - L, metanotal glands in males in: A, E, I Seselia longicercata (Bolivar, 1912) n. gen., n. comb., specimen MNHN-EO-ENSIF12095; B, F, J Seselia patellifera (Bolivar, 1912) n. gen., n. comb., specimen MNHN-EO-ENSIF12097; C, G, K Seselia matyoti Hugel \& Desutter-Grandcolas, n. gen., n. sp., specimen MNHN-EO-ENSIF12111; D, H, L Seselia coccofessei Hugel \& DesutterGrandcolas, n. gen., n. sp., specimen MNHN-EO-ENSIF12115. Scale bars 1 mm. 
Figure 7. Seselia Hugel \& Desutter-Grandcolas, n. gen., hindfemur patterns of coloration of: A, Seselia longicercata (Bolivar, 1912) n. gen., n. comb., specimen MNHN-EO-ENSIF12095; B, Seselia patellifera (Bolivar, 1912) n. gen., n. comb., MNHN-EO-ENSIF12097; C, Seselia matyoti Hugel \& Desutter-Grandcolas, n. gen., n. sp., specimen MNHN-EO-ENSIF12111; D, Seselia coccofessei Hugel \& Desutter-Grandcolas, n. gen., n. sp., specimen MNHN-EO-ENSIF12115. B and C are right femora flipped for comparison purpose. Scale bars $10 \mathrm{~mm}$.

Figure 8. Seselia Hugel \& Desutter-Grandcolas, n. gen., male genitalia in dorsal, ventral and side view of: A-C, Seselia longicercata (Bolivar, 1912) n. gen., n. comb., specimen MNHN-EO-ENSIF12095; D-F, Seselia patellifera (Bolivar, 1912) n. gen., n. comb., specimen MNHN-EO-ENSIF12097; G-I, Seselia matyoti Hugel \& Desutter-Grandcolas, n. gen., n. sp., specimen MNHN-EO-ENSIF12111; J-L, Seselia coccofessei Hugel \& Desutter-Grandcolas, n. gen., n. sp., specimen MNHN-EO-ENSIF12115. Scale bar $1 \mathrm{~mm}$. Abbreviations: see Material and methods.

Figure 9. Seselia Hugel \& Desutter-Grandcolas, n. gen., female copulatory papilla in dorsal view of: A, Seselia longicercata (Bolivar, 1912) n. gen., n. comb., specimen MNHN-EO-ENSIF12096; B, Seselia patellifera (Bolivar, 1912) n. gen., n. comb., specimen MNHN-EO-ENSIF12100; C, Seselia matyoti Hugel \& Desutter-Grandcolas, n. gen., n. sp., specimen MNHN-EO-ENSIF12113; D, Seselia coccofessei Hugel \& Desutter-Grandcolas, n. gen., n. sp., specimen 2010SEYSH058. Scale bar 1 mm.

Figure 10. Phaeogryllus fuscus Bolivar, 1912, male specimen MNHN-EO-ENSIF12265: A, habitus, dorsal view; B, face; C, D, head, pronotum and forewings, dorsal (C) and side (D) views; E, hindfemur; F, terminalia, dorsal view. Abbreviations: epc., epiproct; m.p., maxillary palpus; pc, paraproct; sgen., subgenital plate. Scale bars $1 \mathrm{~mm}$.

Figure 11. Phaeogryllus fuscus Bolivar, 1912, female specimen MNHN-EO-ENSIF12266: A, habitus in dorsal view; B, ovipositor, side view; C-E, copulatory papilla in dorsal (C), ventral (D) and side (E) views. Scale bars $2 \mathrm{~mm}$ (A, B), $0.1 \mathrm{~mm}(\mathrm{C}-\mathrm{E})$.

Figure 12. Phaeogryllus fuscus Bolivar, 1912. Male genitalia of specimen MNHN-EO-ENSIF12265 in dorsal (A), ventral (B) and side (C) views. Abbreviations see Material and methods.

Figure 13. Phalangacris Bolivar, 1912, patterns of coloration of males in dorsal view: A, Phalangacris alluaudi Bolivar, 1912, specimen MNHN-EO-ENSIF2957; B, Phalangacris ferlegro Hugel \& Desutter-Grandcolas, n. sp., specimen MNHN-EO-ENSIF12117; C, Phalangacris sotsote Hugel \& Desutter-Grandcolas, n. sp, specimen MNHN-EO-ENSIF12121. Scale bar 2 mm. 
Figure 14. Phalangacris Bolivar, 1912, A-C, face coloration; D-F, males in side view; G-I, male left forewing in dorsal view, in: A, D, G Phalangacris alluaudi Bolivar, 1912, specimen MNHN-EOENSIF2957; B, E, H Phalangacris ferlegro Hugel \& Desutter-Grandcolas, n. sp., specimen MNHNEO-ENSIF12117; C, F, I Phalangacris sotsote Hugel \& Desutter-Grandcolas, n. sp, specimen MNHN-EO-ENSIF12121. Scale bars $1 \mathrm{~mm}$.

Figure 15. Phalangacris Bolivar, 1912. A-C, hindfemur patterns of coloration of: A, Phalangacris alluaudi Bolivar, 1912, specimen MNHN-EO-ENSIF2957; B, Phalangacris ferlegro Hugel \& Desutter-Grandcolas, n. sp., specimen MNHN-EO-ENSIF12117; C, Phalangacris sotsote Hugel \& Desutter-Grandcolas, n. sp, specimen 2010 MNHN-EO-ENSIF12121. D-E, Phalangacris ferlegro Hugel \& Desutter-Grandcolas, n. sp., female specimen MNHN-EO-ENSIF12118: D, ovipositor; E, copulatory papilla. Scale bars $1 \mathrm{~mm}$.

Figure 16. Male genitalia in species of Phalangacris Bolivar, 1912 in dorsal, side and ventral view respectively: A-C, Phalangacris alluaudi Bolivar, 1912, specimen MNHN-EO-ENSIF2957; D-F, Phalangacris ferlegro Hugel \& Desutter-Grandcolas, n. sp, specimen MNHN-EO-ENSIF12117; G-I, Phalangacris sotsote Hugel \& Desutter-Grandcolas, n. sp., specimen MNHN-EO-ENSIF12121. Scale bar $1 \mathrm{~mm}$. Abbreviations: see Material and methods.

Figure 17. Gryllapterus tomentosus Bolivar, 1912. A, male habitus in dorsal view, specimen deposited in LEM; B-C, male forewing in dorsal (B) and side (C) views, specimen MNHN-EO-ENSIF12269; D, male metanotal gland, dorsal view, specimen MNHN-EO-ENSIF12269; E, face, specimen MNHNEO-ENSIF12269; F, hind femur pattern of coloration, specimen MNHN-EO-ENSIF12270; G-J, male genitalia in dorsal (G), ventral (H), side (I) and ventro-distal (J) views, specimen MNHN-EOENSIF12269. Abbreviations: see Material and methods. Scales $2 \mathrm{~mm}$ (A), $1 \mathrm{~mm}$ (F).

Figure 18. Gryllapterus tomentosus Bolivar, 1912, female. A, habitus in dorsal view, specimen MNHN-EO-ENSIF12270; B, ovipositor, side view, specimen MNHN-EO-ENSIF12270; C-E, copulatory papilla in dorsal (C), ventral (D) and side (E) views, specimen MNHN-EO-ENSIF12272. Scale $1 \mathrm{~mm}$ (A, B), $0.1 \mathrm{~mm}$ (C-E).

Figure 19. Phaloria (Papuloria) insularis (Bolivar, 1912) (A-C, G-I) and Phaloria (Papuloria) bolivari Hugel \& Desutter-Grandcolas, n. sp. (D-F, J-L): A-F, male genitalia in dorsal (A, D), ventral (B, E) and side (C, F) views; G-L, female copulatory papilla in dorsal (G, J), ventral (H, K) and side (I, L) views, scale bar 0.1 mm.Abbreviations: see Material and methods. 
Figure 20. Calling song of Phaloria (Papuloria) insularis (Bolivar, 1912) recorded from Mahé (10pm, $26^{\circ} \mathrm{C}$ ). A, oscillogram of a song bout, showing a succession of motives over 40 s.; B, detailed oscillogram of a a song bout with three motives; $\mathrm{C}$, spectrogram of the three-motive song bout shown in B, showing dominant frequency and two upper harmonics; D, oscillogram of a motive identified in $\mathrm{B}$, showing the successive 14 syllables and their regular envelops.

Table 1. Measurements of Paragryllodes nitida (Bolivar, 1912) n. comb. (in mm).

Table 2. Measurements of Seselia longicercata (Bolivar, 1912) n. gen., n. comb. (in mm).

Table 3. Measurements of Seselia patellifera (Bolivar, 1912) n. gen., n. comb. (in mm).

Table 4. Measurements of Seselia matyoti Hugel \& Desutter-Grandcolas, n. gen., n. sp. (in mm).

Table 5. Measurements of Seselia coccofessei Hugel \& Desutter-Grandcolas, n. gen., n. sp. (in mm).

Table 6. Measurements of Phaeogryllus fuscus Bolivar, 1912 (in mm).

Table 7. Measurements of Phalangacris alluaudi Bolivar, 1895 (in mm). Male syntype: after Bolivar (1895).

Table 8. Measurements of Phalangacris ferlegro Hugel and Desutter-Grandcolas, n. sp. (in mm).

Table 9. Measurements of Phalangacris sotsote Hugel and Desutter-Grandcolas, n. sp. (in mm).

Table 10. Measurements of Gryllapterus tomentosus Bolivar, 1912 (in mm).

Table 11. Measurements of Phaloria (Papuloria) insularis (Bolivar, 1912) (in mm).

Table 12. Measurements of Phaloria (Papuloria) bolivari Hugel \& Desutter-Grandcolas, n. sp. (in mm). 


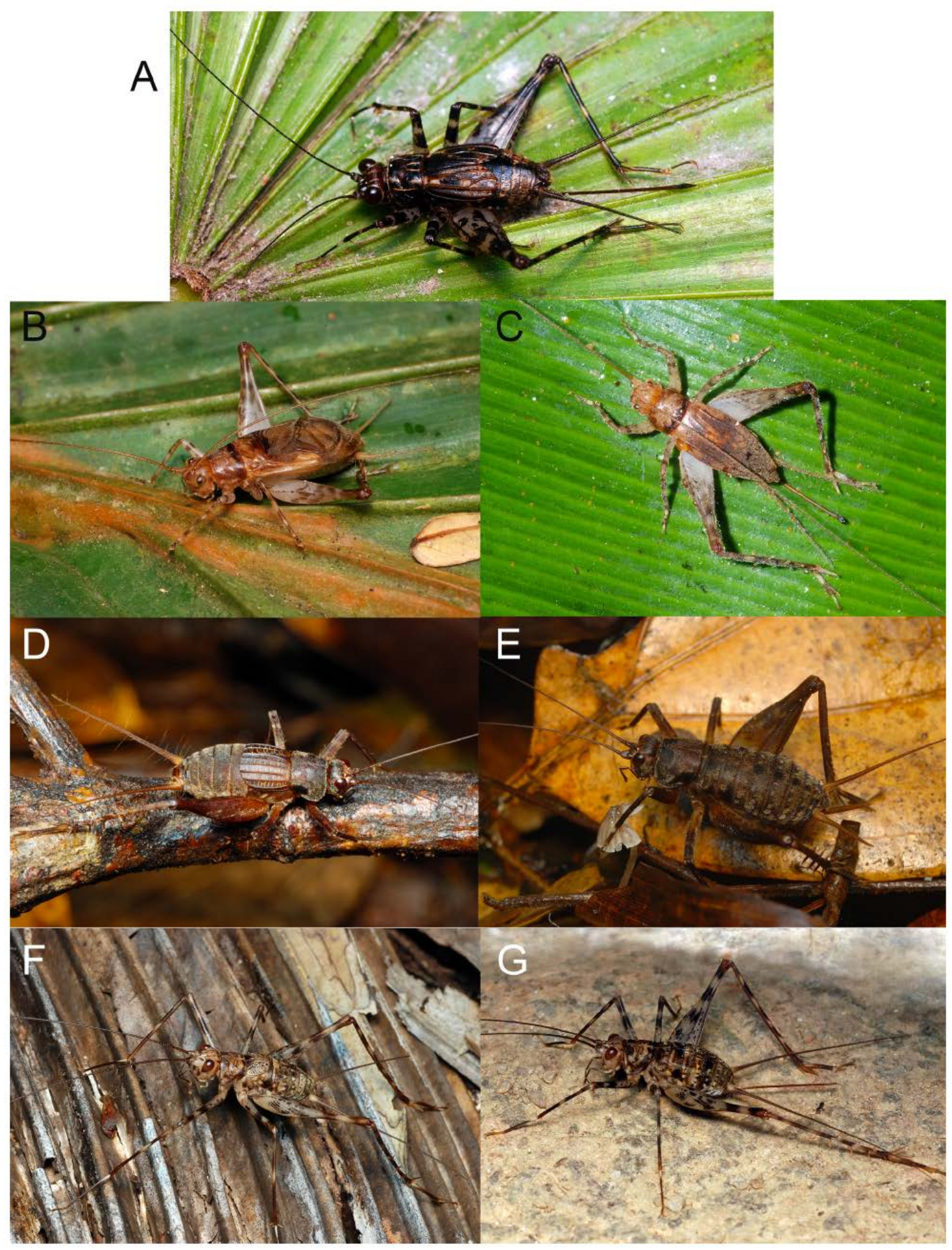

Figure 1. Phalangopsidae crickets from the Seychelles in the wild. A, Paragryllodes nitidula (Bolivar, 1912) n. comb., female. B, Phaloria (Papuloria) bolivari Hugel \& Desutter-Grandcolas, n. sp., male. C, same, female. D, Phaeogryllus fuscus Bolivar, 1912, male. E, same, female. F, Phalangacris ferlegro Hugel \& Desutter-Grandcolas, n. sp. male, G, same, female. 

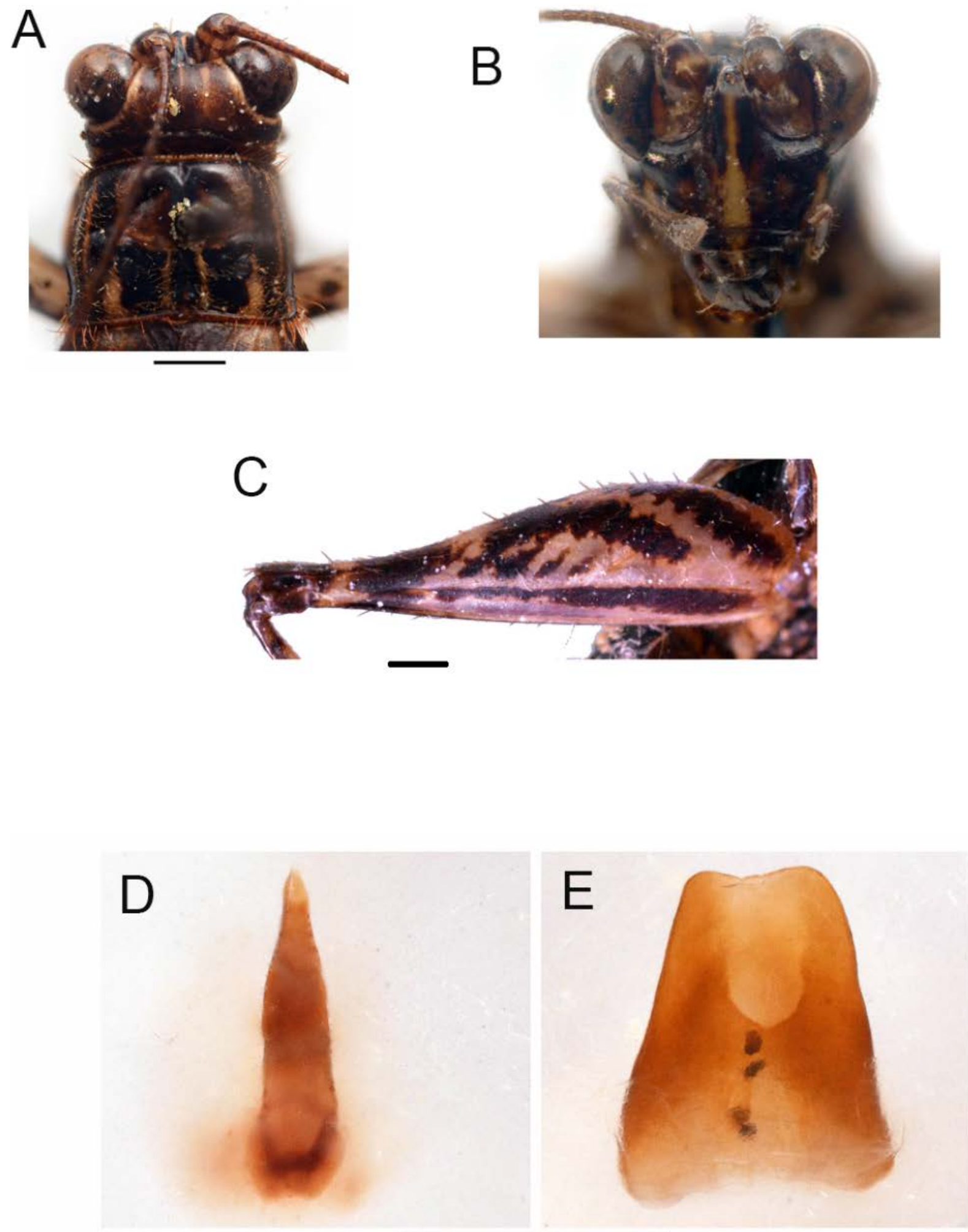

Figure 2. Paragryllodes Karny, 1909: A-D, Paragryllodes nitidula (Bolivar, 1912) n. comb. A, head and pronotum in dorsal view; B, head in face view; some of the light patterns on the black shiny cuticula are reflections and not real patterns; C, hindfemur outer side; D, copulatory papilla in ventral view. E, Paragryllodes milloti (Chopard, 1958), copulatory papilla in ventral view. Scales $1 \mathrm{~mm}$. 


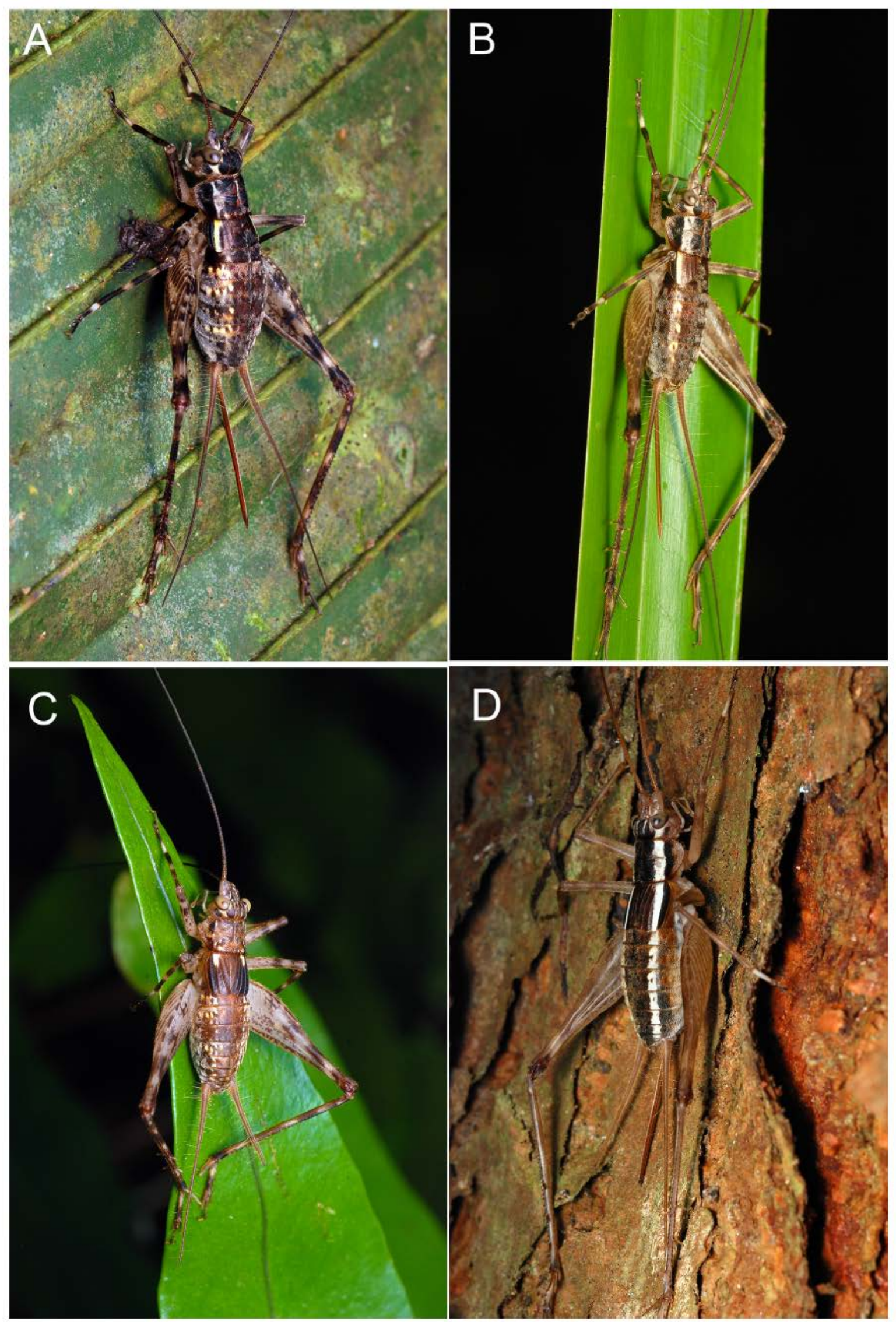

Figure 3. Seselia Hugel \& Desutter-Grandcolas, n. gen. in the wild. A, Seselia longicercata (Bolivar, 1912) n. gen., n. comb., female; B, Seselia patellifera (Bolivar, 1912) n. gen., n. comb.; C, Seselia matyoti Hugel \& Desutter-Grandcolas, n. gen., n. sp.; D, Seselia coccofessei Hugel \& Desutter-Grandcolas, n. gen., n. sp. 


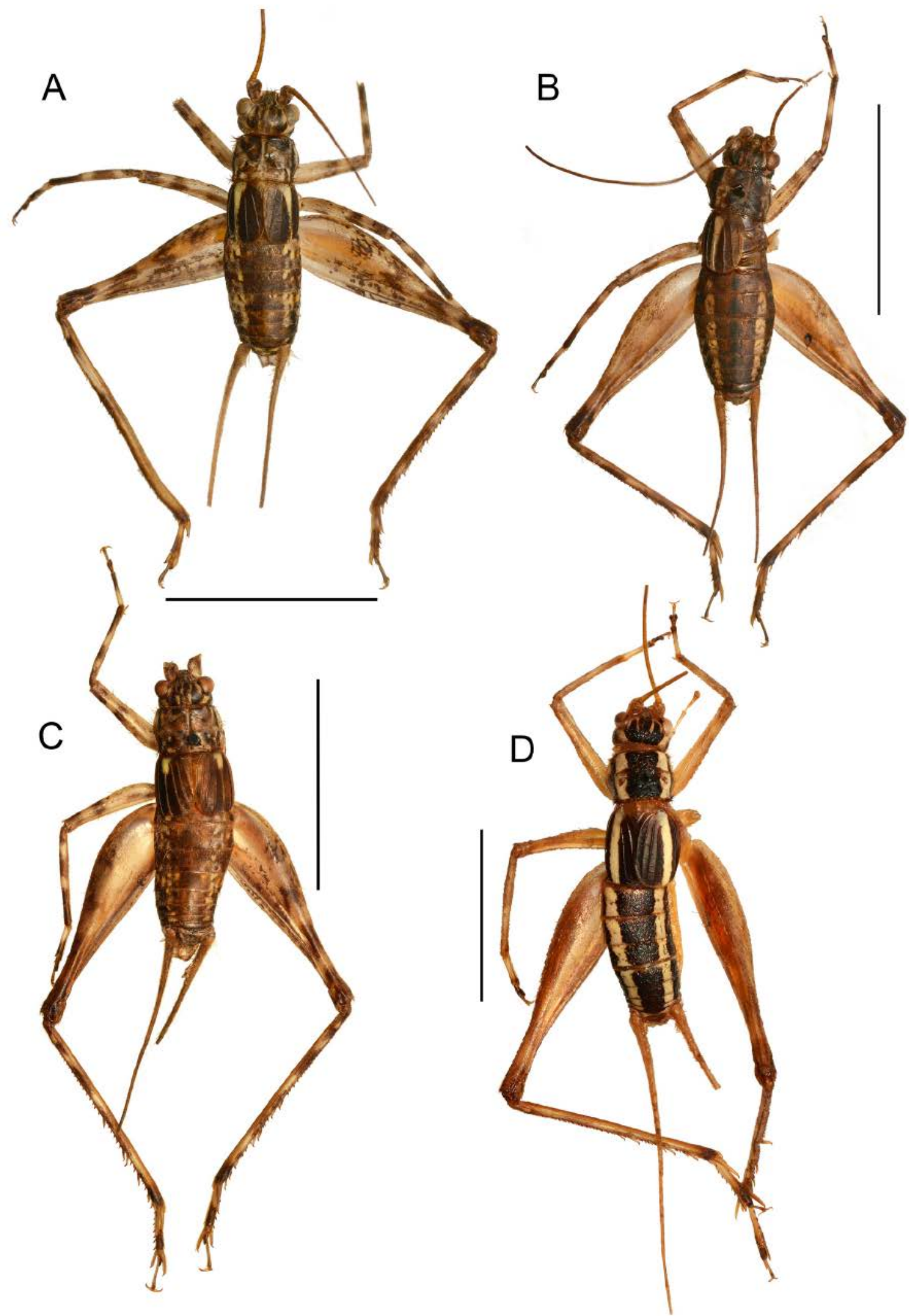

Figure 4. Seselia Hugel \& Desutter-Grandcolas, n. gen., patterns of coloration of males in dorsal view: A, Seselia longicercata (Bolivar, 1912) n. gen., n. comb., specimen MNHN-EO-ENSIF12095; B, Seselia patellifera (Bolivar, 1912) n. gen., n. comb., specimen MNHN-EO-ENSIF12097; C, Seselia matyoti Hugel \& Desutter-Grandcolas, n. gen., n. sp., specimen 2010SEYSH147; D, Seselia coccofessei Hugel \& Desutter-Grandcolas, n. gen., n. sp., specimen 2010SEYSH083. Scale bars $10 \mathrm{~mm}$. 

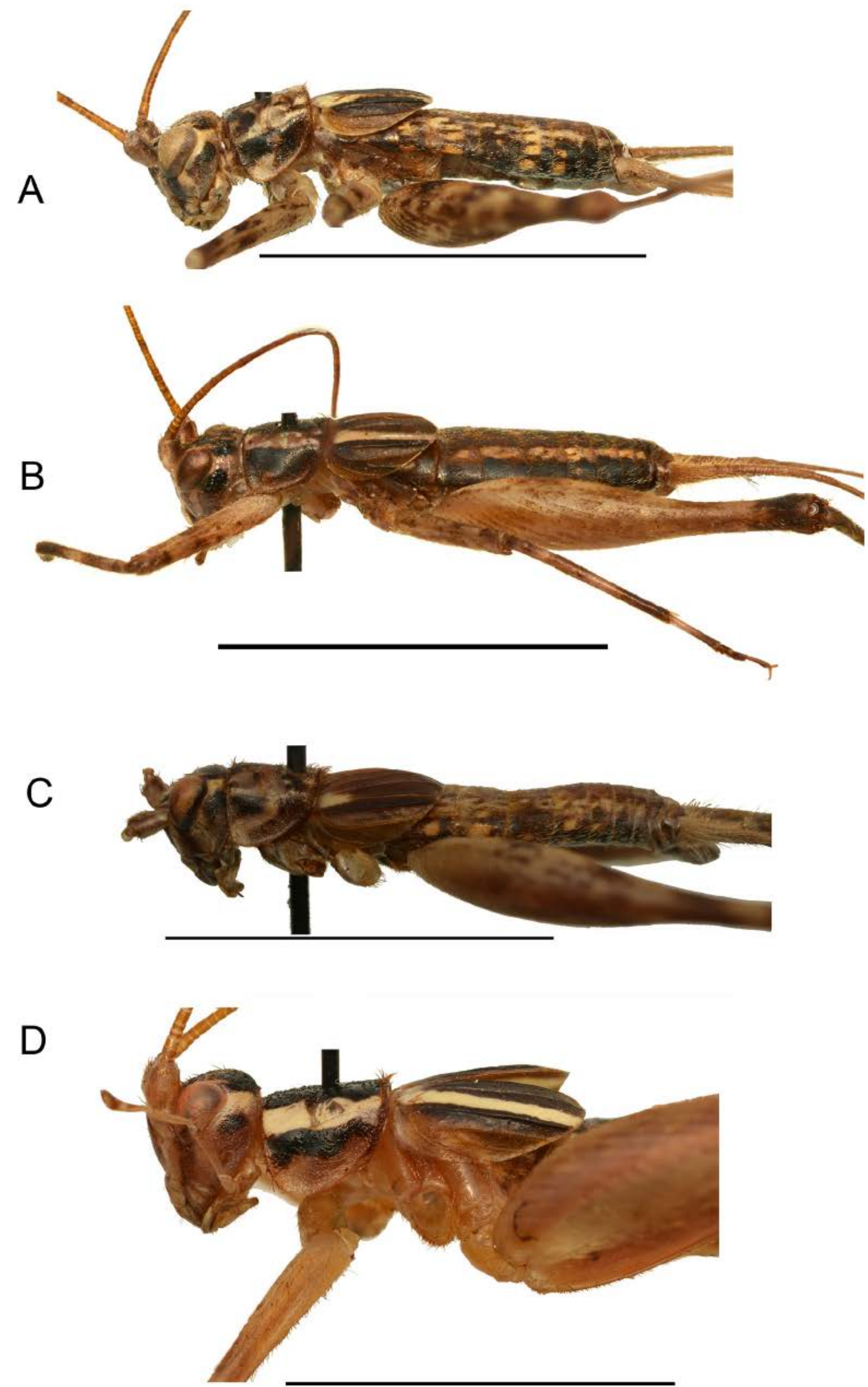

Figure 5. Seselia Hugel \& Desutter-Grandcolas, n. gen., patterns of coloration of males in side view: A, Seselia longicercata (Bolivar, 1912) n. gen., n. comb., specimen MNHN-EO-ENSIF12095; B, Seselia patellifera (Bolivar, 1912) n. gen., n. comb., specimen MNHN-EO-ENSIF12097; C, Seselia matyoti Hugel \& Desutter-Grandcolas, n. gen., n. sp., specimen MNHN-EOENSIF12111; D, Seselia coccofessei Hugel \& Desutter-Grandcolas, n. gen., n. sp., specimen MNHN-EO-ENSIF12115. C and D are right views flipped for comparison purpose. Scale bars $10 \mathrm{~mm}$. 

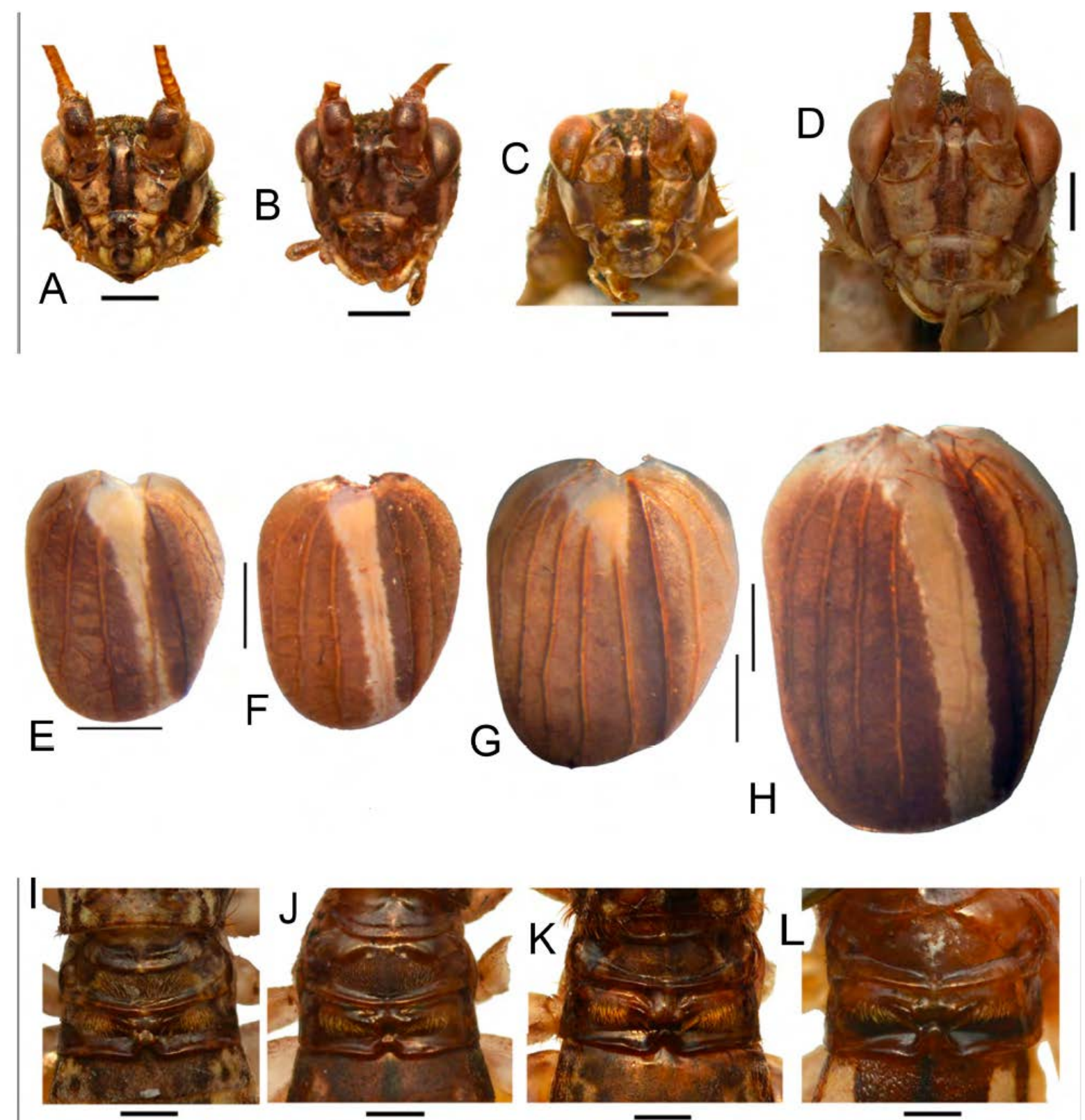

Figure 6. Seselia Hugel \& Desutter-Grandcolas, n. gen. A-D, face coloration; E-H, forewing coloration; I-L, metanotal glands in males in: A, E, I Seselia longicercata (Bolivar, 1912) n. gen., n. comb., specimen MNHN-EO-ENSIF12095; B, F, J Seselia patellifera (Bolivar, 1912) n. gen., n. comb., specimen MNHN-EO-ENSIF12097; C, G, K Seselia matyoti Hugel \& Desutter-Grandcolas, n. gen., n. sp., specimen MNHN-EO-ENSIF12111; D, H, L Seselia coccofessei Hugel \& Desutter-Grandcolas, n. gen., n. sp., specimen MNHN-EO-ENSIF12115. Scale bars 1 mm. 
A

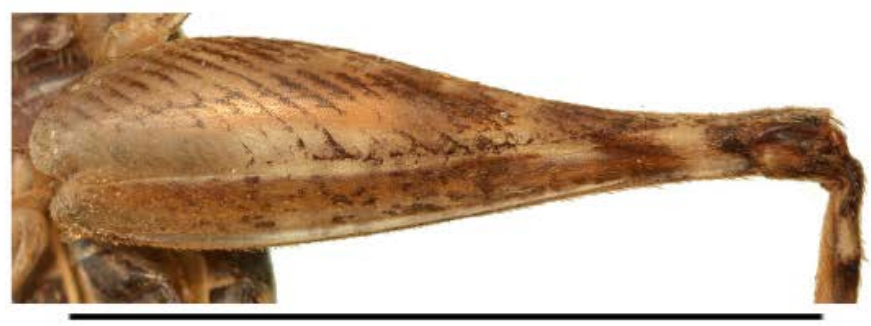

B

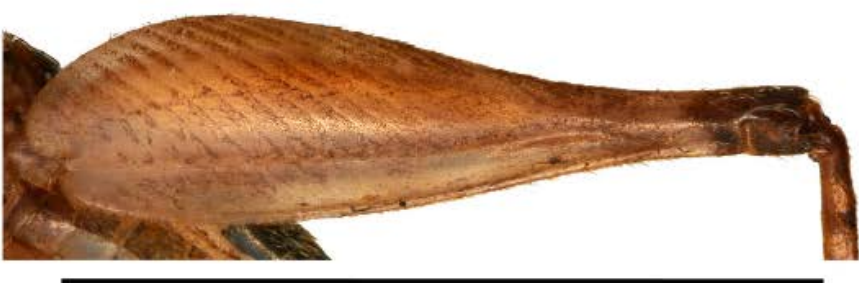

C
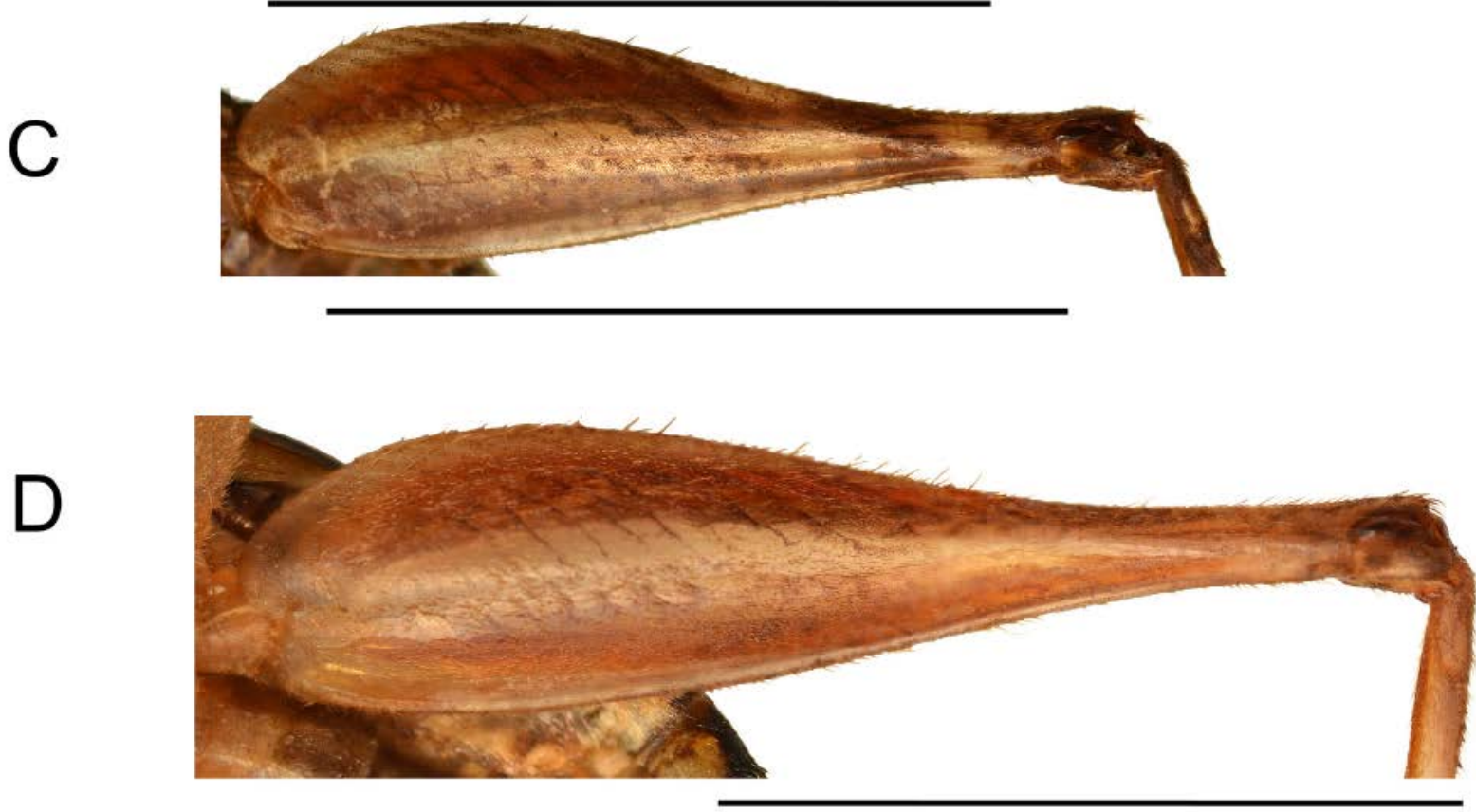

Figure 7. Seselia Hugel \& Desutter-Grandcolas, n. gen., hindfemur patterns of coloration of: A, Seselia longicercata (Bolivar, 1912) n. gen., n. comb., specimen MNHN-EO-ENSIF12095; B, Seselia patellifera (Bolivar, 1912) n. gen., n. comb., MNHNEO- ENSIF12097; C, Seselia matyoti Hugel \& Desutter-Grandcolas, n. gen., n. sp., specimen MNHNEO-ENSIF12111; D, Seselia coccofessei Hugel \& Desutter-Grandcolas, n. gen., n. sp., specimen MNHN-EOENSIF12115. B and C are right femora flipped for comparison purpose. Scale bars $10 \mathrm{~mm}$. 

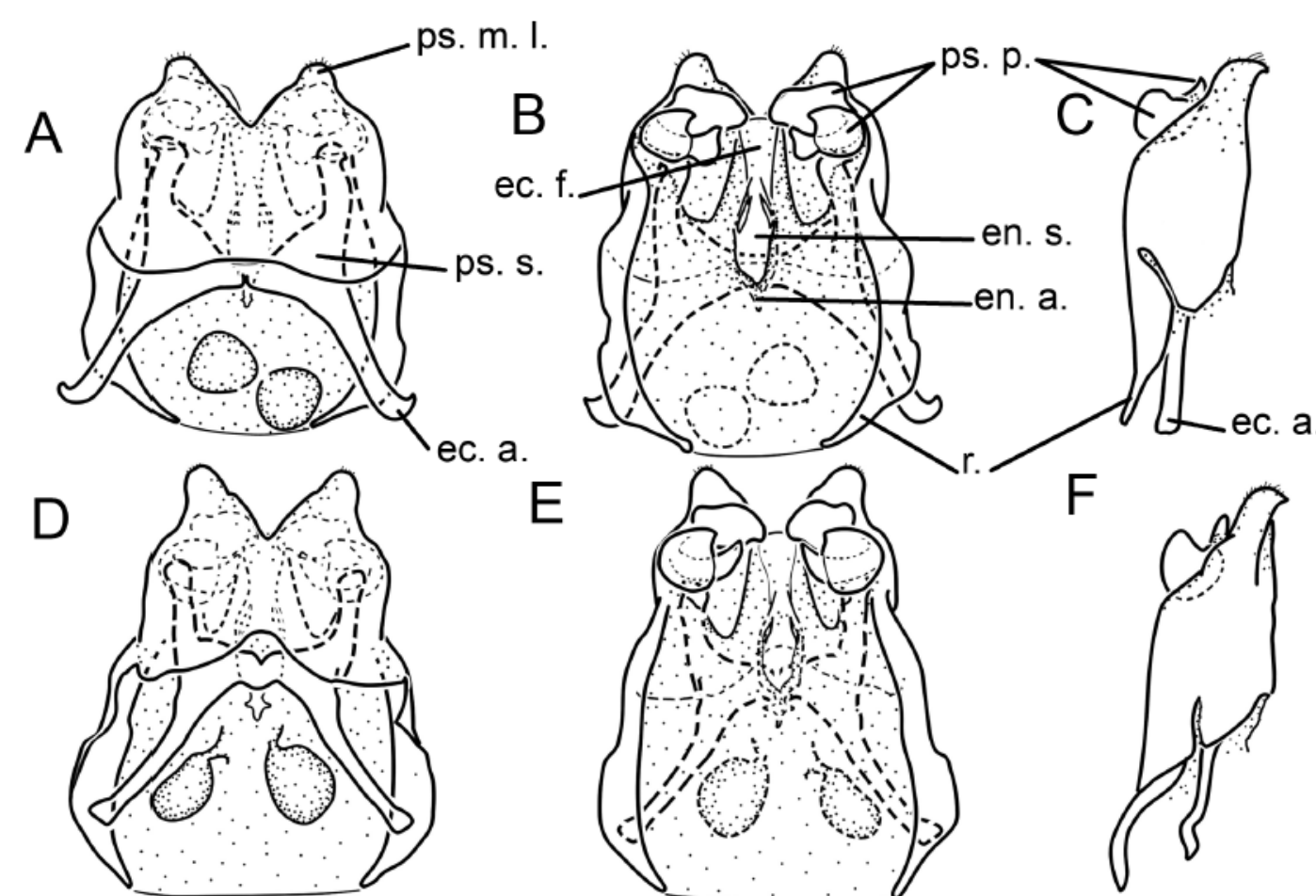

$\mathrm{E}$

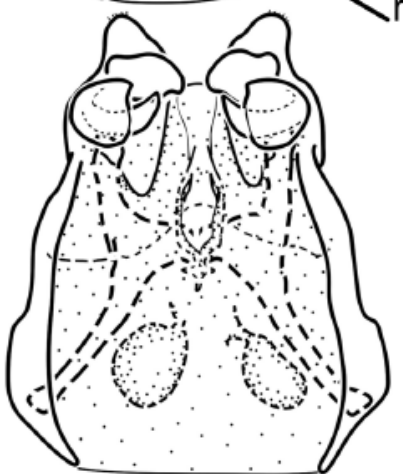

$\mathrm{F}$

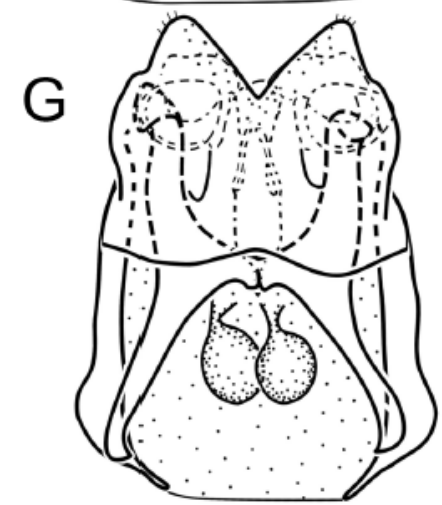

$\mathrm{H}$
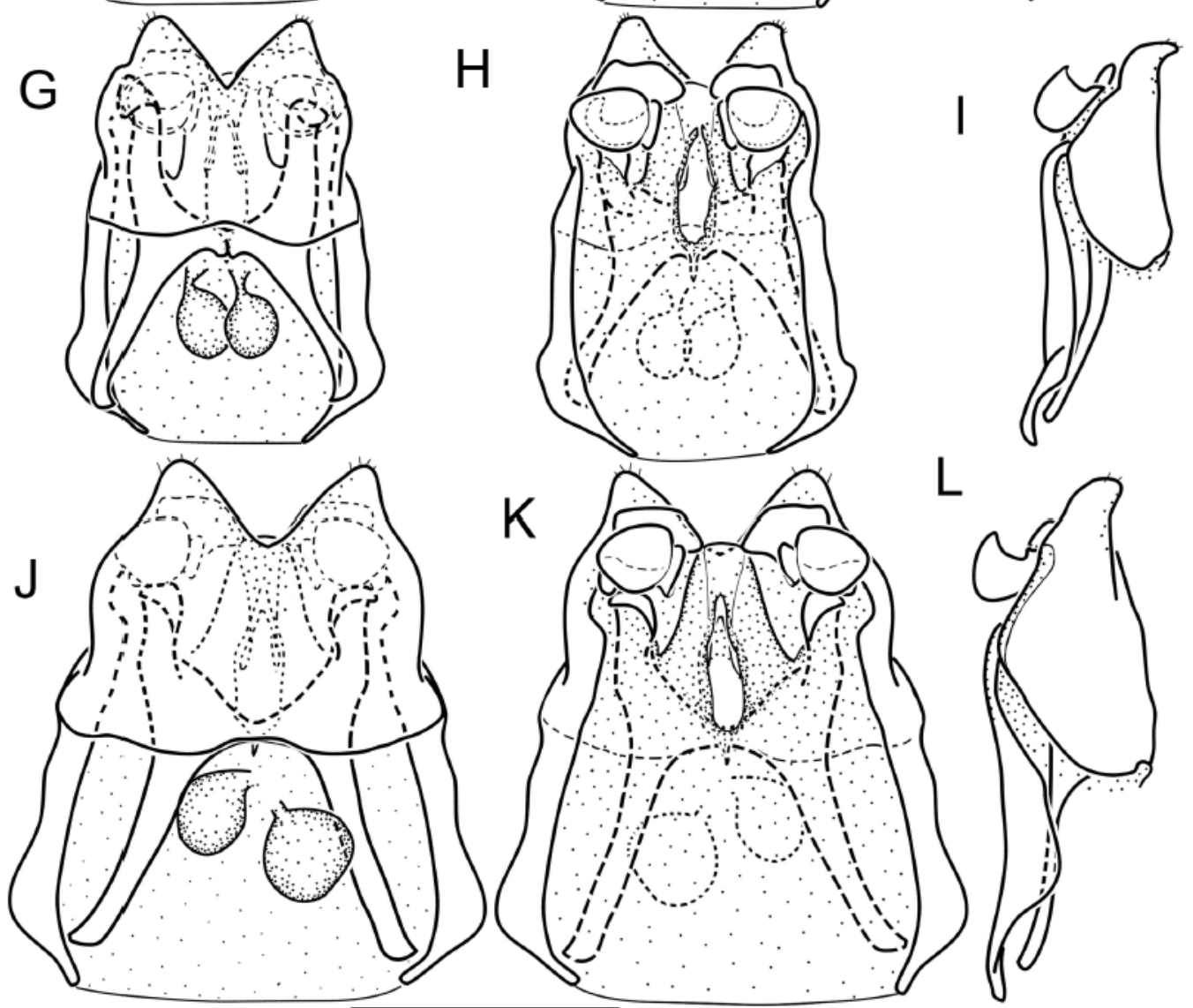

Figure 8. Seselia Hugel \& Desutter-Grandcolas, n. gen., male genitalia in dorsal, ventral and side view of: A-C, Seselia longicercata (Bolivar, 1912) n. gen., n. comb., specimen MNHN-EO-ENSIF12095; D-F, Seselia patellifera (Bolivar, 1912) n. gen., n. comb., specimen MNHN-EO-ENSIF12097; G-I, Seselia matyoti Hugel \& Desutter-Grandcolas, n. gen., n. sp., specimen MNHN-EO-ENSIF12111; J-L, Seselia coccofessei Hugel \& Desutter-Grandcolas, n. gen., n. sp., specimen MNHN-EOENSIF12115. Scale bar $1 \mathrm{~mm}$. Abbreviations: see Material and methods. 


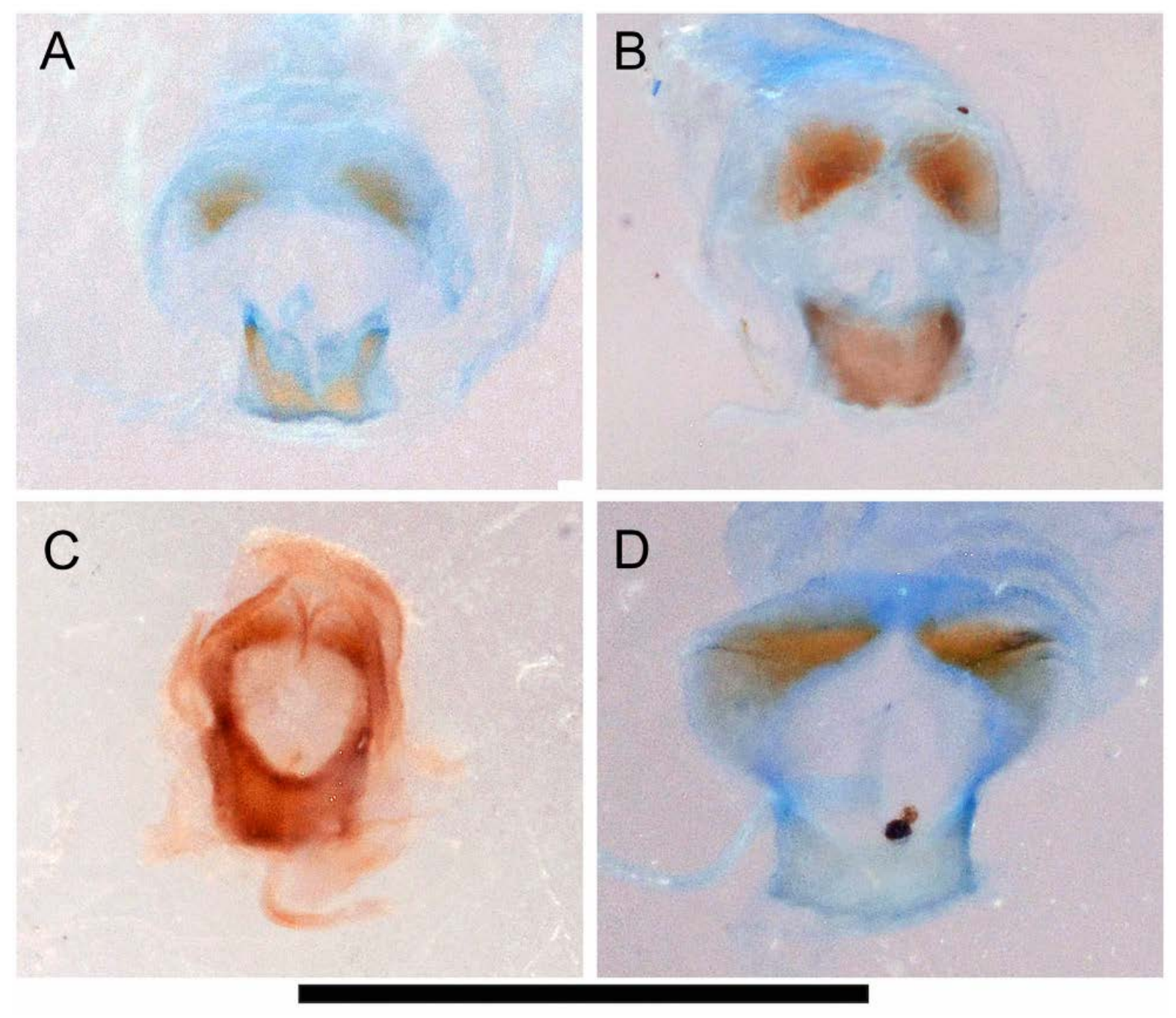

Figure 9. Seselia Hugel \& Desutter-Grandcolas, n. gen., female copulatory papilla in dorsal view of: A, Seselia longicercata (Bolivar, 1912) n. gen., n. comb., specimen MNHN-EO-ENSIF12096; B, Seselia patellifera (Bolivar, 1912) n. gen., n. comb., specimen MNHN-EO-ENSIF12100; C, Seselia matyoti Hugel \& Desutter-Grandcolas, n. gen., n. sp., specimen MNHN-EOENSIF12113; D, Seselia coccofessei Hugel \& Desutter-Grandcolas, n. gen., n. sp., specimen 2010SEYSH058. Scale bar $1 \mathrm{~mm}$. 


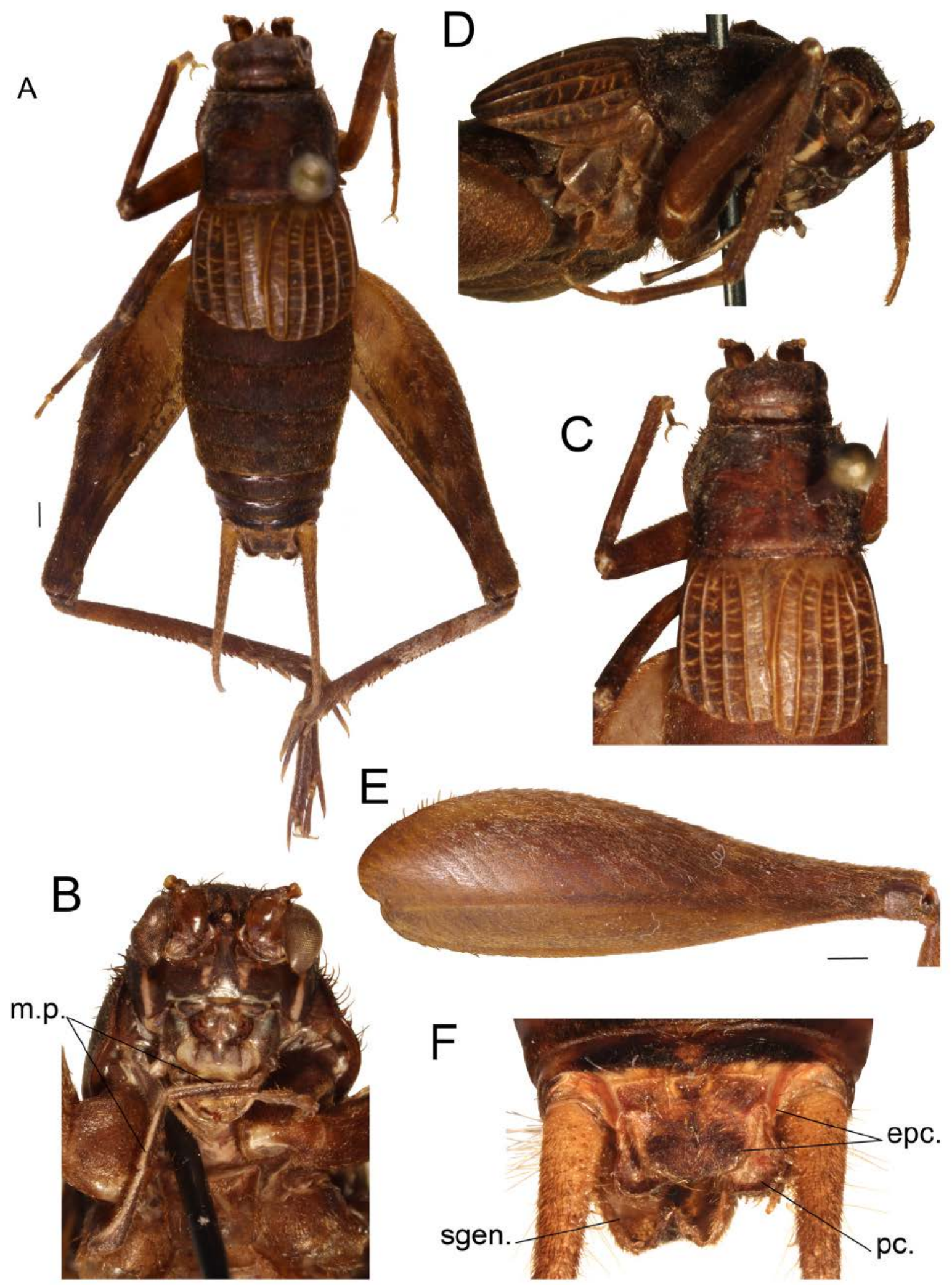

Figure 10. Phaeogryllus fuscus Bolivar, 1912, male specimen MNHN-EO-ENSIF12265: A, habitus, dorsal view; B, face; C, D, head, pronotum and forewings, dorsal (C) and side (D) views; E, hindfemur; F, terminalia, dorsal view. Abbreviations: epc., epiproct; m.p., maxillary palpus; pc, paraproct; sgen., subgenital plate. Scale bars 1 mm. 


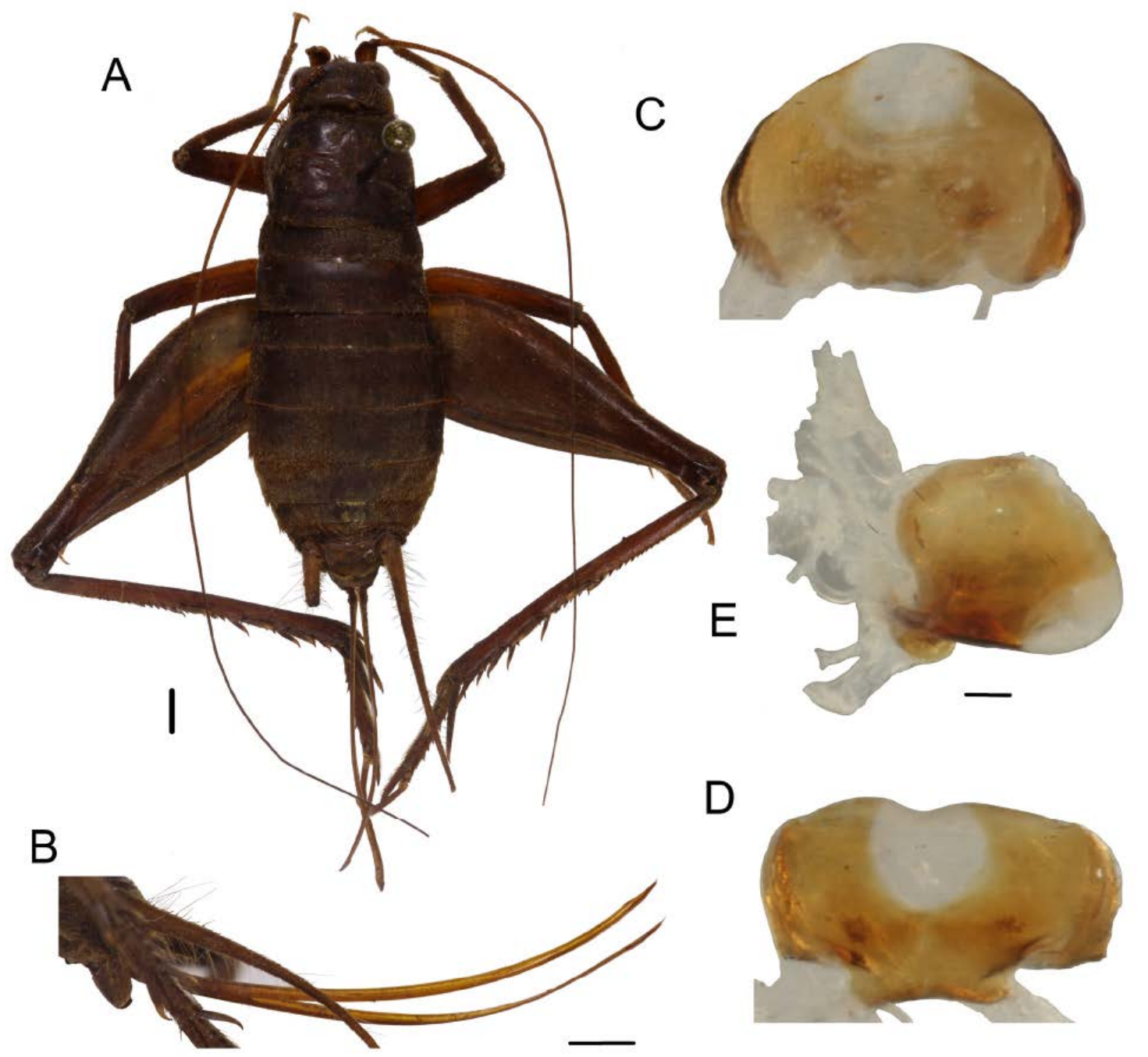

Figure 11. Phaeogryllus fuscus Bolivar, 1912, female specimen MNHN-EO-ENSIF12266: A, habitus in dorsal view; $B$, ovipositor, side view; C-E, copulatory papilla in dorsal (C), ventral (D) and side (E) views. Scale bars 2 mm (A, B), $0.1 \mathrm{~mm}$ (C-E). 

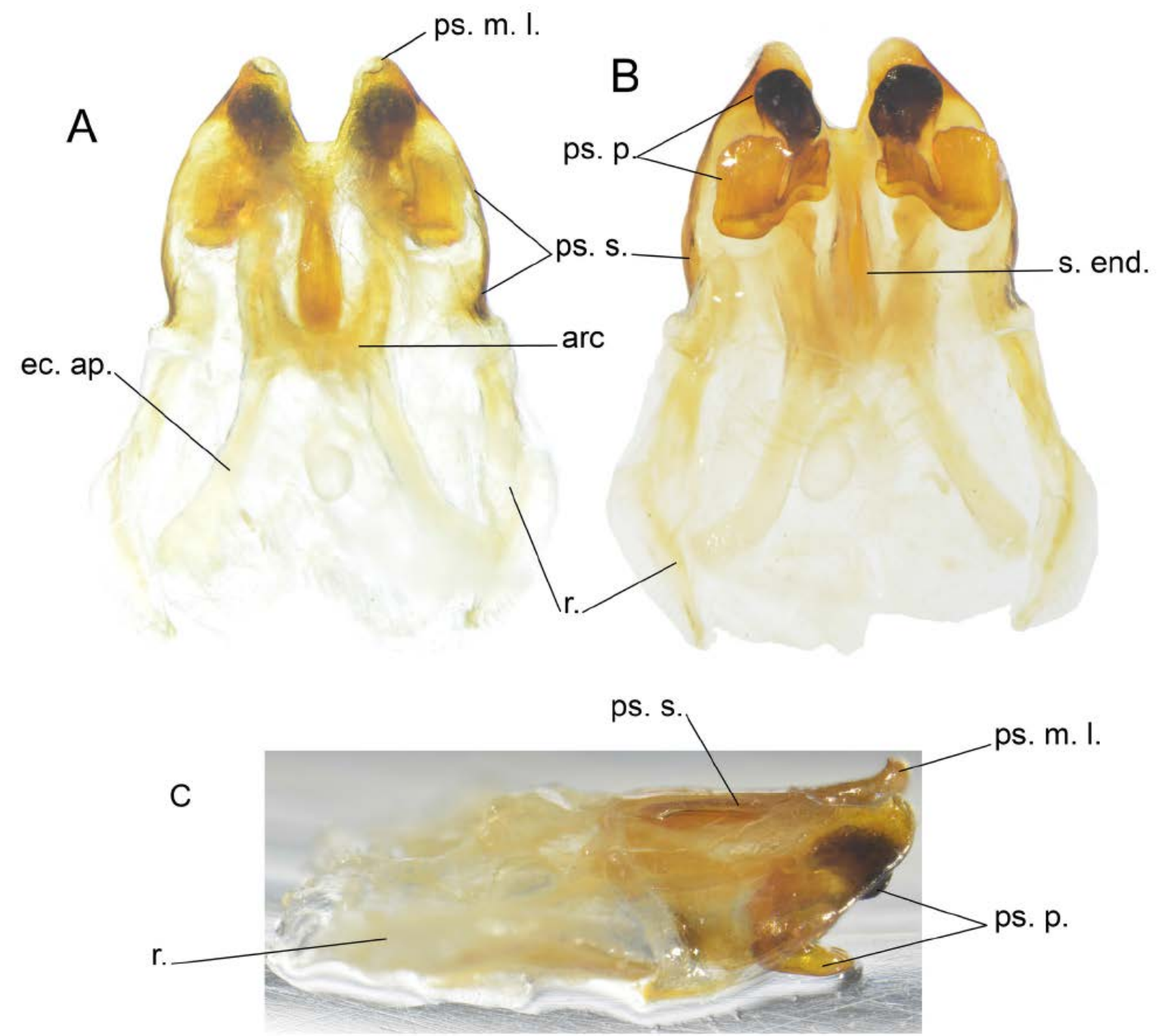

Figure 12. Phaeogryllus fuscus Bolivar, 1912. Male genitalia of specimen MNHN-EO-ENSIF12265 in dorsal (A), ventral (B) and side (C) views. Abbreviations see Material and methods. 

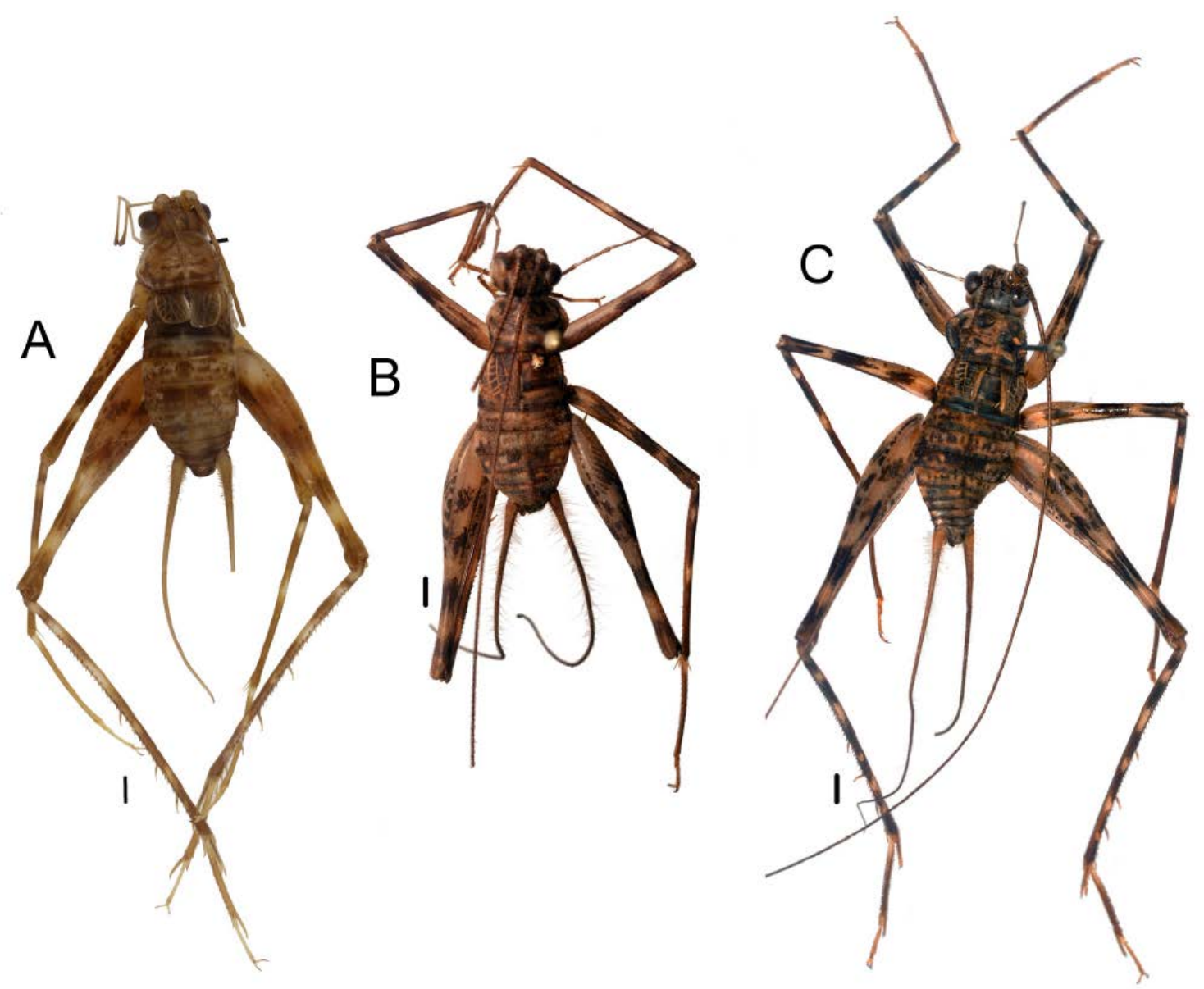

Figure 13. Phalangacris Bolivar, 1912, patterns of coloration of males in dorsal view: A, Phalangacris alluaudi Bolivar, 1912, specimen MNHN-EO-ENSIF2957; B, Phalangacris ferlegro Hugel \& Desutter-Grandcolas, n. sp., specimen MNHNEO-ENSIF12117; C, Phalangacris sotsote Hugel \& Desutter-Grandcolas, n. sp, specimen MNHNEO-ENSIF12121. Scale bar $2 \mathrm{~mm}$. 

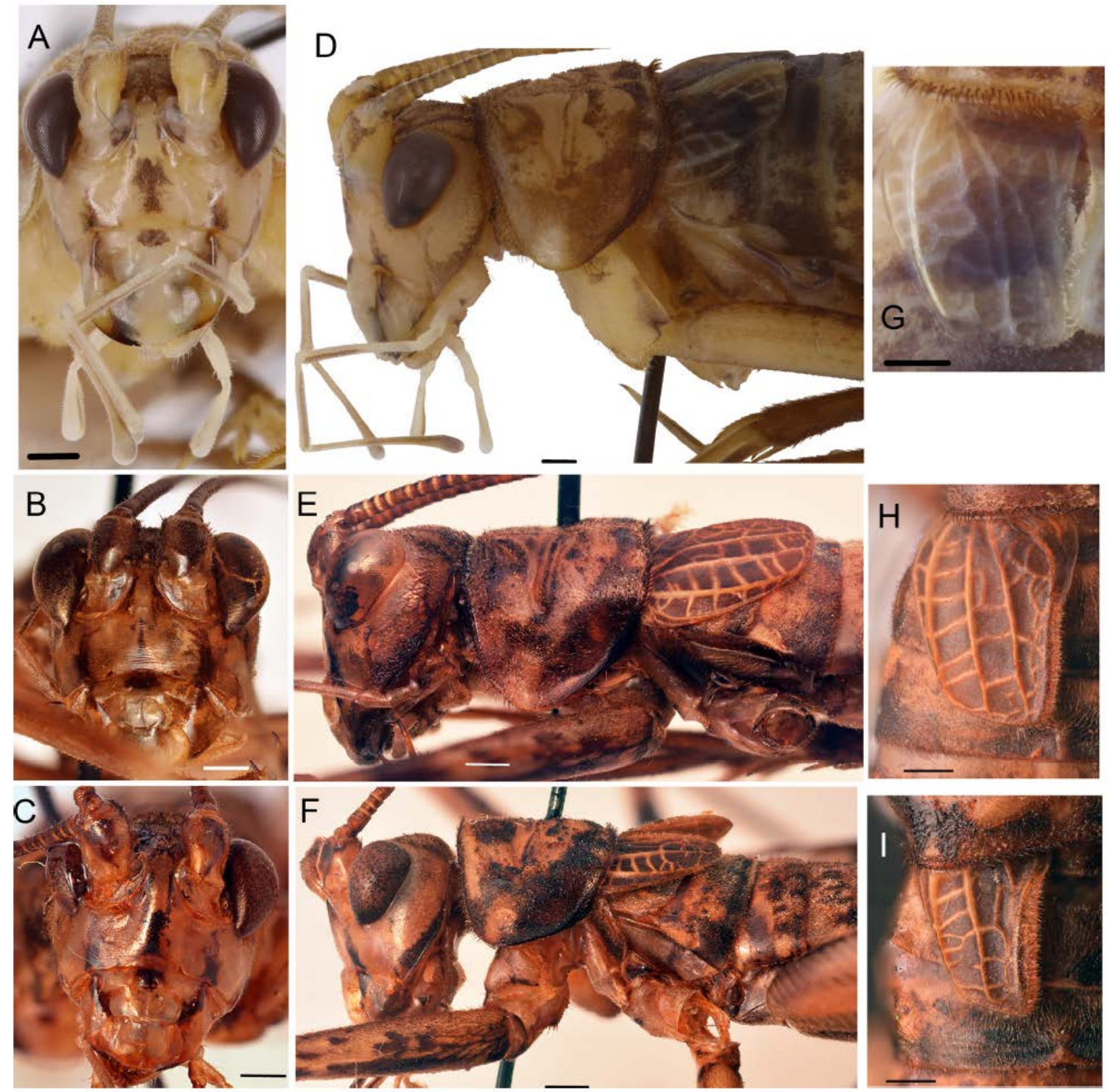

Figure 14. Phalangacris Bolivar, 1912, A-C, face coloration; D-F, males in side view; G-I, male left forewing in dorsal view, in: A, D, G Phalangacris alluaudi Bolivar, 1912, specimen MNHN-EO-ENSIF2957; B, E, H Phalangacris ferlegro Hugel \& Desutter-Grandcolas, n. sp., specimen MNHN-EO-ENSIF12117; C, F, I Phalangacris sotsote Hugel \& Desutter-Grandcolas, n. sp., specimen MNHN-EO-ENSIF12121. Scale bars $1 \mathrm{~mm}$. 


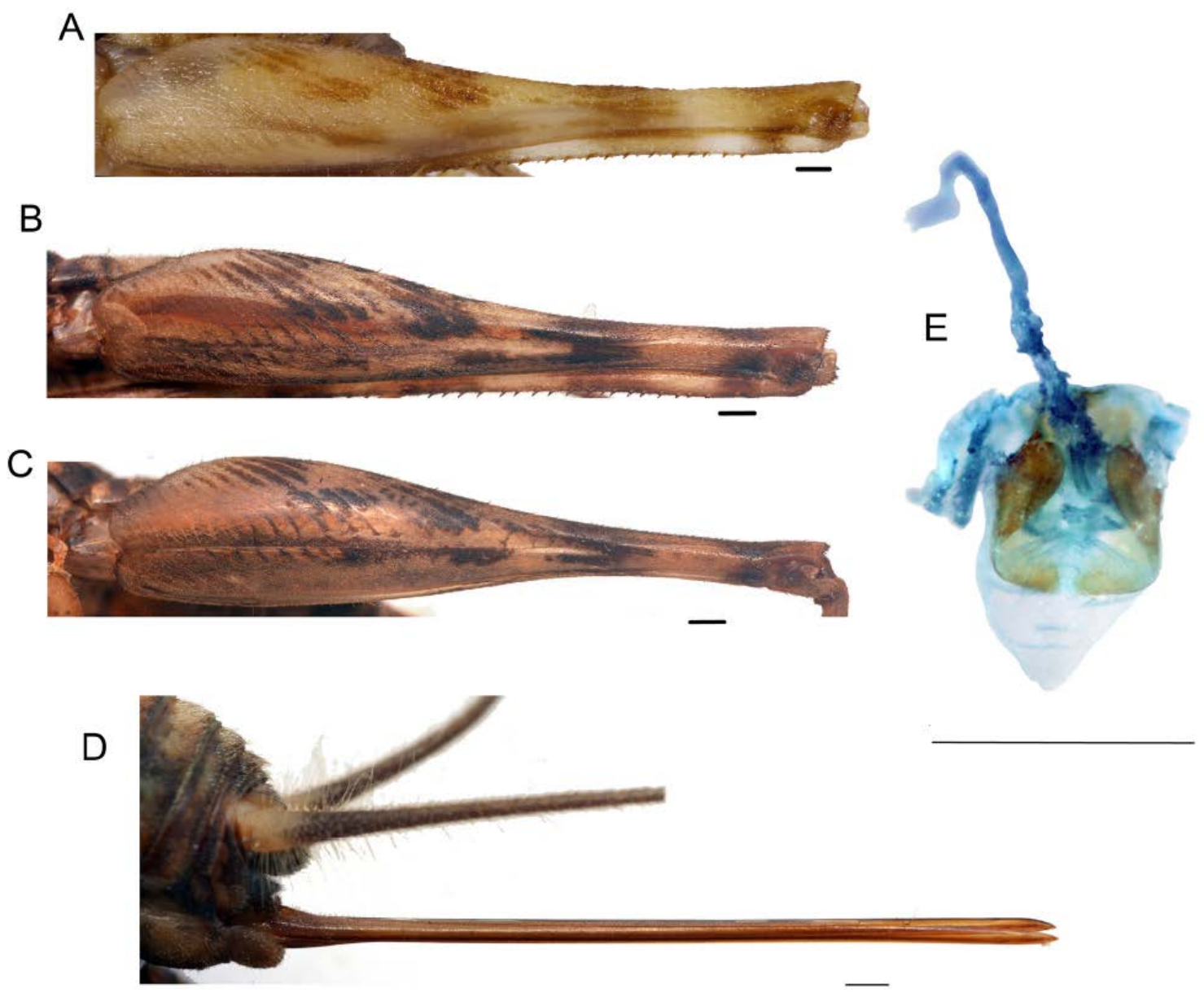

Figure 15. Phalangacris Bolivar, 1912. A-C, hindfemur patterns of coloration of: A, Phalangacris alluaudi Bolivar, 1912, specimen MNHN-EO-ENSIF2957; B, Phalangacris ferlegro Hugel \& Desutter-Grandcolas, n. sp., specimen MNHN-EOENSIF12117; C, Phalangacris sotsote Hugel \& Desutter-Grandcolas, n. sp., specimen 2010 MNHN-EOENSIF12121. D-E, Phalangacris ferlegro Hugel \& Desutter-Grandcolas, n. sp., female specimen MNHN-EOENSIF12118: D, ovipositor; E, copulatory papilla. Scale bars $1 \mathrm{~mm}$. 

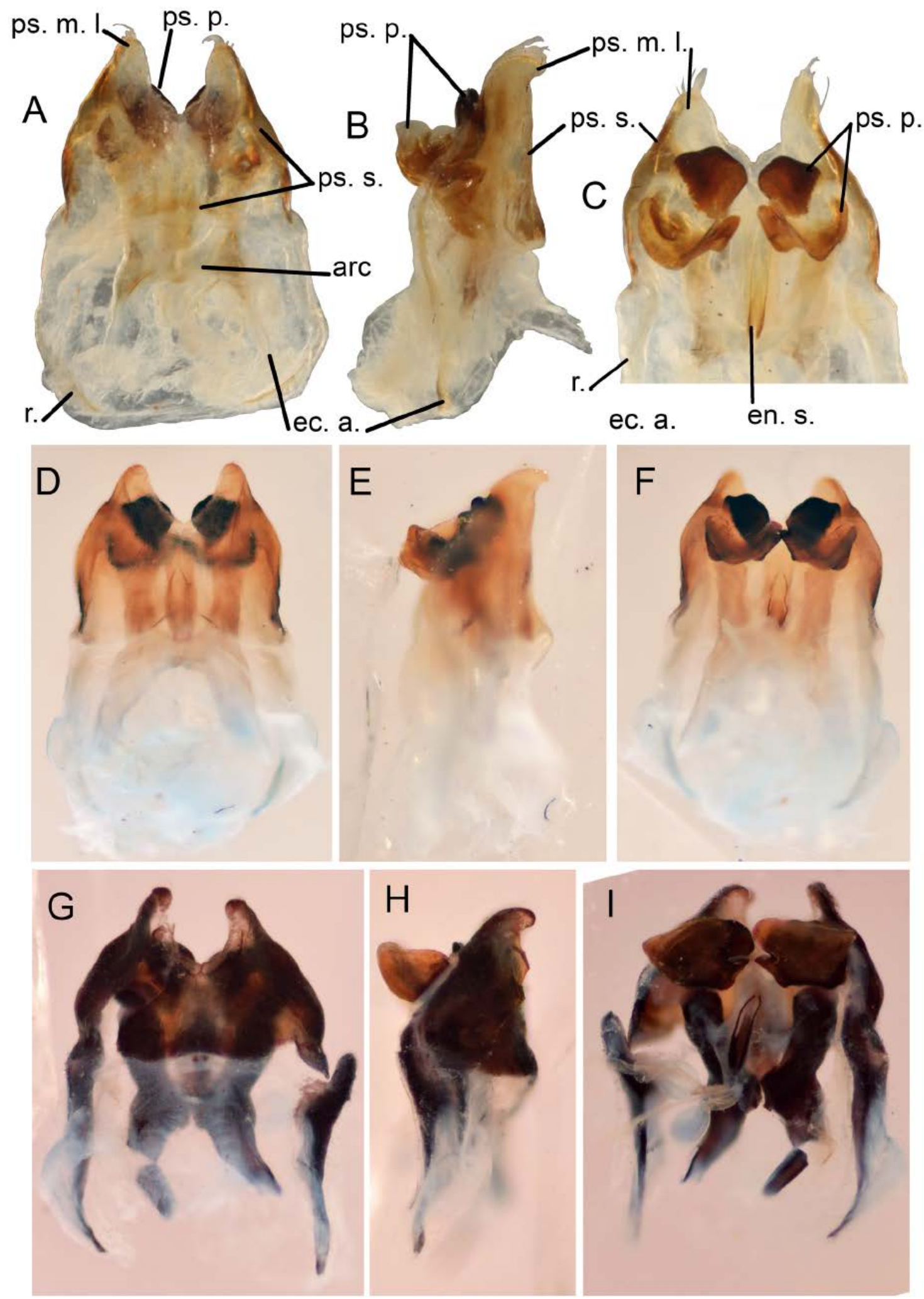

Figure 16. Male genitalia in species of Phalangacris Bolivar, 1912 in dorsal, side and ventral view respectively: A-C, Phalangacris alluaudi Bolivar, 1912, specimen MNHN-EO-ENSIF2957; D-F, Phalangacris ferlegro Hugel \& Desutter-Grandcolas, n. sp., specimen MNHN-EO-ENSIF12117; G-I, Phalangacris sotsote Hugel \& DesutterGrandcolas, n. sp., specimen MNHN-EO-ENSIF12121. Scale bar $1 \mathrm{~mm}$. Abbreviations: see Material and methods. 

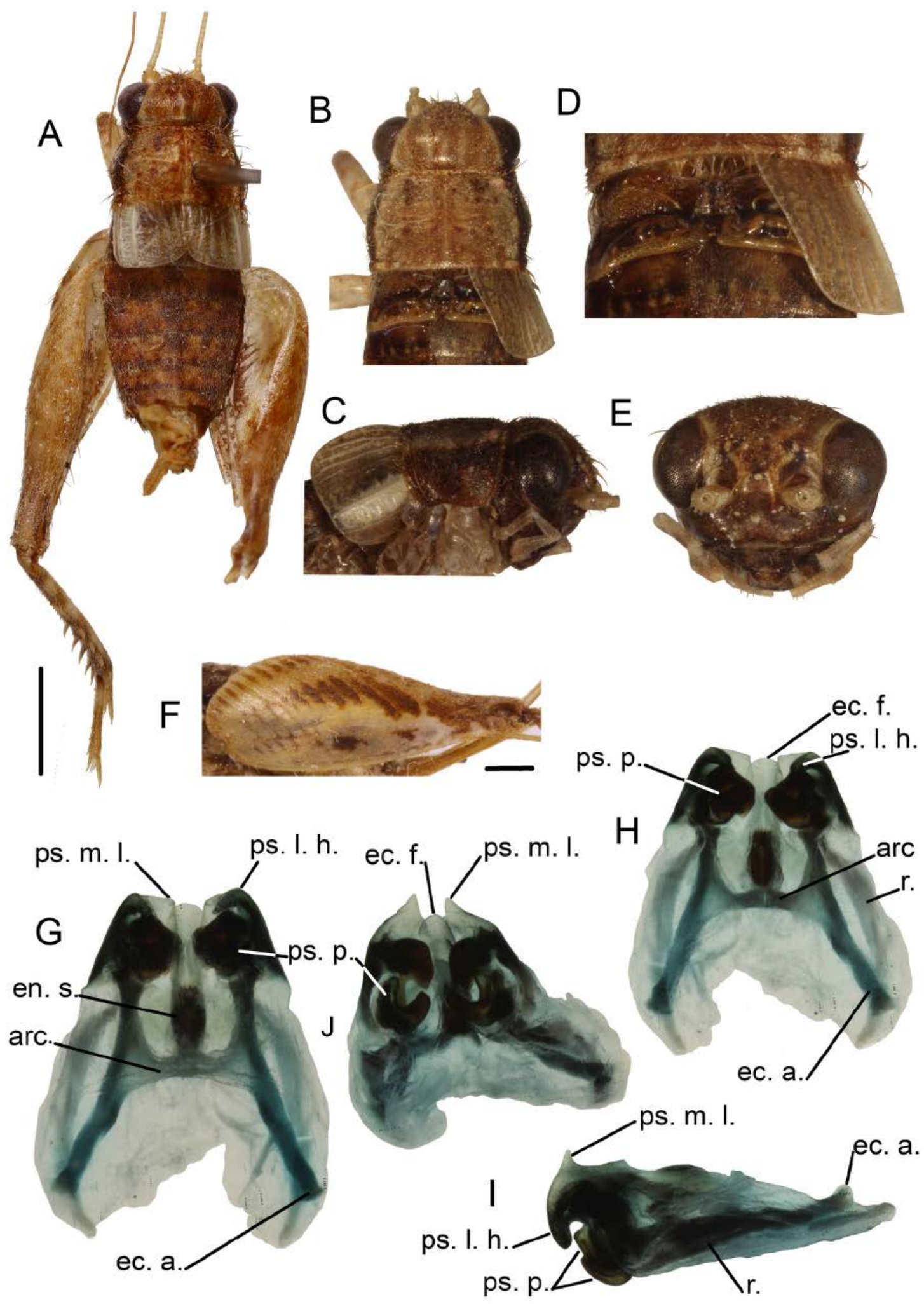

Figure 17. Gryllapterus tomentosus Bolivar, 1912. A, male habitus in dorsal view, specimen deposited in LEM; B-C, male forewing in dorsal (B) and side (C) views, specimen MNHN-EO-ENSIF12269; D, male metanotal gland, dorsal view, specimen MNHN-EO-ENSIF12269; E, face, specimen MNHN-EO-ENSIF12269; F, hind femur pattern of coloration, specimen MNHNEO-ENSIF12270; G-J, male genitalia in dorsal (G), ventral (H), side (I) and ventro-distal (J) views, specimen MNHN-EO-ENSIF12269. Abbreviations: see Material and methods. Scales 2 mm (A), 1 mm (F). 


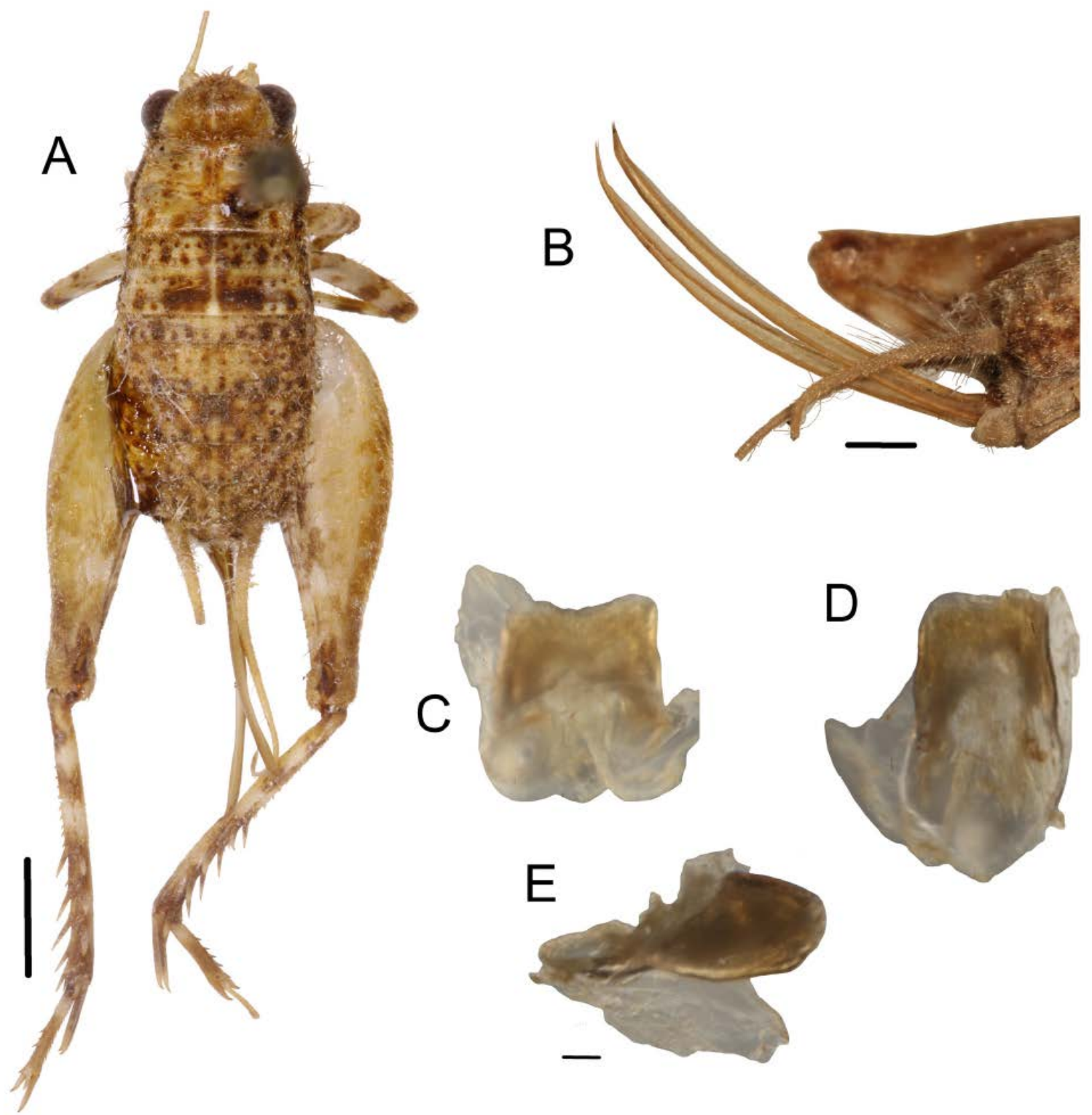

Figure 18. Gryllapterus tomentosus Bolivar, 1912, female. A, habitus in dorsal view, specimen MNHN-EOENSIF12270; B, ovipositor, side view, specimen MNHN-EO-ENSIF12270; C-E, copulatory papilla in dorsal (C), ventral (D) and side (E) views, specimen MNHN-EO-ENSIF12272. Scale $1 \mathrm{~mm}$ (A, B), $0.1 \mathrm{~mm}$ (C-E). 

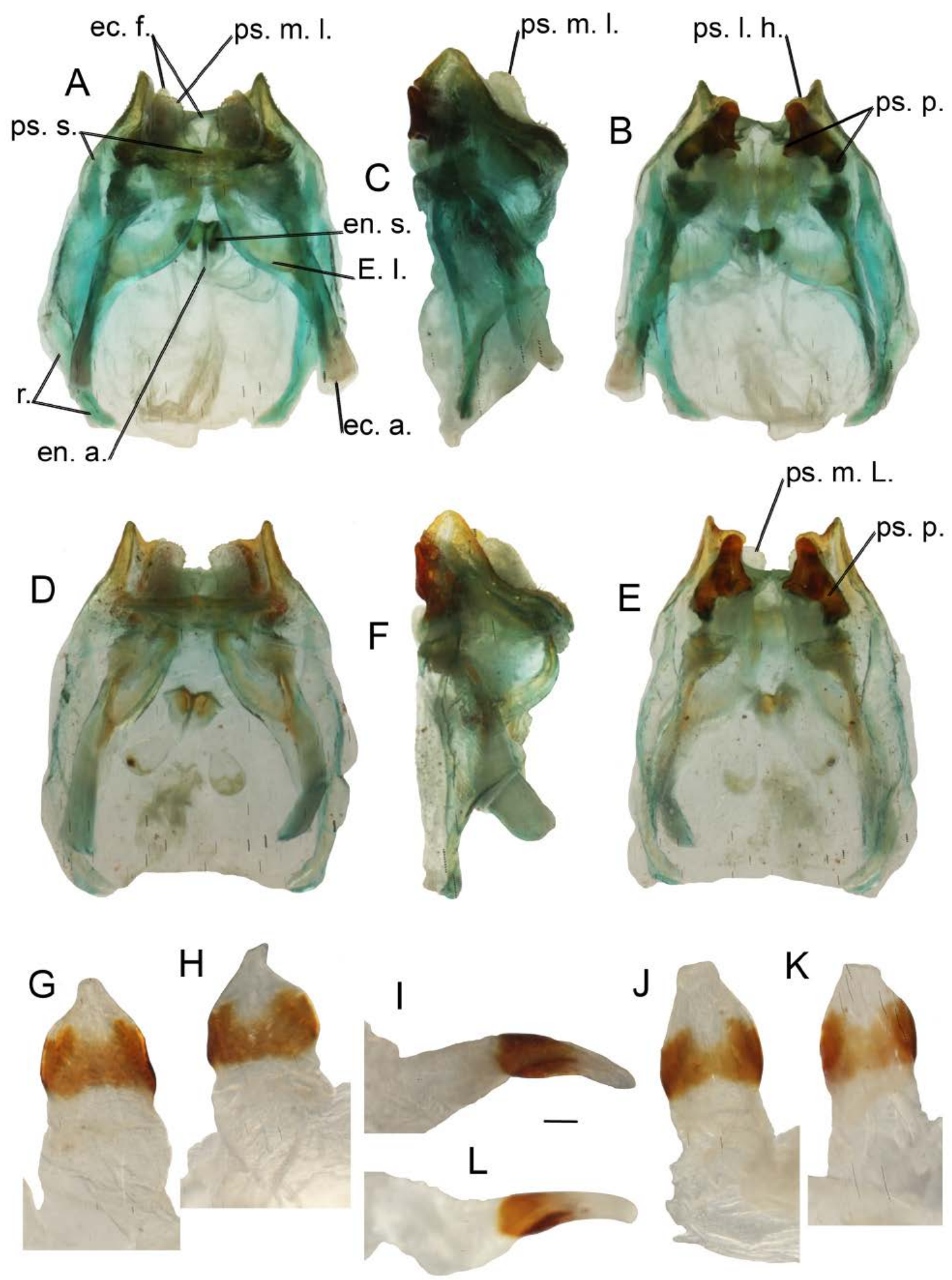

Figure 19. Phaloria (Papuloria) insularis (Bolivar, 1912) (A-C, G-I) and Phaloria (Papuloria) bolivari Hugel \& Desutter-Grandcolas, n. sp. (D-F, J-L): A-F, male genitalia in dorsal (A, D), ventral (B, E) and side (C, F) views; G$\mathrm{L}$, female copulatory papilla in dorsal $(\mathrm{G}, \mathrm{J})$, ventral $(\mathrm{H}, \mathrm{K})$ and side (I, L) views, scale bar $0.1 \mathrm{~mm}$. Abbreviations: see Material and methods. 

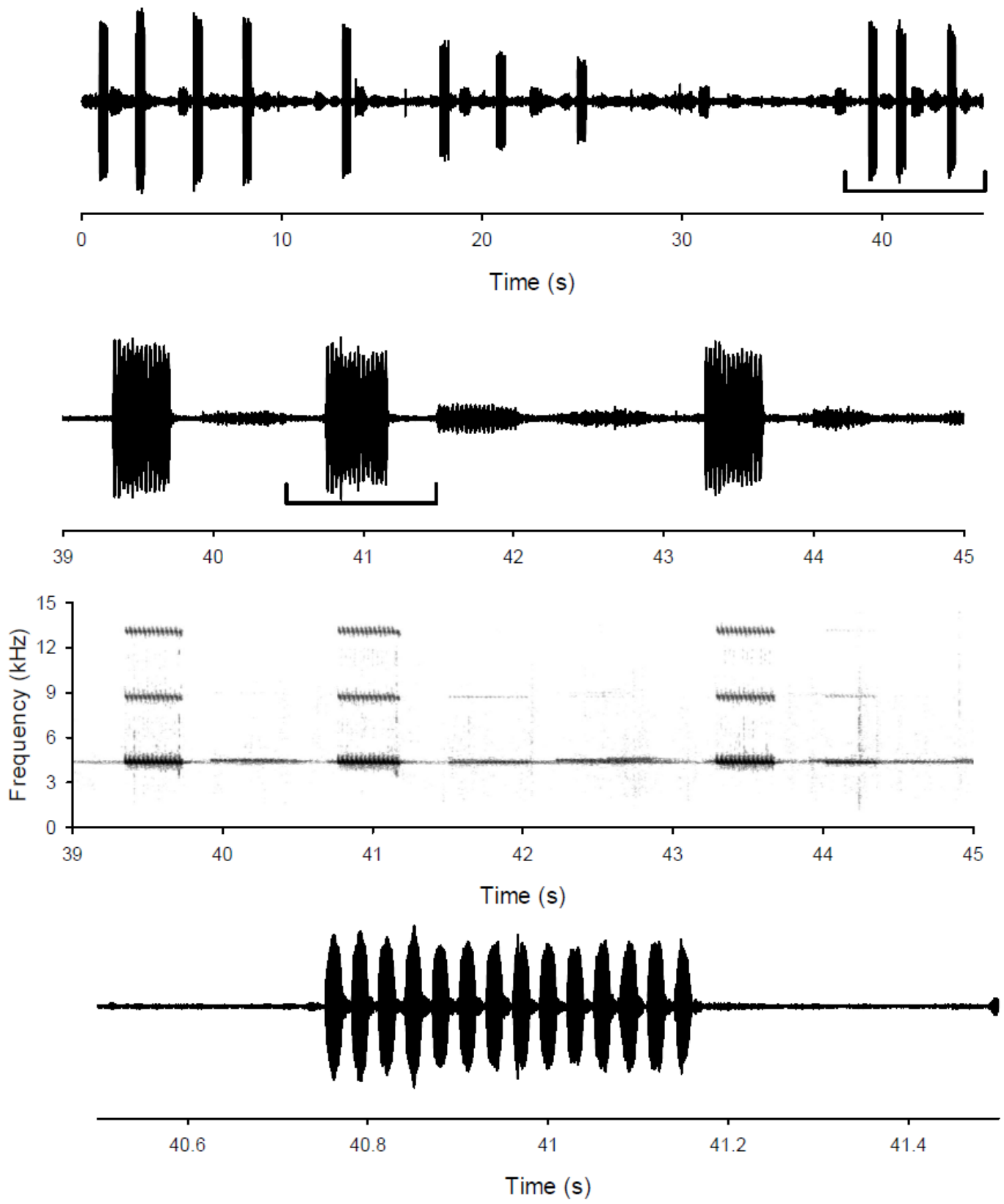

Figure 20. Calling song of Phaloria (Papuloria) insularis (Bolivar, 1912) recorded from Mahé (10pm, 26 $)$. A, oscillogram of a song bout, showing a succession of motives over $40 \mathrm{~s}$;; B, detailed oscillogram of a song bout with three motives; C, spectrogram of the three-motive song bout shown in B, showing dominant frequency and two upper harmonics; D, oscillogram of a motive identified in B, showing the successive 14 syllables and their regular envelops. 
